Florida International University

FIU Digital Commons

$10-20-2020$

\title{
A Proposed Social Cognitive Career Development Model for Adults with Intellectual Disabilities
}

Amanda M. Giust

agius001@fiu.edu

Follow this and additional works at: https://digitalcommons.fiu.edu/etd

Part of the Adult and Continuing Education Commons

\section{Recommended Citation}

Giust, Amanda M., "A Proposed Social Cognitive Career Development Model for Adults with Intellectual Disabilities" (2020). FIU Electronic Theses and Dissertations. 4591.

https://digitalcommons.fiu.edu/etd/4591

This work is brought to you for free and open access by the University Graduate School at FIU Digital Commons. It has been accepted for inclusion in FIU Electronic Theses and Dissertations by an authorized administrator of FIU Digital Commons. For more information, please contact dcc@fiu.edu. 


\title{
FLORIDA INTERNATIONAL UNIVERSITY
}

\author{
Miami, Florida
}

\section{A PROPOSED SOCIAL COGNITIVE CAREER DEVELOPMENT MODEL FOR ADULTS WITH INTELLECTUAL DISABILITIES}

A dissertation submitted in partial fulfillment of the

\author{
requirements for the degree of \\ DOCTOR OF EDUCATION
}

in

ADULT EDUCATION \& HUMAN RESOURCE DEVELOPMENT

by

Amanda M. Giust

2020 
To: Dean Michael R. Heithaus

College of Arts, Sciences and Education

This dissertation, written by Amanda M. Giust, and entitled A Proposed Social Cognitive Career Development Model For Adults With Intellectual Disabilities, having been approved in respect to style and intellectual content, is referred to you for judgment. We have read this dissertation and recommend that it be approved.

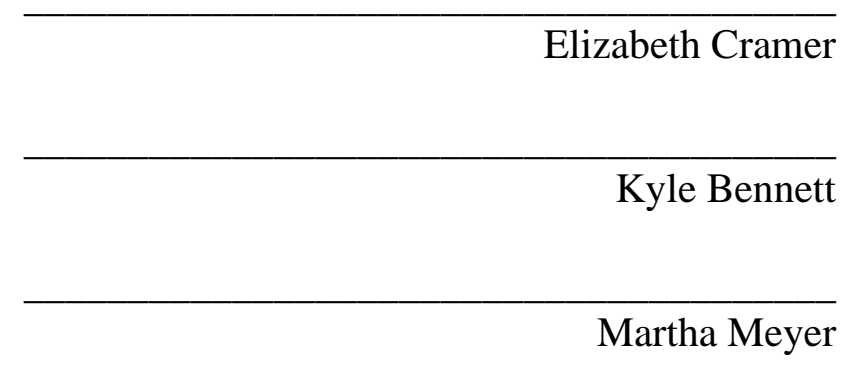

Date of Defense: October 20, 2020

Thomas G. Reio, Jr., Major Professor

The dissertation of Amanda M. Giust is approved.

Dean Michael R. Heithaus

College of Arts, Sciences and Education

Andrés G. Gil

Vice President for Research and Economic Development and Dean of the University Graduate School

Florida International University, 2020 


\title{
ABSTRACT OF THE DISSERTATION
}

\section{A PROPOSED SOCIAL COGNITIVE CAREER DEVELOPMENT MODEL FOR ADULTS WITH INTELLECTUAL DISABILITIES}

by

\author{
Amanda M. Giust
}

Florida International University, 2020

\author{
Miami, Florida
}

Professor Thomas G. Reio, Jr., Major Professor

This non-experimental, correlational research tested a hypothesized employment model using the Social Cognitive Career Theory (SCCT) for individuals with ID who have completed high school in Miami, Florida, USA. The variables examined in the study were (a) environmental supports and barriers (e.g., family expectations, available community resources) (b) personal attributes (e.g., self-determination), (c) career behavior, and (d) the outcome of employment. Results of the logistic and hierarchical regression models demonstrated that the hypothesized model accounted for $22.3 \%$ of the variance in reported employment attainment. In both regression models, the personal attributes variable was statistically significant to employment outcome and the career behavior variable was statistically significant, however, with a negative link to the employment outcome. In addition, positive correlations were found between the environmental supports and barriers, personal attributes, and career behavior variables. 


\section{TABLE OF CONTENTS}

CHAPTER

PAGE

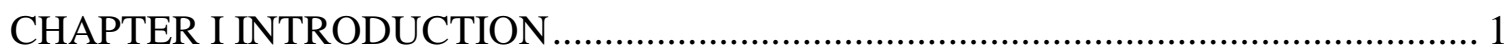

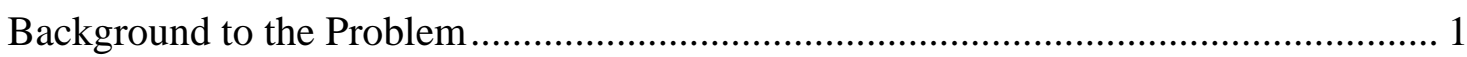

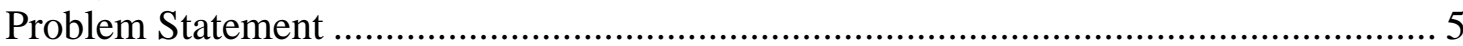

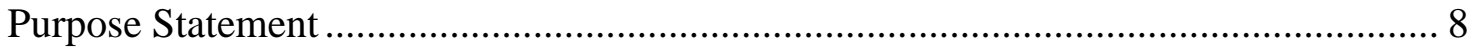

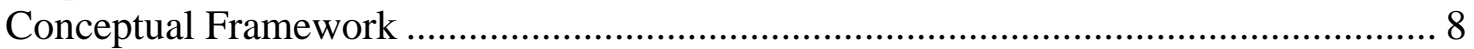

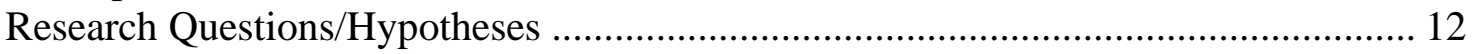

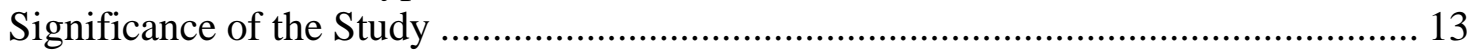

Delimitations of the Study .............................................................................. 15

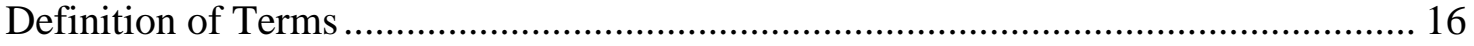

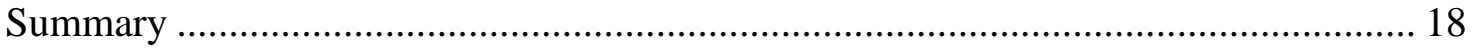

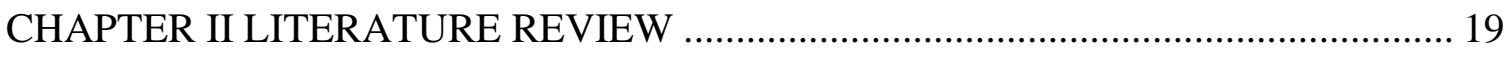

Historical Perspectives on Career Development ........................................................ 19

The Supported Work Model ................................................................................ 20

Customized Employment Model ........................................................................... 21

Postsecondary Education Programs..................................................................... 22

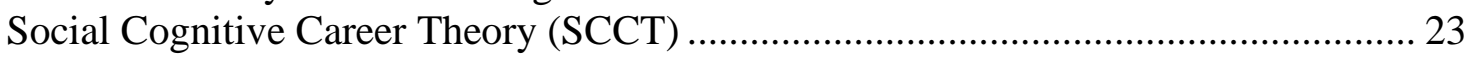

Adapting the SCCT Model.................................................................................. 25

Environmental Supports \& Barriers …………………........................................ 26

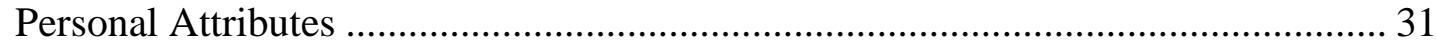

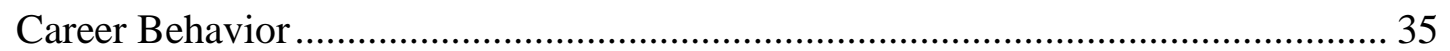

A Proposed Employment Model ............................................................................... 39

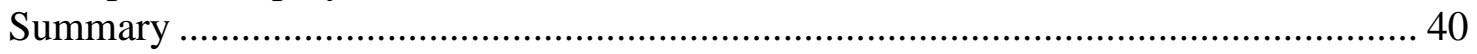

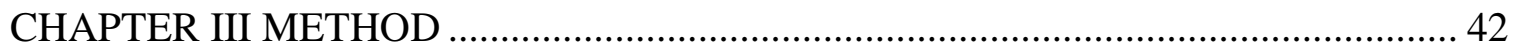

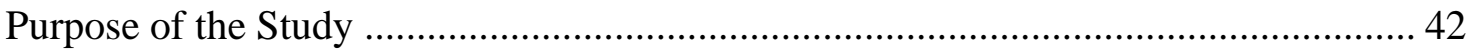

Research Questions and Hypotheses …………....................................................... 42

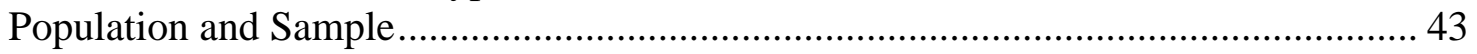

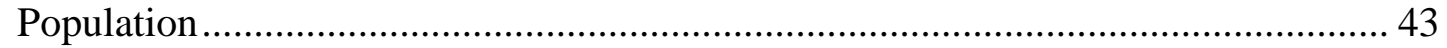

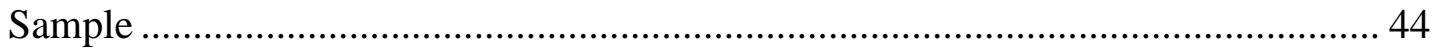

Ethical Considerations.................................................................................... 45

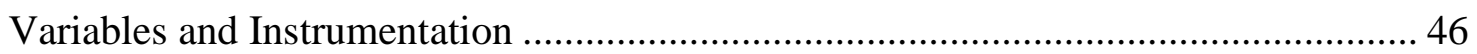

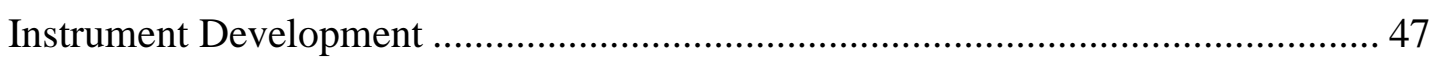

Pilot Testing Procedures .................................................................................. 54

Data Collection Procedures ............................................................................... 55

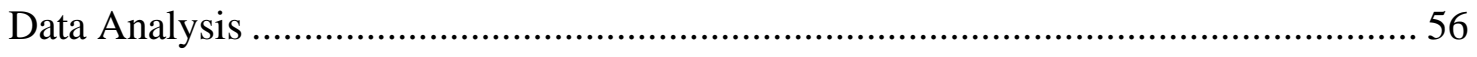

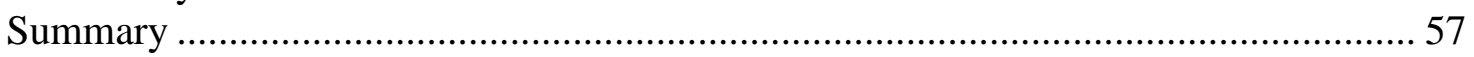

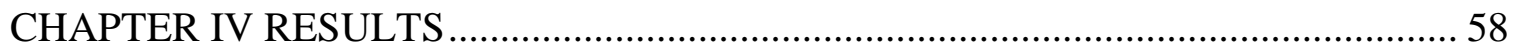

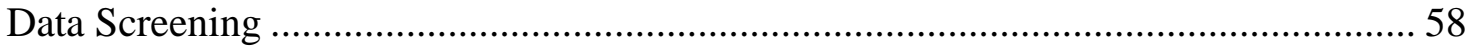

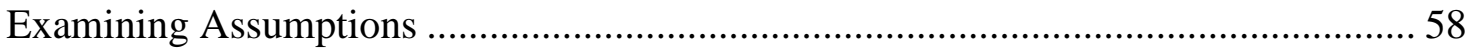

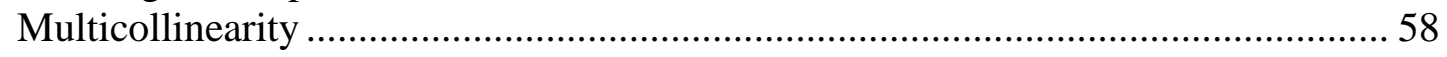




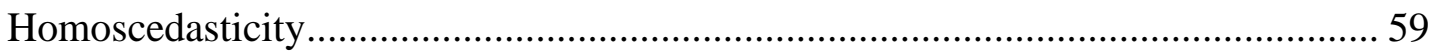

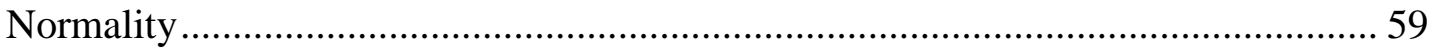

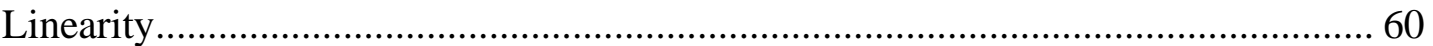

Addressing Violations of Personal Attributes Variable ............................................ 60

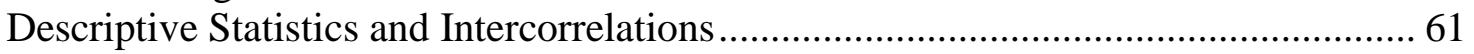

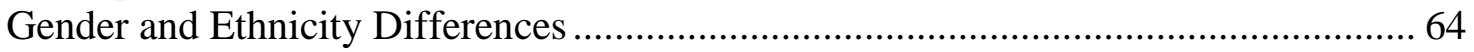

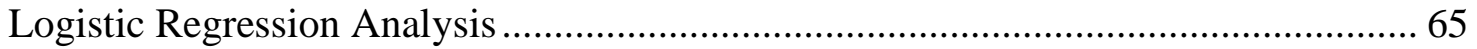

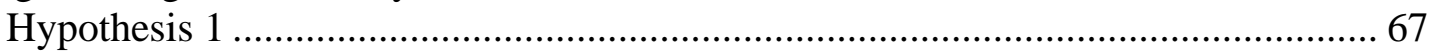

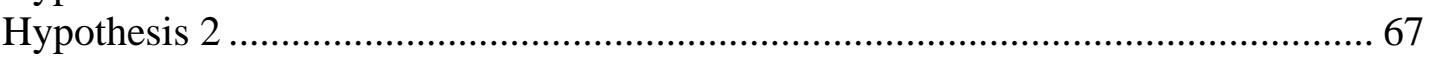

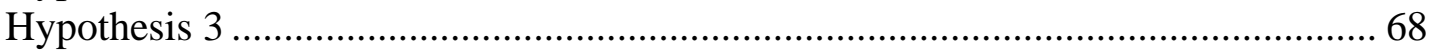

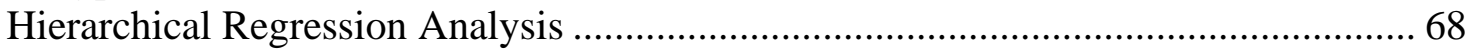

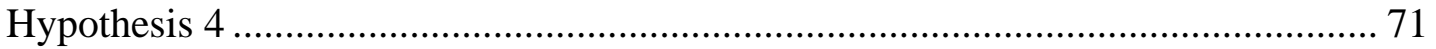

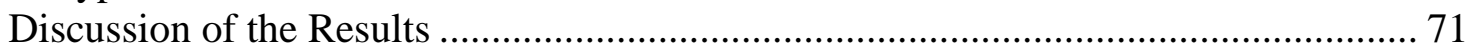

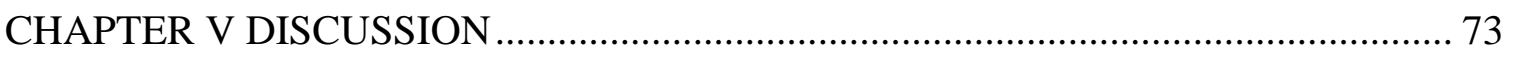

Summary of Results ..................................................................................... 73

Limitations and Recommendations for Future Research .......................................... 74

Personal Attributes .................................................................................. 74

Environmental Supports and Barriers................................................................. 79

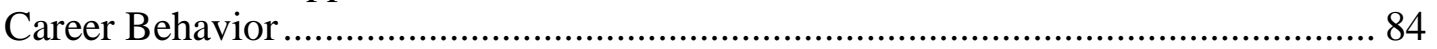

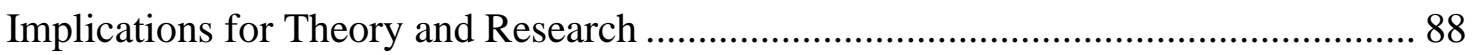

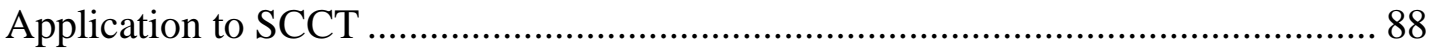

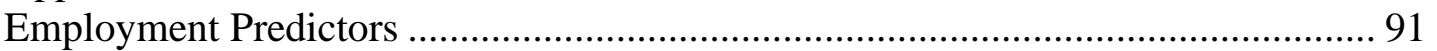

Quantitative Research on Individuals with ID ....................................................... 94

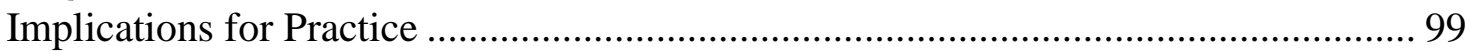

Implications for Service Providers ..................................................................... 99

Implications for HRD Professionals .................................................................... 103

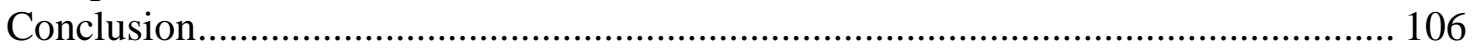

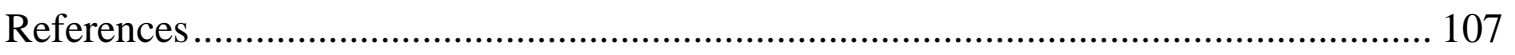

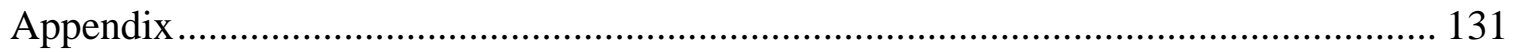

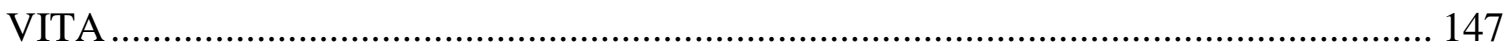




\section{LIST OF TABLES}

TABLE

PAGE

1. Demographic Distribution of Sample .......................................45

2. Scales, Subscales, and Items Per Scale....................................48

3. Intercorrelations of Independent Variables' Subscales..........................62

4. Intercorrelations of Research Variables......................................64

5. Classification Table of Logistic Regression Analysis...........................66

6. Summary Results of Logistic Regression Analysis of Study Variables Predicting Employment ........................................................66

7. Classification Table of Hierarchical Logistic Regression.......................69

8. Summary Results of Hierarchical Logistical Regression Analysis of Study

Variables Predicting Employment Outcome................................... 70 


\section{CHAPTER I}

\section{INTRODUCTION}

This chapter will cover the background to the problem, the problem statement, and purpose statement. The research questions, conceptual framework, significance of the study, and definition of terms will follow.

\section{Background to the Problem}

According to the most recent population-based studies, approximately 11 out of every 1,000 people, or roughly $1 \%$ of the population, have been diagnosed with an Intellectual Disability (ID; Maulik et al., 2011; Witwer et al., 2014). Intellectual Disability is a specific class of developmental disabilities that can be defined as "a severe limitation in intellectual skills and adaptive behavior" (Schalock \& Luckasson, 2013, p. 662). Diagnosis of ID requires the measurement of intellectual and adaptive functioning via comprehensive medical exam and is typically diagnosed before the age of 18 (Harris, 2006; Schalock \& Luckasson, 2013). In all cases, an IQ test is administered with IQ below 70 indicating severe intellectual limitations. There are four degrees of impairment based on intellectual: mild (IQ = 50-69), moderate (IQ = 35-49), severe (IQ = 20-34), and profound (IQ < 20). Approximately $85 \%$ of individuals diagnosed with ID fall in the mild range (van Bokhoven, 2011). Additional limitations in adaptive behavior in three areas are considered during diagnosis: conceptual (e.g., language, reasoning, knowledge, problem-solving), social (e.g., interpersonal skills, communication), and practical (e.g., independent living, money skills, self-care; Salvador-Carulla et al., 2018). In addition, individuals diagnosed with ID have underdeveloped cognitive or social-emotional regulation, which is necessary for performing everyday tasks (Borkowski et al., 2007). 
Due to these deficits, historically, people diagnosed with ID have been segregated and have had limited access to education leading to segregated employment or unemployment (Burge et al., 2007; Grigal et al., 2011).

The personal and economic benefits of securing paid employment for those with ID have been well-documented in the literature including integration into the community (Kiernan, 2000; Lysaght et al., 2009), increased independence and autonomy (Kiernan, 2000; Trainor, 2017), establishment of an identity (Lysaght et al., 2009), expansion of social networks (Akkerman et al., 2014; Lysaght et al., 2009; Trainor, 2017), adoption of daily structure and activity (Lysaght et al., 2009), increased self-determination and empowerment (Reid \& Bray, 1997; Trainor, 2017), and increased financial resources (Lysaght et al., 2009; Trainor, 2017). Receiving income allows individuals increased selfsufficiency meaning less reliance on government funding and increased return on investment in the form of tax revenue and exchange for goods and services (Cimera, 2010; Niemiec et al., 2009). These findings, paired alongside gradual societal shifts towards acceptance of people with disabilities, have led to four decades of legislation and policy changes focused on employment outcomes for individuals with ID (Gadbow \& DuBois, 1998; Martinez, 2012).

Prior to the 1970s, individuals with ID in the United States were not viewed as contributing members to the working society; therefore, leading to the placement of many individuals with ID in institutions (Shyman, 2013). Those that had an opportunity to work were typically placed in sheltered workshops or segregated work environments where individuals work aside others with disabilities typically for pay significantly below minimum wage (Wehman \& Moon, 1988). The shift in American policy began with two 
key Acts passed through Congress: (a) The Education for All Handicapped Children Act of 1975, later reauthorized as the Individuals with Disabilities Education Improvement Act (IDEA), which focused on integration of all students into schools and (b) The Rehabilitation Act of 1973, which focused on integration into employment settings for people with severe disabilities. These two landmark Acts led to a series of employment initiatives (e.g., Ticket to Work and Work Incentives Improvement Act of 1999, New Freedom Initiative), demonstrating the American government's commitment to employment for this population (Boeltzig et al., 2008).

The employment initiatives mandated changes in the educational services and the systems of support made available for individuals with ID, ultimately providing more opportunities for employment (Kiernan, 2000). Beginning in the 1980s, the eminent job model was the supported work approach (Wehman \& Kregel, 1985), which provided onthe-job support by a professional, typically referred to as a job coach, and natural supports (e.g., coworker, supervisor). Supported employment created a twofold shift in the employment focus by: (a) providing support on the job instead of only before the job (Butterworth et al., 2012; Callahan et al., 2011) and (b) allowing individuals with ID, regardless of significance of disability, to achieve employment (Callahan et al., 2011; Wehman et al., 1998).

Revisions to policy in the early 2000s alongside the introduction of the internet to the American workforce spurred changes to the employment preparation of all youth, with and without disabilities (Carter, Trainor, et al., 2010; Kiernan, 2000). The employment approach evolved to integrated employment with naturally occurring supports, and in some cases self-employment (Butterworth et al., 2000; Butterworth et 
al., 2011; Dotson et al., 2013; Kiernan, Hoff, Freeze, \& Mank, 2011). A job model called customized employment emerged around the same time period with a focus on negotiating between individual employment needs and employer needs (Riesen et al., 2015). The customized employment model encouraged job restructuring in organizations, which allowed for more employment opportunities that paid at minimum wage or above. From that time period forward, competitive employment - work performed in an integrated setting with wages comparable to those individuals without disabilities - had become the target outcome of employment preparation programs (Callahan et al., 2011). By early 2011, nearly half of the United States had either developed or were in the process of developing a policy that would establish competitive employment as the primary service to be funded for individuals with ID (Callahan et al., 2011).

Despite the policy and legislation in conjunction with changes to the education system and funded programs, few measures have been put into place to determine the nationwide employment rate for individuals with ID (Nord et al., 2013). Researchers have conducted large-scale studies and have found that individuals with ID are still not being hired at the same rate as their nondisabled peers (Grigal et al., 2011). Wehman et al. (1998) argued that the unemployment rate (60-70\%) for the population with ID remained unchanged despite the advances in policy and training techniques. In 2000, in a U.S. Department of Education sanctioned research study, analysis of The National Longitudinal Transition Study-2 (NLTS2) revealed that $70 \%$ of students with disabilities listed employment after graduation as a post-school goal (Cameto et al., 2004). However, reported employment outcomes for students with ID continuously demonstrated that those goals were not being achieved. In 2010, for example, the estimated employment 
rate of the adults with disabilities was $33.9 \%$ compared with the rate of $75.4 \%$ for individuals without a disability (Erickson et al., 2010). These findings aligned with research conducted around the same period of time by Chapman et al. (2010) in which students were surveyed two years post-high school; four in ten youth with disabilities were employed as compared to six in ten in the general population. In 2013, a U.S. national survey of 1,017 individuals with ID revealed only $34 \%$ of people with ID reported having employment and of those employed, only 53\% were in competitive employment placements (Siperstein et al., 2013). Additionally, unemployment rate trends indicated that individuals with ID were more likely to become unemployed over time. In a 15-year longitudinal study conducted by Spreat and Conroy (2015) indicated the number of individuals employed in the sample went from $82.4 \%$ to $49.1 \%$ from 1994 2009. The discrepancy in employment outcomes has persisted despite ongoing efforts to bridge the gap between individuals with and without disabilities.

\section{Problem Statement}

Attempts to identify the root cause of the gap in employment for those with ID have been prevalent in the literature for the past three decades with a concentration on educational service delivery and employment predictors. Trainor (2017) cited studies sanctioned by the U.S. Department of Education (e.g., National Longitudinal Transition Study-2 [NLTS-2]) as a potential reason for the surge in research on educational service delivery. In a review of 387 articles in a peer-reviewed journal with a focus on career development for exceptional individuals between 1978 and 2012, the most common topical areas included, program evaluation and program development (18.8\%), teacher

professional development (10.3\%), and transition or educational planning (10\%; Madaus 
et al., 2013). Though analysis of educational service delivery has led to positive educational changes, it inadvertently excluded the voices of adults with ID. For example, researchers who analyzed the NLTS-2 or other government sanctioned studies only examined individuals up to 28 years old (Carter et al., 2015; Gonzalez et al., 2011; Shogren \& Plotner, 2012). Similarly, research on employment predictors for the population were found to be limited to those in transition programs, typically up to 22 years old (Test et al., 2009).

In addition to a significant portion of the population being excluded from the literature, research on predictors of employment has been inconclusive. In a survey of 22 evidence-based articles from 1984-2009, Test et al. (2009) outlined 16 employment predictor categories which included: (a) educational service delivery variables (inclusion in general education courses, interagency collaboration, paid employment/work experiences, student support, program of study, occupational courses, high school diploma status, transition program, vocational education, and work study), (b) personal attributes (career awareness, self-determination/self-advocacy, social skills, and self-care) and (c) family involvement. Each predictor variable was researched separately and varied in significance to the overall outcome. For example, work experience variables in ten studies ranged in effect size from .05 to $.55, p<.05$ to $p<.01$ (Test et al., 2009). The literature over the past few decades has documented significant predictors of employment (e.g., internships) and highlighted success stories of specific service delivery components (e.g., customized employment model) in certain groups of individuals with disabilities, but has not been translated into sustained improvement in employment outcomes for the population with ID (Wehman et al., 2018). 
Due to the diversity of employment predictors and other unique challenges individuals with ID face in terms of career development (e.g., personal guardianship), researchers have described the employment problem as particularly complex (Nord et al., 2018; Wehman, 2006). Carter et al. (2011) argued that in part the complexity persists due to the lack of literature that examines the specific relationships between research variables (e.g., career development) and the individual's overall experience. Socialcognitive factors (personal, environmental, and behavioral) as outlined in the socialcognitive theory (Bandura, 1986), have been identified as influencing the life experiences of individuals with ID. For example, Murray (2003) postulated that multiple contexts of the individual, school, family, and community act as risk factors or protective factors for youth with disabilities such as ID. Thus, suggesting that these factors directly impact whether the individual has positive or negative post school outcomes.

Social-cognitive influences have also been prevalent in legislative priorities set forth by the U.S. government for those with disabilities. For example, IDEA (2004) introduced the right to the least restrictive environment for the individual, therefore, using the assumption that social behavior is impacted by the environment. The selfdetermination initiative created by the Office of Special Education and Rehabilitative Services (OSERS) introduced self-determination into the special education curriculum, therefore, using the assumption that personal attributes impact student outcomes (Ward, 2005). Moreover, research of the population of ID has demonstrated that personal attributes (e.g., self-determination), environmental factors (e.g., family expectations), and behavioral factors (e.g., engagement in career development experiences) impact employment outcomes (Mazzotti, 2014; Simonsen \& Neubert, 2013; Test et al., 2009; 
Wehmeyer \& Palmer, 2003). A social-cognitive approach examining the effects of personal, environmental, and behavior factors on career behavior has the potential to assist researchers in understanding how and if employment is acquired by individuals with ID.

\section{Purpose Statement}

The purpose of this research study was to test a hypothesized social-cognitive employment model for individuals with ID in Miami, Florida, USA who have completed high school by examining the association between family expectations, available community resources, self-determination, engagement in career behavior, and the outcome of employment.

\section{Conceptual Framework}

The framework for this study is provided by social cognitive theory and its core assumption that cognitive, affective, biological factors, behavior patterns, and environmental events all influence one another (Bandura, 1999). The basic tenants of social-cognitive theory include behavioral capability, observational learning, reinforcement, expectations, and self-efficacy. It can be argued that the underlying assumptions of the social-cognitive theory have been evident in employment preparation practices used for individuals with ID. There has been a continued emphasis on job matching, where the skills of the individual with ID are matched to jobs that require said skills, assuming that the capability to produce the behavior is necessary prior to employment acquisition (Migliore et al., 2018; Wehman, 1985). In addition, using job shadowing, where individuals with ID shadow an employee through parts of the work day to observe job tasks, as an employment preparation technique has continued to be 
highlighted in the literature, assuming that learning skills through observation is a necessary component of job acquisition (Cease-Cook et al., 2015; Luecking, 2009).

The underpinnings of the social-cognitive theory related to career development was expanded upon in the Social Cognitive Career Theory (SCCT), a theory that aimed to further explain employment outcomes while accounting for relations between constructs such as abilities, needs, and interests (Lent et al., 1994). The SCCT posits that environments expose individuals to an array of potential career choices; therefore, influencing behavior choices in terms of employment (Lent et al., 1994). Environmental factors have been established as crucial to career development for those with ID as said factors can act as supports or barriers (Grigal \& Hart, 2012; Neubert \& Leconte, 2013). Available job or career preparation options in the community have been identified as predictors to employment (Burge et al., 2007). Even with opportunities available in the community, families can have legal authority to determine individual participation (Grigal \& Hart, 2012). In addition to legal authority, expectations from family members have been demonstrated to impact the types of career behavior in which the individual is engaged (Doren et al, 2012; Folk et al., 2012).

Another environmental factor in the SCCT is feedback, either external or internal, which contributes to the opinions the individual has of oneself (Lent et al., 1994) Research supports this assumption as family environments that allow the individual to make choices initiate the self-determination process (Argan \& Krupp, 2011; Berry \& Hardman, 1998). Personal attributes such as self-determination are then influenced and predicted by family expectations and perceived encouragement or feedback (Folk et al, 2012; Turnbull \& Turnbull, 1996; Turner \& Lapan, 2002). Therefore, higher expectations 
from family members have been linked either directly or indirectly to improved employment outcomes (Blacher et al., 2010; Carter et al., 2012; Folk et al., 2012).

The personal attribute of self-efficacy has been identified as the cornerstone of the SCCT, suggesting that the observation and awareness of careers, practice of job-related skills, and feedback lead to the formation of a set of individual standards (Lent et al., 1994). This assumes that perceived career self-efficacy affects other career related behavior patterns as the individual sets goals, evaluates outcomes, and makes choices (Argan \& Krupp, 2011). In the functional model of self-determined behavior for people with ID developed by Wehmeyer (1999), self-efficacy is one of eight identified constructs of self-determination, suggesting significant conceptual overlap. Research has demonstrated a correlation between higher levels of self-determination in individuals with ID and employment acquisition (Carter et al., 2012; Shogren et al., 2015; Wehmeyer \& Palmer, 2003). Goal setting, though not a stand-alone predictor for employment, has an established relationship to self-determination in individuals with ID (Shogren et al., 2018).

The practice of skills or behaviors in the area of employment is referred to as engagement in the SCCT. It has been postulated that career interests ultimately affect the type of engagement in career-related activities, which lead to additional career goals, creating a pattern of behavior (Lent et al., 1994). Research supports this assumption as career development experiences including school-sponsored work (Carter et al., 2012; Joshi et al., 2012), participation in internships (Gadbow \& DubBois, 1998; Luecking \& Fabian, 2000), job shadowing (Luecking, 2009), paid community employment (Benz, 
2000; Carter et al., 2012), and paid employment (Grigal \& Deschamps, 2012; Test et al., 2009) have all been noted as predictors for employment.

An employment model was formed following the principles of the SCCT (environmental supports and barriers, personal attributes, and career behavior) and the aforementioned assumptions in the literature. As postulated by the SCCT, environmental supports and barriers, personal attributes, and career behavior influence performance attainment (Lent et al., 1994). The performance attainment in this model is employment defined as conducting any work for pay as an employee or in a self-employment setting (U.S. Bureau of Labor Statistics, 2015). The environmental supports and barriers variable has two factors denoted in the literature as influencing employment choices: family expectations and available community resources (Timmons et al., 2011). The personal attribute variable includes self-determination which has been linked to employment outcomes (Shogren et al., 2015). The career behavior variable includes career development experiences (e.g., internship, job shadowing) completed by the individual which have been identified as predictors to employment (Carter et al., 2012; Luecking \& Fabian, 2000).

The hypothesized employment model (see Figure 1) suggests that if individuals with ID are provided with family expectations that involve employment outcomes and have access to career development experiences that allow the individual to prepare for employment, then the individual will display higher levels of self-determination, engage in more career behavior, and ultimately gain employment. Furthermore, as asserted in the SCCT, career behavior and personal attributes are interrelated, assuming that more 
engagement in career behavior will correlate with higher reports of self-determination (Lent et al., 1994).

\section{Figure 1}

\section{Hypothesized Employment Model}

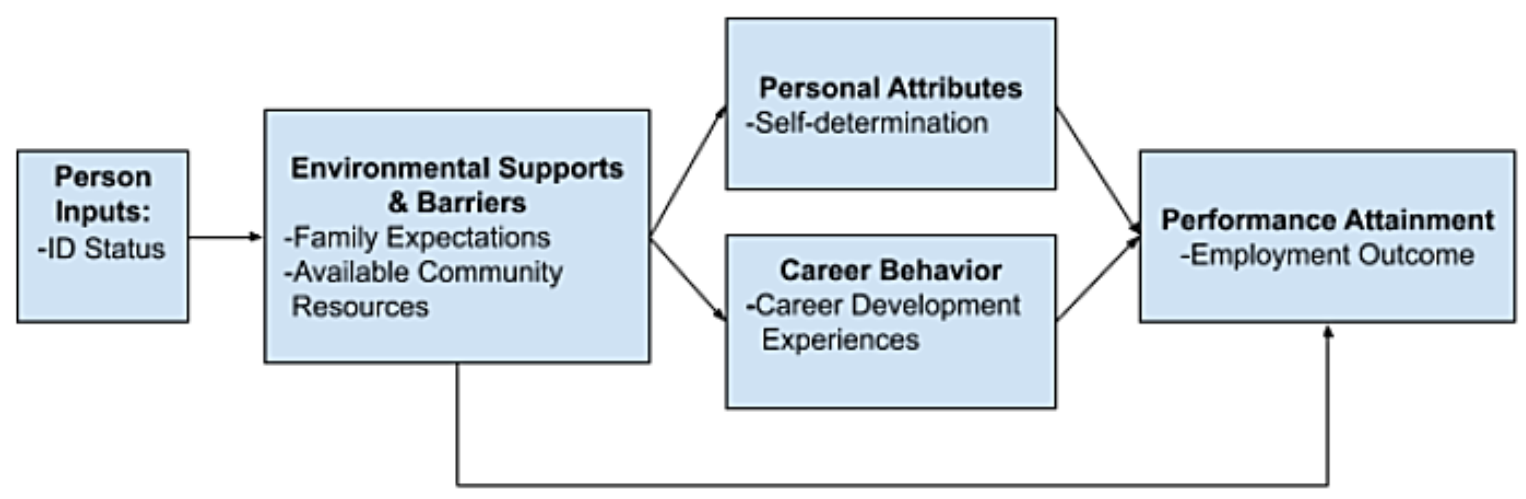

Note. This model was adapted from Lent, Brown, \& Hackett (1994).

\section{Research Questions/Hypotheses}

The overarching research questions were: (a) What is the association between the personal attribute of self-determination and performance attainment of employment of individuals with ID? (b) What is the association between participation in career behavior and performance attainment of employment of individuals with ID? (c) What is the association between family expectations, available community resources, and performance attainment of employment of individuals with ID? and (d) What are the unique contributions of personal attributes and career behavior on employment attainment after controlling for environmental supports and barriers (i.e., family expectations and available community resources)?

H1: When working with individuals with ID, reports of higher self-determination will be positively linked to attaining employment. 
$\mathrm{H} 2$ : When working with individuals with ID, reports of higher levels of involvement in career behavior will be positively linked to attaining employment.

H3: When working with individuals with ID, reports of high family expectations and larger quantities of available community resources (e.g., educational programs) will be linked positively to attaining employment.

H4: Personal attributes and career behavior will make a unique contribution to employment attainment after controlling for environmental supports and barriers (i.e., family expectations and available community resources).

\section{Significance of the Study}

Adding knowledge for the purpose of closing the gap in employment for those with ID is of interest to policymakers, state legislatures, vocational rehabilitation professionals, and HR professionals (Flippo \& Gardner, 2011). Federal policy and research hold a symbiotic relationship as federal policy changes require research to explore the related employment outcomes (Trainor, 2017). As federal policy continues to prioritize the gap in employment, research on why it persists can influence future legislative decisions. Adults with ID who have completed high school and seeking employment assistance are the primary customers of vocational rehabilitation professionals (Domin \& Butterworth, 2013). Research investigating factors that influence employment is of use to vocational rehabilitation professionals assisting individuals with ID to reach their employment goals. In the field of human resource/development (HR/D), there continues to be a lack of information on hiring individuals with ID (Kocman et al., 2018). Further exploration of the career influences on individuals with ID can assist in 
closing the research gap, offering HR professionals insight on how to increase the number of individuals with ID in the current workforce.

The conceptual enrichment of the Social Cognitive Career Theory (SCCT) is of interest to researchers as it provides a structure for understanding the factors affecting career development and outcomes specifically for those with ID. Though the SCCT has been applied to diverse groups of individuals (Panagos \& DuBois, 1999; Sung \& Connor, 2017), application to those with ID is limited. No quantitative research currently exists with individuals with ID in the United States utilizing the SCCT framework; therefore, the study outcomes can lay the groundwork for extending SCCT and further research in this area.

The examination of employment outcomes of individuals with ID is of interest to the individuals directly impacted. Flippo and Gardner (2011) argued that all people have the right to work in the American society, yet there is often a discrepancy between the career goals of people with ID and actual opportunities made available to them (Corbett \& Barton, 1992). Working normalizes the life experience by fulfilling the needs of the individuals in the areas of social opportunities, sense of belonging and identity, and personal autonomy (Lysaght et al., 2012; Manning \& Gaudelli, 2006; Trainor, 2017). Exploration of this topic can provide insight leading to more employment opportunities and the related positive outcomes that impact everyday life for this population.

Further research on employment outcomes for individuals with ID is of great interest to corresponding family members. The financial impact of disabilities on family members has been well documented with families of individuals with disabilities being more at risk for poverty than those without disabilities (Emerson, 2007; Fujiura \& 
Yamaki, 2000). Employment of individuals with ID leads to additional household income, decreasing the financial burden. In addition, this research study provides an opportunity to expand upon on how environmental factors such as family expectations and support can impact career paths of individuals with ID (Carter et al., 2012; Doren et al., 2012; Lindstrom et al., 2007).

\section{Delimitations of the Study}

The first delimitation of the present study includes the parameters of the population sample. Although it would be ideal to study the entire population of those with ID, this research study is limited to individuals diagnosed with ID in South Florida. The offerings of educational programs and vocational rehabilitation services vary depending on the allocation of state resources (Epler \& Ross, 2015). Therefore, the findings of the present study reflect those of one state and its available resources. In addition, due to the nature of South Florida's population structure, demographic variables such as race may impact research outcomes. For example, in some research studies individuals of Hispanic/Latino or African American descent were less likely to become employed than white individuals (Kaya, 2018). The next delimitation concerns possible gender, racial, ethnic and cultural influences on career development among those with disabilities (Turnbull \& Turnbull, 2001). Though it might have been best to include all kinds of gender, racial, ethnic and cultural influences in this study, this research focuses on allowing for the sample's ethnic diversity, understanding this may affect generalization of the findings to the greater population.

Another delimitation is the absence of categorical breakdown of employment outcome. For example, researchers have argued that sheltered or segregated employment 
is a less desirable outcome than integrated employment (Simonson \& Neubert, 2013). Thought it might have been beneficial to include employment setting in this study, this research focuses on the overall career experience of the individual. The final delimitation of this study includes the variance in intellectual functioning (i.e., mild, moderate) that occurs in individuals with ID (Trainor, 2017). Studies have found that severity of impairment negatively affects employment outcomes (Francis, 2004; Spreat \& Conroy, 2015). The present study limits its examination to individuals with mild ID; therefore, additional intellectual functioning variance was excluded. Additionally, comorbidity, the presence of more than one disability, may affect career outcomes (Sung \& Connor, 2017). The current study limits its research to individuals with the disability label of ID; however, it does not exclude secondary disability labels (e.g., seizures) that may enhance or detract individuals from gaining employment.

\section{Definition of Terms}

Competitive employment is paid employment in a fully integrated work setting alongside non-disabled peers (Kiernan et al., 2011).

Employment refers to conducting any work for pay as an employee or in a selfemployment setting. Unpaid internships, volunteer work, or unpaid job training programs are not included in this definition (U.S. Bureau of Labor Statistics, 2015).

Intellectual disability (ID) refers to a type of developmental disability characterized by significant limitations in both intellectual functioning and in adaptive behavior, which covers social and practical skills (Schalock, 2010).

Job coach is a trained professional assisting an individual with disabilities with on-the-job skills, social interactions, and training. In some cases, the job coach secures 
employment, communicates with families, and communicates with the individual's supervisor (Wehman \& Hill, 1985).

Job matching is "Pairing job requirements to student abilities" (Wehman \& Hill, 1985, p. 270).

Job shadowing refers to an employment experience that continues for an "extended time often a full workday or several workdays, spent by a youth in a workplace accompanying an employee in the performance of his or her daily duties" (Luecking, 2009, p.13).

Natural Supports refers to any person in the work environment that assists the individual with a disability either by instruction or by choice. These supports can come in the form of a specified coworker, job supervisor, or job trainer (Wehman \& Hill, 1985).

Self-Determination refers to "acting as the primary causal agent in one's life and making choices and decisions regarding one's quality of life free from undue external influence or interference" (Wehmeyer, 1996, p. 24).

Self-Efficacy refers to the judgment or appraisal of one's abilities and effectiveness (Bandura, 1977).

Transition refers to "movement from school to post-school activities, including post-secondary education, vocational education, integrated employment (including supported employment), continuing and adult education, adult services, independent living, or community participation" (IDEA, 1990). 


\section{Summary}

Chapter I addressed the historically low employment rates of individuals with ID and the previous employment predictors noted in the literature. A social-cognitive approach to further understanding career development of individuals with ID was proposed using an employment model. The employment model concentrated on the attainment of employment and its relationship to family expectations, available community resources, self-determination, and career behavior. Validation of this model could lead to an enhanced understanding of the career development process of individuals with ID and its impact on achieving employment. 


\section{CHAPTER II}

\section{LITERATURE REVIEW}

Chapter II provides an overview of the historical and philosophical perspectives on career development for the population with ID. The Social Cognitive Career Theory (SCCT) will be reintroduced and its validity of application to career development for individuals with ID will be reported. Key factors of the SCCT including environmental supports and barriers, personal attributes, and career behavior will be discussed in terms of influencing employment outcomes.

\section{Historical Perspectives on Career Development}

The progression of philosophical views on disability have evolved over the past four decades, influencing legislation and career development activities. Previous to the 1970s, the philosophical perspective of society was the traditional or biomedical model of disability (Scotch, 2000). Disabilities were viewed as a medical diagnosis with emphasis on finding a cure, leading to the segregation of many individuals (Linker, 2013). The single source of employment during this time was sheltered workshops or segregated supervised workplaces for people specifically with mental disabilities (Black, 1992). In the 1970s, philosophical perspectives began to shift towards a social model of disability that held society accountable for the barriers people with disabilities faced (Novak, 2015). Landmark legislative changes occurred such as The Rehabilitation Act of 1973 that recognized disability as a natural part of the human experience and mandated equal employment access to people with disabilities (Silverstein, 2010). These legislative amendments spurred the creation of vocational programs which focused on integrating the population of ID into the workforce (Dotson et al., 2013). 


\section{The Supported Work Model}

The supported work model was constructed using the ideology that attaining integrated employment could be made possible by providing the appropriate levels of ongoing support to the individual (Wehman \& Hill, 1985). In this model, the individuals with ID were placed in jobs selected by a teacher or job coach with considerations regarding abilities and other non-work factors (i.e., travel mobility). A trained professional (i.e., job coach) then provided on the job training to the individual, while also advocating on behalf of the individual to the employer (Wehman \& Hill, 1985). Though the supported work model was the first step towards employment integration, limitations of the model have been recognized. Critics of the supported work approach noted that individuals were placed on the basis of job readiness, but few were ever deemed ready to participate (Novak, 2015). In addition, use of the model by staff without proper training often led to people with ID continuing to be placed in segregated employment settings (Agran et al., 2018).

At the beginning of the 1990s, the Individuals with Disabilities Education Act (IDEA, 1990) was amended to continue the integration of students with disabilities into educational settings and mandated appropriate services during the transition from school to post-school activities including employment. Around the same time period, the Office of Special Education and Rehabilitative Services (OSERS) was created in the U.S. Department of Education. This initiative funded 26 model demonstration projects to examine self-determination in individuals with disabilities (Ward, 2005). Throughout the 1990s, the degree to which individuals with ID were allowed to participate and have a choice in the services received expanded, minimizing the amount of choices made for 
them by service professionals (Wehman et al., 1999). In 2002, the U.S. Department of Labor, Office of Disability \& Employment Policy (ODEP) outlined a new employment model that met the needs of both the individuals with disabilities and the employers (Griffin et al., 2008).

\section{Customized Employment Model}

The key difference between the supported work model and the customized employment model was the emphasis on the interests and abilities of the individual (Griffin et al., 2008). The supported work model trained individuals the skills necessary for available jobs whereas the customized employment model used the individual strengths in negotiation with employers to find or customize a job fit (Callahan et al., 2011; Nazarov et al., 2012). The customized employment model eliminated the idea of job readiness, allowing more individuals to participate in employment activities (Nazarov et al., 2012). The flexibility of the customized employment model allowed for new routes to employment such as job restructuring (altering the job description to meet the needs of employee and employer) and self-employment, therefore, providing even more job opportunities for the individuals with ID transitioning to the workforce (Butterworth et al., 2000; Butterworth, et al., 2012). One potential drawback cited was the timeconsuming nature of the model; negotiating with potential employers was unrealistic for rehabilitation counselors with heavy caseloads (Griffin et al., 2008). In addition, there has been a lack of empirical data replicated to demonstrate the overall effectiveness of the model (Riesen et al., 2015). Despite these limitations, many programs to date report using the supported work model, customized employment, or a combination of both models (Butterworth et al., 2012). 


\section{Postsecondary Education Programs}

In 2008, the Higher Education Opportunity Act (HEOA) was revised to allow individuals with ID the opportunity to attend institutions of higher education to prepare for employment (Kleinert et al., 2012). Shortly after, the Workforce Innovative and Opportunity Act (WIOA, 2014) implemented funding for programs or initiatives that placed individuals with disabilities in competitive employment, integrated employment that pays minimum wage or higher (Joseph et al., 2017). These changes in legislation led to the formation of postsecondary education (PSE) programs, housed in institutes of higher education (e.g., college, university), that served as an additional transition option to prepare individuals with ID for competitive employment (Grigal et al., 2012). Research posited that completing any type of postsecondary program increased employability for individuals with ID (Getzel et al., 2001); however, career exploration and employment training were used in the majority of PSE programs (Petcu et al., 2015; Zafft et al., 2004). Similar to other employment models, PSE programs offered job development with job coaches, natural supports, unpaid work experiences, and paid work experiences in the curriculum (Grigal et al., 2012; Petcu et al., 2015). One best practice used in PSE programs not present in other supported employment models was personcentered planning, or a future planning model in which the individual is the focal point and directs the process by identifying strengths, weaknesses, goals, interests, and supports (Hart et al., 2010). A major limitation of the study of PSE programs is the varying programmatic structure, therefore, direct links between program components and

outcomes have not been explored (Prohn et al., 2018). These legislative and career model 
developments over the past four decades have demonstrated the shifting focus towards the individual and their career goals and choices.

\section{Social Cognitive Career Theory (SCCT)}

The Social Cognitive Career Theory or SCCT was developed by Robert W. Lent, Steven D. Brown, and Gail Hackett in 1994 to predict and explain the processes by which employment choices are made and careers are attained. The SCCT focused on three

personal constructs that interact with each other: self-efficacy, outcome expectations, and goal setting - all of which are affected by environmental and behavioral influences (Lent et al., 1994). The broad understanding of career development with the specific focus on the individual makes it a useful tool to explore the complexities of the population with ID. Additionally, the cyclical nature of the SCCT allows researchers to capture individuals' development through changing contexts, making it an ideal theory to use throughout the lifespan (Lent et al., 1994). The SCCT has been heavily researched and used to explain career development in a variety of diverse populations in a range of both qualitative and quantitative studies.

Applications of the SCCT as a framework have been utilized in studies of adolescents and young adults with varying disabilities including learning disability, epilepsy, developmental disability, and intellectual disability. In 1999, a study of 96 students (ages 14-18) with learning disabilities was conducted exploring the interaction between self-efficacy, personal attributes (e.g., ability), and career interests (Panagos \& DuBois, 1999). Outcomes of the study demonstrated a positive links between selfefficacy and career interest $\left(R^{2}=.25, p<.001\right)$ and self-efficacy combined with outcome expectations accounted for a significant amount of career interest scores $\left(R^{2}\right.$ s ranging 
from .25 to $.25, p<.01$; Panagos \& DuBois, 1999). A similar regression model study was conducted in 2017 on 90 participants (ages 18-25) with epilepsy (Sung \& Connor, 2017). Results indicated positive effects of the following variables to work participation: selfefficacy $\left(R^{2}=.168, p<.001\right)$, goal decidedness $\left(R^{2}=.25, p<.001\right)$, vocational outcome expectations $\left(R^{2}=.42, p<.001\right)$, and perceived support $\left(R^{2}=.39, p<.001\right)$. Sung and Connor (2017) also found that anxiety, depression, perceived barriers, and seizure activity were negatively related to work participation.

For individuals with ID in particular, the SCCT framework has been applied in qualitative studies in the United States and quantitative studies internationally. In a qualitative study of the career exploration and college awareness of 12 high school students with ID in the United States, major themes emerged in the areas of selfdetermination as related to self-efficacy, perceived barriers and supports, and consideration of career and college interests and goals (Gibbons et al., 2016). The researchers utilized criteria to increase credibility including triangulation, rigor, and member checking. In a quantitative study of self-efficacy and career interests of 129 adults with ID in Italy, self-efficacy was found to be correlated with multiple career interests. For example, realistic self-efficacy beliefs accounted for realistic career interests $\left(R^{2}=.43\right)$, artistic self-efficacy beliefs accounted for artistic interests $\left(R^{2}=.56\right)$, and social self-efficacy beliefs accounted for social interests $\left(R^{2}=.50\right.$; Nota et al., 2010).

These selected studies highlight the validity of the SCCT with populations with disabilities. The SCCT assumed that self-efficacy, or the belief that one can complete a task, mediates between the previous skills learned and performance attainment (Smith \& Fouad, 1999). Findings in studies of populations with disabilities aligned with this 
assumption, finding linkages between self-efficacy, career interests, and work

participation in groups of diverse abilities $\left(R^{2}=.168\right.$ to .56$)$ similar to previous findings of those without disabilities $\left(R^{2}=.40\right.$ to .50 ; Lent et al., 1994; Lent et al., 2005). The selected studies also highlighted perceived supports and barriers as key variables of the SCCT in the population with ID. Similar findings had been found on those without disabilities as supports and barriers significantly impact self-efficacy (Lent et al., 2001; Lent et al., 2005). Additionally, supports have been found to offset barriers in the SCCT model (Lent et al., 2005), similar to what was found in the research on those with ID (Gibbons et al., 2016).

\section{Adapting the SCCT Model}

The SCCT model focuses on many key constructs to career development over time that can be used for diverse populations (Lent et al., 1994). However, the research using the SCCT model on individuals with ID is modest in size and varies in terms of elements of the SCCT (Lent et al., 2013). For example, the only empirical study on individuals with ID focused primarily on career preferences, interests, and self-efficacy beliefs (Nota et al., 2010). Given the unique environmental challenges that individuals with ID in the United States face depending on locale (e.g., availability of programs or services), a further investigation of the environmental factors impacting multiple facets of employment preparation is needed (Retish \& Raiter, 1999). Additionally, the ongoing focus of legislation on career preparation in combination with the variety of employment models currently being used calls for further investigation of career development participation (Butterworth et al., 2012). The adaptation of the SCCT model will focus on environmental factors, personal attributes (e.g., self-determination), and career behavior. 


\section{Environmental Supports \& Barriers}

\section{Family Expectations}

Family members are the first environmental influence on children and their talk about working ultimately instills career values and expectations (Timmons, Hall, Bose, Wolfe, \& Winsor, 2011). Vocational interests of adolescents overall have been found to be influenced by family variables (Lapan et al., 1999). The vocational identity of children, beginning from early school years, is impacted by immediate or extended family members (Whiston \& Keller, 2004). Unlike adolescent peers that may begin to develop separate career interests during high school, individuals with disabilities' career decision-making remains in familiar areas (e.g., career choices of family members; Morningstar, 1997). In a study of 71 students with various disabilities ages 14-21, the majority noted career interests that were developed because of family connections (Morningstar, 1997). Thus, placing more emphasis on family in terms of career development for those with ID.

Research has demonstrated that influences from family members, along with other environmental factors, can act as either supports or barriers to employment for individuals with ID (Murray, 2003). As individuals transition into young adulthood, families prepare for more separation; however, families of individuals with ID are less likely to encourage acquisition of goals leading to independence (e.g., employment; Dixon \& Redacliff, 2001). This was demonstrated in a study of summer work predictors of 136 students with severe disabilities where family members' desire for the students to work positively or negatively impacted summer work outcomes. Of those with summer employment, $22.7 \%$ were the result of family members assisting with the job search. 
Alternatively, families not wanting the student to work accounted for $36 \%$ of those not working during the summer (Carter, Ditchman, et al., 2010). Similar results were found in a study of 338 transition-aged students with developmental disabilities, where family work preferences predicted employment outcomes $\left(R^{2}=19, p=.00\right.$; Simonsen \& Neubert, 2013).

The career expectations of family members have been found to have great influence on career development (Lindstrom \& Benz, 2002; Whiston \& Keller, 2004). Results of a survey of 16 individuals with ID from four vocational rehabilitation organizations demonstrated that high family expectations (e.g., gaining employment) were related to strong employment goals (Timmons et al., 2011). In contrast, family expectations for those with severe disabilities tend to be lower; therefore, impacting the types of career development experiences the individual participates in and after school (Grigal et al., 2011; Grigal \& Neubert, 2004). Family expectations for part-time and fulltime employment were found to be lower for individuals with severe disabilities in a study of 673 family members of individuals with intellectual or developmental disabilities (Gilson et al., 2018). A study of 59 individuals with learning disabilities, staff, and family members, found that low family career expectations limited employment interests and options (Lindstrom et al., 2007). Comparable results were found in a qualitative study of 15 individuals with ID ages 19-30, where families were cited as contributing to low job retention as the result of the expectation of potential failure of the individual with ID at work (Dixon \& Redacliff, 2001). Consequently, family expectations can impact the career behavior of individuals with ID. 
In addition to shaping career development, family expectations have been linked to personal attributes of those with ID. Self-worth and self-confidence have been designated as critical factors in developing self-determination (Wehmeyer, 2014), both of which have been linked to family expectations (Blackorby \& Wagner, 1996; Kohler \& Field, 2003). Wehmeyer (1999) created a widely-recognized self-determination model which denotes environmental factors impacting opportunities that affect the development of characteristics necessary for self-determination. The model posits that expanding the amount of options available to individuals with disabilities allows for the learning of new skills, leading to higher expectations and increased levels of self-determination over time (Wehmeyer, 1999). It has been found that families of individuals with ID are more likely to be overprotective, consequently limiting the practice of choice-making and other selfdetermined behaviors (Dixon \& Redacliff, 2001; Field, 1996). In studies on adults with and without disabilities conducted by Field (1996), participants indicated families acted as supports and barriers to becoming self-determined.

In Wehmeyer's (1999) model, self-efficacy is listed as a key component of selfdetermined behavior. Self-efficacy and self-determination are interrelated, whereas, low self-efficacy equates to low self-determination and the affiliated decision-making abilities in those with ID (Agran \& Krupp, 2011). Similar to previous research on selfdetermination outcomes, family expectations were found to affect the self-efficacy of 139 middle school students (Turner \& Lapan, 2002). Thus, family expectations can impact the individual with ID's self-efficacy, leading to self-determination.

Direct relationships to employment attainment and family expectations have been cited in the literature. In a case study of six women with learning disabilities, Lindstrom 
and Benz (2002) found that family expectations were a predictor of attaining career goals. Correspondingly, Turner and Lapan (2002) found that family expectations were related to the achievement of career goals for those with disabilities. In an examination of data from the National Longitudinal Transition Study 2 (NLTS-2), students with ID whose parents expected employment upon completion of high school were found to be 58 times more likely to be employed during a two-year follow up than those whose parents did not expect employment (Papay \& Bambara, 2014). Another examination of the NLTS-2 uncovered parallel results with family expectations of employment increasing the odds of being employed (OR $=1.73, p<.0001$; Wehman et al., 2015). Dixon and Redacliff (2001) found that family members of employed individuals with ID often made initial contact to employment agencies. In addition, families in the study offered verbal encouragement and, in some cases, physical rewards for finding and retaining jobs (Dixon \& Redacliff, 2001). As the literature suggests, families' expectations of individuals participating in employment can impact career outcomes.

\section{Availability of Community Resources}

Similar to family expectations, available resources in the community have been found to enhance or impede employment outcomes. In a study of 40 mothers of adolescents with disabilities, two major categories affecting career outcomes were identified: school and community (Lehmann \& Roberto, 1996). Those adolescents with an array of available courses and vocational programs at school had overall more positive school experiences (Lehmann \& Roberto, 1996). This aligns with the literature citing access to various choices and opportunities in schools along with strong support systems as necessary components of quality schools for those with disabilities (Brigharm et al., 
2006). An examination of the National Longitudinal Transition Study-2 (NLTS-2) found that participating in the community increased the odds of gaining employment by 1.16 times (Wehman et al., 2015). However, once individuals with disabilities leave high school, opportunities in the community can vary, leading to unique challenges (Retish \& Raiter, 1999). In the study by Lehmann and Roberto (1996), the general community was cited as an impeding factor on future expectations for those with more severe disabilities. Similar results were found in a study of 673 family members where lack of accessibility to programs that support individuals on the job was cited as a major employment concern (Gilson et al., 2018). In addition, factors such as access to public transportation and the community setting have been found to influence participation in career experiences, in turn, affecting employment outcomes (Gilson et al., 2018; Sima et al., 2015). Therefore, availability of community resources can influence the career behavior of individuals with ID.

Successful career experiences are one of the most influential factors in the development of self-efficacy (Bandura, 1997), therefore available career development options in the community for those with ID provide opportunities for development of self-determination characteristics. In a study of 111 students with cognitive disabilities involved in a summer work experience program, 67\% reported feeling prepared to work in the community upon program completion (McConnell et al., 2018). The availability of inclusive career experiences for those with ID is of importance as work experiences that occur in inclusive environments allow for vicarious learning by observing others modeling career behaviors (Bandura, 1997). An empirical study of 31 adults with ID ages 24 to 62-years-old supported this concept as participants that moved from restrictive 
vocational environments to competitive employment settings demonstrated increased self-determination ( $M=101.6$ to $M=109.71$; Wehmeyer \& Bolding, 2008). Availability of career development experiences then can influence self-determination characteristics.

The accessibility to career development options have also been cited as predictors for employment. In an examination of the National Education Longitudinal Study of 1988-1994, Harvey (2002) found that having access to vocational education in high school accounted for $21 \%$ of employment outcomes for individuals with and without disabilities. Similarly, access to occupational preparation and guidance in high school accounted for $37 \%$ of employment outcomes in a follow up study of 38 students in special education (Roessler et al., 1990) and access to community-based training for 104 students with severe disabilities accounted for $39 \%$ of employment outcomes (White \& Weiner, 2004). A study of 1,054 youth with disabilities found a causal relationship between early exposure to work experiences and employment outcomes (Mamun et al., 2018). Therefore, access to early work experiences is crucial as it has a significant effect on post school employment.

\section{Personal Attributes}

Historically, individuals with ID have been found to lack self-determination characteristics in comparison to peer groups without disabilities. Wehmeyer (1994) found that students ages 13-20 with disabilities held more external locus of control and less internal responsibility for success than other groups without disabilities. The acquisition of these characteristics is critical as the level of self-determination during high school years has been found to be a significant predictor of self-determination as individuals transition from school (Shogren et al., 2015). In a longitudinal study of 779 students with 
disabilities, the self-determination level at the first checkpoint significantly predicted the self-determination level at the second checkpoint $(\beta=0.512, p<.001)$ and the second checkpoint significantly predicted the third checkpoint $(\beta=0.487, p<.001$; Shogren et al., 2015).

The literature both on individuals with ID and the SCCT suggests that selfdetermination characteristics are integral to employment (Lent et al., 1994; Wehmeyer, 1999). The self-determination model outlined by Wehmeyer (1999) denoted the necessity of the presence of self-determination characteristics (e.g., self-regulation, self-realization) in individuals with ID to analyze feedback from family members or supports and adjust career behavior accordingly. To adjust work behavior, individuals require self-regulation, or the process of observing and evaluating one's behavior (Whitman, 1990). For example, a qualitative study of two individuals with ID working in a restaurant identified continuous improvement of performance and willingness to learn as the top two factors for employment success (Feerasta, 2017). Other characteristics of self-determination have also been identified as significant to facing the barriers to employment, including selfawareness and feeling empowered to problem-solve (Thoma \& Getzel, 2005). The selfdetermination characteristics of self-realization, empowerment, and autonomy were found to be significant mediators between school factors and post school outcomes (Shogren et al., 2017). Similar results were found in a study of students with learning disabilities where self-regulation $\left(R^{2}=.243, p=.03\right)$ and empowerment $\left(R^{2}=.283, p=\right.$ .02) significantly correlated with pay per hour (Wehmeyer \& Schwartz, 1997).

The relationship between self-determination and career outcomes consists of indirect influences on career behavior and direct influences on employment acquisition. 
Factors that contribute to career behavior and development as originally outlined by Super (1983) included the willingness of the individual to explore available careers and participate in school or community-based opportunities or activities. The possession of self-determination affects how individuals with ID utilize community resources to fulfill personal responsibilities (e.g., employment; Wehmeyer, 1999), therefore, affecting career behavior. Individuals seeking assistance and resources for employment outside of their immediate network (e.g., the internet) are more likely to transfer that skill to career behavior (McConnell et al., 2012; Thoma \& Getzel, 2005). Considering individuals with disabilities with self-determination skills are more likely to achieve personal goals, feel more social responsibility, and possess more problem-solving abilities, self-determination directly affects career-based decision-making (Agran \& Krupp, 2001; Berry \& Hardman, 1998). For example, an individual with ID may express self-determination by choosing a preferred career development experience (Field et al., 1998).

Empirical research supports this relationship as individuals with higher levels of self-determination have been found more likely to participate in job training or career development experiences after high school leading to other positive post school outcomes (Wehmeyer \& Palmer, 2003). Higher levels of self-determination have been associated with employment attainment, job satisfaction, and job retention (Shogren et al., 2015; Wehmeyer \& Palmer, 2003). In a study of 94 students with varying types of disabilities over a three-year period, results indicated that students with higher levels of selfdetermination were more likely to have a job by the first year follow up and more likely to hold a job or receive job training by the third year (Wehmeyer \& Palmer, 2003). Comparatively, a longitudinal study of 779 students ages 14-21 with disabilities 
demonstrated that the initial influence of self-determination on employment continued as students moved further from high school (Shogren et al., 2015). In a chi-square analysis of 94 students with disabilities, those with high self-determination were more likely to attain employment that provided benefits ( $p=.021$; Wehmeyer \& Palmer, 2003). In addition, self-determination scores combined with IQ and participation in vocation classes were found to account for $81 \%$ of reported pay rates (Wehmeyer \& Schwartz, 1997). Thus, the literature suggests that possessing self-determination skills leads to increased career behavior and positive employment outcomes.

Though research uses self-determination as an aggregate of several characteristics (Palmer et al., 2012; Shogren et al., 2015; Shogren et al., 2018; Wehmeyer \& Palmer, 2003), self-efficacy, or the confidence in oneself to perform a job or task (Tierney \& Farmer, 2002), has been found to be standalone predictor of employment outcomes. In a study of 1,147 employed adults, self-efficacy was found using the SCCT to account for 82\% of occupational choices (Donnay \& Borgen, 1999). A meta-analysis of 114 studies found self-efficacy to be a profound characteristic in regards to work behavior with an average correlation of $\mathrm{G}\left(r_{+}\right)=.38, p<.01$ between self-efficacy and work performance (Stajkovic \& Luthans, 1998). For those with disabilities specifically, self-efficacy was found to be correlated with length of employment $(r=.383, p<.01)$ in a study of 84 individuals receiving vocational rehabilitation services (O'Sullivan et al., 2012). In addition to employment outcomes, self-efficacy has been found to impact overall selfdetermination in those with disabilities. In a study of 168 students with varying disabilities, self-efficacy was found to be a significant predictor of self-determination $\left(s r^{2}\right.$ 
$=.019, p<.01 ;$ Lee et al., 2012). Therefore, self-efficacy can influence selfdetermination as well as employment outcomes.

\section{Career Behavior}

Studies have found individuals with ID participate in fewer career development experiences than those students with other types of disabilities. In a study of 34 high schools, nine of the 20 career development activities offered by the school were not offered to students with ID (Carter et al., 2010). Engagement in career development experiences has been associated with improved employment outcomes for the population with ID (Wehman, 2013). In a study of 136 youth with severe disabilities in 29 different high schools, having work experience during the spring led to 1.66 odds increase of summer employment (Carter et al., 2010). A similar odds ratio was round in a study of the National Longitudinal Transition Study (NLTS), in which individuals who had two or more jobs in school were approximately twice as likely to be competitively employed out of school than those who did not have as many jobs (Doren \& Benz, 1998).

Carter et al. (2012) found that most career development models emphasize the importance of individuals with ID accessing an array of career development experiences and supports offered during or outside of school. Luecking (2009) identified seven main types of career development experiences: career exploration, job shadowing, job sampling, service learning, internships, apprenticeships, and paid employment. These seven types of experiences provide an exploration of various careers, on the job training, and paid employment opportunities. Research has demonstrated these three types of career experiences lead to employment for individuals with ID (Chadsey-Rusch et al., 1991; Joshi et al., 2012). In a longitudinal study of 1,650 students with varying 
disabilities, those who participated in career skills training programs that included multiple types of experiences were 1.5 times more likely to gain competitive employment than those that did not participate (Flexer et al., 2011). It is important to note that individuals participating in career skills training programs while remaining segregated may not display positive employment outcomes. In a study of 409 students with ID, no significance between a career skills training program and employment outcomes were reported with researchers citing nearly $80 \%$ of the students not being in inclusive settings as the probable causation (Baer et al., 2011).

\section{Career Exploration}

Career exploration activities are the most commonly offered services to individuals with ID. In an analysis of the National Longitudinal Transition Study-2 (NLTS-2), 74\% of respondents participated in job searches and $67.8 \%$ were involved in job readiness training (Park \& Bouck, 2018). The relationship between career exploration and employment outcomes has primarily been found to be indirect; however, when compounded with other factors has been found to be an employment predictor. Career exploration is based on the principle that to be career ready, a person must become aware of their interests, strengths, and skills (Cease-Cook et al., 2015). Participation in career behavior has been correlated with these career readiness skills including refining career interests, determining career goals, and working towards a dream job (Timmons et al., 2011). Trembath et al. (2010) found that unpaid work such (e.g., volunteering, job shadowing) assisted individuals with ID with determining career paths and exploring job options. In a study of 11 individuals with ID, using career exploration software was found to assist with identifying career preferences while also enhancing self-determination 
skills (Stock et al., 2003). Career exploration indirectly affects employment by assisting individuals with ID in selecting jobs consistent with their abilities, interests, and goals while also providing exposure to new career options (Kluesner et al., 2005). In cases where individuals are attending postsecondary (PSE) programs, career exploration has been correlated with employment outcomes. In a study of national data from over 60 PSE programs, students who participated in volunteering and community service were 3.06 times more likely ( $p=.036)$ to earn at or above minimum wage (Qian et al., 2018).

\section{On the Job Training}

On the job training includes hands-on activities such as internships and apprenticeships. There has been a cited relationship between these types of career activities and positive employment outcomes (Shandra \& Hogan, 2008). In an examination of the National Longitudinal Transition Study-2 (NLTS-2), hands-on work experiences were found to be significant predictors of employment (Carter et al., 2012). Luecking (2009) defined internships as an assignment of specific tasks during a predetermined timeframe. Whether paid or unpaid, internships have been found to be beneficial to individuals with ID by providing opportunities for individuals with ID to demonstrate on the job skills (Luecking \& Fabian, 2000) and collect employment references for future work (Gadbow \& Dubois, 1998). In an examination of The National Longitudinal Survey of Youth 1997, participation in internships was found to be related to higher hourly compensation $(\beta=.101, p<.01$; Shandra \& Hogan, 2008). Similar to internships, apprenticeship style programs have also demonstrated positive employment outcomes. A study of an inclusive PSE vocational skills training program preparing students to become support professionals reported an $84 \%$ employment rate at program 
completion and $88 \%$ job retention rate at one year follow up. Students from the study cited the ability to practice skills in real world settings as critical to feeling prepared for competitive employment (Zhang et al., 2018).

\section{Paid Employment}

The positive relationship between paid work experiences and employment outcomes has been well documented. Paid work experiences whether in school or in the community have been found to increase the odds of post school employment (Carter et al., 2012). In a review of articles covering competitive employment prediction from 2010 to 2017 , seven of the 13 selected articles found paid employment to be a significant predictor in some cases more than doubling the likelihood of employment attainment (Southward \& Kyzar, 2017). Similar results were found in a follow up study of 1,547 students with disabilities, students who held paying jobs when exiting high school were 3.8 times more likely to be employed one year after high school completion (Rabren et al., 2002). Students who attend PSE programs in conjunction with paid employment demonstrated more significant outcomes. In a nationwide study of PSE programs, students with prior work experience paid at or above minimum wage were 3.30 times more likely $(p<.01)$ to have a job paid at or above minimum wage during the program (Qian et al., 2018). In a similar sample, the odds of post program employment significantly increased if the student obtained a paid job while in the PSE program $(\mathrm{OR}=$ $14.841, p<.001)$ or if the student held a paid job prior to beginning the program $(\mathrm{OR}=$ $2.803, p<.001$; Grigal et al., 2018). According to the literature, participating in career development experiences helps individuals understand their strengths and weaknesses in 
various settings and acquire new career skills, hence increasing the behavior necessary for attaining employment.

\section{A Proposed Employment Model}

The review of the literature demonstrated the interrelationships between the SCCT (Lent et al., 1994) constructs in terms of individuals with ID. Environmental factors including family expectations and available community resources have been found to act as supports or barriers to the development of the personal attributes selfdetermination as well as the engagement in career behavior (Gibbons et al., 2016; Papay \& Bambara, 2014). The personal attribute of self-determination has been found to increase career behavior and employment outcomes (Wehmeyer \& Palmer, 2003; Wehmeyer \& Schwartz, 1997). Career development experiences including career exploration (Quian et al., 2018), on-the-job training (Luecking \& Fabian, 2000), and paid employment (Southward \& Kyzar, 2017) have been found to be significant predictors of employment. As a result of the relationship between self-determination, career behavior, and employment outcomes, environmental supports and barriers both directly and indirectly impact the attainment of employment. Currently, empirical research examining the associations between the three SCCT constructs (environmental factors, personal attributes, career behavior) and employment outcomes for individuals with intellectual disabilities is limited (Lent et al., 2014). Using the SCCT and the concepts in the literature, an adapted employment model was created to predict career outcomes for those with ID (See Figure 2). 
Figure 2. Hypothesized employment model adapted from Lent, Brown, \& Hackett (1994)

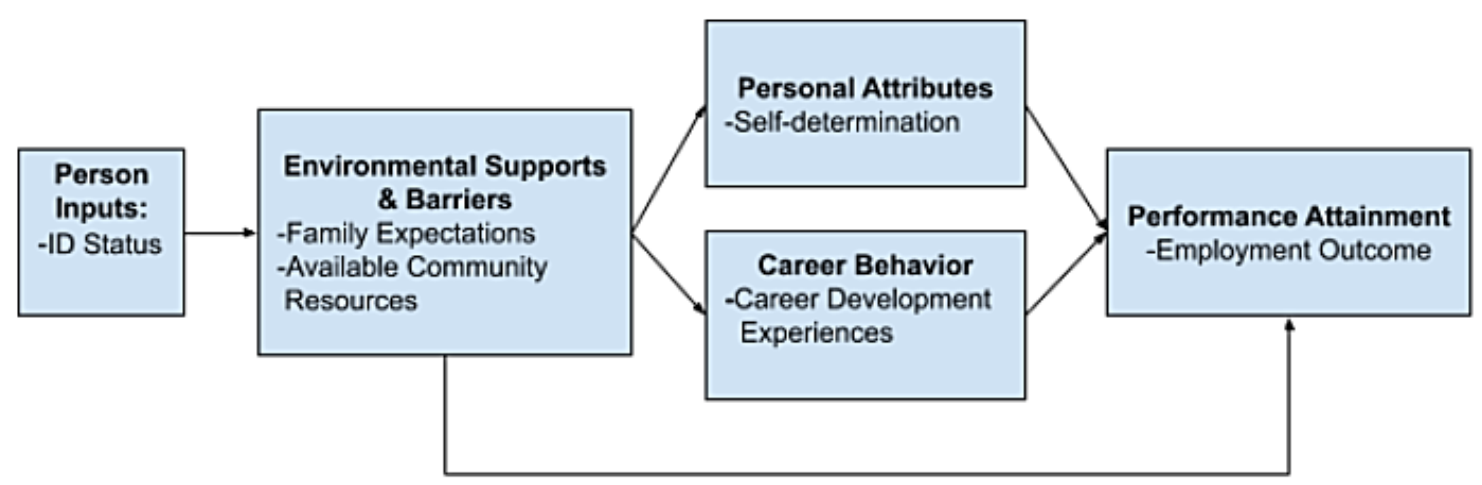

To understand why some individuals are achieving employment while a majority are remaining unemployed, the factors surrounding career behavior must be fully understood (Wehman et al., 2018). The SCCT constructs in the hypothesized model affect individuals with ID throughout the lifespan (Lent et al., 1994) which encompasses adults with ID who are not entering the workforce. One best practice noted in the literature to increase employment for individuals with disabilities is providing an array of career development opportunities with trained supports (Carter et al., 2012). This employment model may assist those professionals working with adults with ID and their families to implement additional programs or activities that can enhance the probability of becoming employed.

\section{Summary}

This chapter examined the literature on societal and legislative views on career development for individuals with ID and the corresponding career development models that have been implemented. Following was a discussion of the Social Cognitive Career Theory (SCCT) and the variables impacting career development including environmental 
factors, personal attributes, and career behavior. Finally, an employment model adapted from the SCCT was proposed. 


\section{CHAPTER III}

\section{METHOD}

This section begins with the purpose of the study and the research questions repeated from Chapter I. Following is a description of the research design, the population and sample, and the variables and instruments used to measure the variables. The chapter concludes with a discussion of the procedures for data collection and data analysis.

\section{Purpose of the Study}

The purpose of this research study was to test a hypothesized social-cognitive employment model for individuals with ID in Miami, Florida, USA who have completed high school by examining the association between family expectations, available community resources, self-determination, engagement in career behavior, and the outcome of employment.

\section{Research Questions and Hypotheses}

The overarching research questions were: (a) What is the association between the personal attribute of self-determination and performance attainment of employment of individuals with ID? (b) What is the association between participation in career behavior and performance attainment of employment of individuals with ID? (c) What is the association between family expectations, available community resources, and performance attainment of employment of individuals with ID? and (d) What are the unique contributions of personal attributes and career behavior on employment attainment after controlling for environmental supports and barriers (i.e., family expectations and available community resources)? 
H1: When working with individuals with ID, reports of higher self-determination will be positively linked to attaining employment.

H2: When working with individuals with ID, reports of higher levels of involvement in career behavior will be positively linked to attaining employment.

H3: When working with individuals with ID, reports of high family expectations and larger quantities of available community resources (e.g., educational programs) will be linked positively to attaining employment.

H4: Personal attributes and career behavior will make a unique contribution to employment attainment after controlling for environmental supports and barriers (i.e., family expectations and available community resources).

\section{Population and Sample}

\section{Population}

The population of interest was composed of adults (both male and female, age 22 and older) diagnosed with an intellectual disability in the mild range (IQ = 50-69),. The age group was selected to represent individuals who have transitioned to adulthood and are no longer receiving services from the local school district. The mild range of ID was selected for two reasons: (a) to ensure all participants had the ability to complete at least a 30-minute survey that was read aloud in English and (b) to maximize the number of eligible participants given the parameters (85\% of individuals with ID are considered to be in the mild range; van Bokhoven, 2011). The participants were selected from three different non-profit agencies that serve individuals with disabilities in Miami, Florida. The population selected included individuals regardless of employment status or type of current employment (e.g., competitive employment). 


\section{Sample}

Non-probabilistic sampling methods were used for the present study as the sample required individuals specifically with a diagnosis of mild ID. Convenience sampling was used by identifying intermediaries at each non-profit location to gain access to the organization and to identify potential candidates with a diagnosis of mild ID (Lennox et al., 2005; Nicholson et al., 2013). Convenience sampling is a common method used for hard to reach populations where an available sample is used to generalize to the entire population (Valerio et al., 2016). There were three independent variables in the current study. For prediction methods, a sample size of 5 to 50 individuals per variable is suggested (Green, 1991). An initial sample size of 75 individuals was chosen to maximize statistical power.

A total of 76 participants ages 22-66 $\left(M_{\text {age }}=38.0, S D=11.24\right)$ completed the survey at three non-profit locations. Of the 76 participants, the majority of respondents reported having a job $(n=57 ; 75 \%)$. Due to the unique demographic makeup of South Florida, the demographics of the sample were reported in comparison with those of the Miami-Dade County, Florida. The demographic distribution of participants is displayed in Table 1. 


\section{Table 1}

Demographic Distribution of Sample

\begin{tabular}{|c|c|c|c|c|}
\hline \multirow[t]{3}{*}{ Variables } & \multicolumn{2}{|c|}{ Sample } & \multicolumn{2}{|c|}{ Miami-Dade County, Florida 2019} \\
\hline & & & \multicolumn{2}{|c|}{ Population Estimates } \\
\hline & $n$ & $\%$ & $n$ & $\%$ \\
\hline \multicolumn{5}{|l|}{ Gender } \\
\hline Male & 34 & $44.7 \%$ & $1,317,715$ & $48.5 \%$ \\
\hline Female & 38 & $51.3 \%$ & $1,399,224$ & $51.5 \%$ \\
\hline Prefer Not to Answer & 3 & $4.0 \%$ & - & - \\
\hline \multicolumn{5}{|l|}{ Race } \\
\hline Hispanic/Latino & 41 & $53.9 \%$ & $1,877,405$ & $69.1 \%$ \\
\hline African American/Black & 20 & $26.3 \%$ & 486,332 & $17.9 \%$ \\
\hline White/Non-Hispanic & 13 & $17.2 \%$ & 353,202 & $13 \%$ \\
\hline Asian & 2 & $2.6 \%$ & 51,621 & $1.9 \%$ \\
\hline
\end{tabular}

Note. $N=76$.

Miami-Dade County 2019 Estimates retrieved from United States Census Bureau (2019). QuickFacts: Miami-Dade County. http://www.census.gov/quickfacts/fact/table/miamidadecountyflorida

\section{Ethical Considerations}

In addition to the acquired Institutional Review Board approval from FIU, this study followed the international ethics guidelines set by the International Association for the Scientific Study of Intellectual Disabilities. That is, the power imbalance between the researcher and participants was acknowledged through the adaptation of the research 
design to ensure respect for the participants and maximize research integrity (Dalton \& McVilly, 2004; Griffin \& Balandin, 2004). One method utilized in this study to address the unequal power dynamics was the incorporation of a Board of three individuals with ID not participating in the study who were utilized as consultants (Kitchin, 2000). The Board provided an outsider perspective to ensure that the data collection was properly representing the voices of the population. In addition, reduction of coercion was considered throughout the duration of the study (Griffin \& Balandin, 2004). One method of minimizing coercion included intermediaries being instructed not to communicate information about the research study to the participants (McDonald \& Kidney, 2012).

\section{Variables and Instrumentation}

The study utilized an online survey in alignment with the Tailored Design Method (Dillman, 2007). The Tailored Design Method was used because it allows the ability to use a small percentage of a population and generalize results to the greater population. The online survey contained a total of three scales, one per independent variable. The independent variables were as follows: environmental supports and barriers, personal attributes, and career behavior. The dependent variable was the outcome of employment. The dependent variable was measured by a dichotomous (i.e., No or Yes; coded 0 or 1) question "Do you have a job?" This format for the dependent variable was selected because previous literature on predictor variables cited The National Longitudinal Transition Study-2 (NLTS-2), which measured employment by asking if the individual was currently employed at the time of the study. Demographic information was also gathered at the beginning of the survey and included three questions: an openended age question, a multiple-choice gender question, and a dropdown list of 
races/ethnicities (i.e., African American/Black, Hispanic/Latino). All questions in the survey were selected because of ease of comprehension and were written in complete sentences (Dillman, 2007). In addition, all questions related to the variables were closedended to increase test-retest reliability scores (Perry, 2004). Dichotomous questions requiring a "yes" or "no" answer were avoided whenever possible to reduce acquiescence bias (Heal \& Sigelman, 1995; Perry, 2004). No Likert-style questions were used in this study to ensure that answers required only concrete-level thinking (Hartley \& MacLean, 2006).

\section{Instrument Development}

An instrument was developed with three scales, one per independent variable: career behavior, personal attributes, and environmental supports and barriers. Each scale was in a checklist format with answers coded as 0 (not checked) or 1 (checked). All three scales included subscales which are described hereafter. The responses from the subscales were combined resulting in a total number value per scale for each participant. Please refer to Table 2 for a detailed list of the three scales, corresponding subscales, and total number of items per scale. 


\section{Table 2}

Scales, Subscales, and Items Per Scale

\begin{tabular}{|c|c|c|c|}
\hline Scale & & Subscales & $\begin{array}{l}\text { No. of } \\
\text { Items }\end{array}$ \\
\hline \multirow{4}{*}{$\begin{array}{l}\text { Career Behavior Scale } \\
(\# \text { items }=22 ; \alpha=.768)\end{array}$} & & Vocational-Related Services & 5 \\
\hline & & Work-Based Experiences & 8 \\
\hline & & Workplace-Support Services & 4 \\
\hline & & $\begin{array}{l}\text { Training on Vocational- } \\
\text { Related Services }\end{array}$ & 5 \\
\hline \multirow{3}{*}{$\begin{array}{l}\text { Personal Attributes Scale } \\
(\# \text { items }=29 ; \alpha=.637)\end{array}$} & & Independence & 11 \\
\hline & & $\begin{array}{l}\text { Acting on Preferences, } \\
\text { Beliefs, Interests, \& Abilities }\end{array}$ & 12 \\
\hline & & Self-Realization & 6 \\
\hline \multirow{7}{*}{$\begin{array}{l}\text { Environmental Supports } \\
\text { \& Barriers Scale } \\
(\# \text { items }=40 ; \alpha=.721)\end{array}$} & Family & General Family Support & 5 \\
\hline & & $\begin{array}{l}\text { Family Employment } \\
\text { Expectations }\end{array}$ & 7 \\
\hline & & $\begin{array}{l}\text { Family Independence } \\
\text { Expectations }\end{array}$ & 7 \\
\hline & $\begin{array}{l}\text { Community } \\
\text { Resources }\end{array}$ & Transportation Services & 5 \\
\hline & & Community Programs & 6 \\
\hline & & Education Programs & 7 \\
\hline & & Other Community Resources & 3 \\
\hline
\end{tabular}




\section{Career Behavior Scale}

To examine what types of career behavior the participants had engaged in, the vocational-related support services section of a larger survey originally conducted by Petcu et al. (2015) was adapted for use by individuals with ID. This national survey was created to capture the supports and services offered by postsecondary education (PSE) programs by surveying Directors of the programs. The original survey consisted of a vocational-related support services section and programmatic features section (e.g., institution size, program length). For the present study, only the vocational-related support section was used as PSE programs were implemented for individuals specifically diagnosed with ID and represent the most current snapshot of employment preparation (Papay \& Bambara, 2011). Though no validity evidence was reported for this measure, the questions were derived from existing literature on vocational preparation for individuals with ID (Petcu et al., 2015).

The career behavior scale in the present survey consisted of four checklists: vocational-related services (e.g., person-centered planning), work-based experiences (e.g., internships), workplace-support services (e.g., job coach), and training on related vocational-services (e.g., disability benefits; Petcu et al., 2015). The adapted format eliminated the distinction between on-campus work and off-campus work experiences, as not all participants may have participated in a PSE program. Separate items on the checklists were coded either " 0 " if it was not checked or " 1 " if it were. The four checklists had the following value ranges: vocational-related services (0-5), work-based experiences (0-8), workplace-support services (0-4), and training on related vocational services (0-5). The total value range of the career behavior scale was 0 to 22 and 
reliability analysis demonstrated a Cronbach's $\alpha$ of .768. Please refer to the Appendix for the full survey.

\section{Personal Attributes Scale}

The functional model of self-determined behavior for people with ID developed by Wehmeyer (1999) suggests significant conceptual overlap between self-efficacy and self-determination. Self-efficacy was one of eight identified constructs that contribute to self-determined behavior in the population with ID; therefore, the measurement of selfdetermination is comprised in part by self-efficacy.

To measure the personal attribute of self-determination, The Arc's SelfDetermination Scale was selected for adaptation. The scale was selected as it is rooted in the functional theory that self-determination emerges across the lifespan (Shogren et al., 2008 ) and since its creation in 1995 , has since been recognized as a valid and reliable tool for measurement with people with intellectual disabilities (Verdugo et al., 2015). Upon its development, the scale underwent a factor analysis which provided construct validity evidence. Additionally, the scale returned a Cronbach's $\alpha$ of .89 demonstrating reliability (Wehman, 1996). More recently, a two-group confirmatory factor analysis was conducted on the scale and provided considerable evidence of validity measures (Seo et al., 2015). There are two versions of The Arc's Self-Determination Scale, one of which is specifically for adults with ID, designed for administration to individuals or small groups (Wehmeyer et al., 2014). The original adult scale had four sections: autonomy, selfregulation, psychological empowerment, and self-realization. Two major adaptations were made to The Arc's Self-Determination Scale for use in the present study (a) changing the format of the survey from Likert-scale (e.g., I do sometimes, I do most of 
the time) to a checklist format (e.g., select all statements that reflect what you do on a regular basis) and (b) omitting self-regulation section as it was not intended for a selfreported study. The adaptation of Likert-scale items was made because there has been compelling research suggesting that individuals with lower reading or comprehension levels have difficulty answering five-point Likert scales (Chachamovich et al., 2009; Hartley \& MacLean, 2006). Answering a Likert-scale question requires the intellectual ability to match items in order of magnitude and rank items from concrete to abstract in a scale format (Cummins, 1997). The adaptation from this format maximizes the number of individuals with mild ID to complete the survey.

The finalized personal attributes scale consisted of three checklists adapted from The Arc's Self-Determination Scale: independence (e.g., I choose how to spend my own personal money); acting on preferences, beliefs, interests, and abilities (e.g., I make longterm career plans); and self-realization (e.g., I am confident in my abilities). Separate items on the checklists were coded either " 0 " if it was not checked or " 1 " if it were. The three checklists then had the following value ranges: independence (0-11); acting on preferences, beliefs, interests, and abilities (0-12); and self-realization (0-6). The total value range of the personal attributes scale was 0 to 29 and reliability analysis demonstrated a Cronbach's $\alpha$ of .637. Please refer to the Appendix for the full survey.

\section{Environmental Supports and Barriers Scale}

The environmental supports and barriers scale was comprised of two sections based on the literature: family expectations and community resources. 


\section{Family Expectations.}

To examine perceived family expectations, three subscales were created using both findings from previous literature and an adaptation of the Future Expectations Scale for Adolescents (FESA). The FESA was developed to determine the extent of which individuals believe statements about the future and has been typically administered to adolescents and family members in at-risk environments (McWhirter \& McWhirter, 2008). The FESA underwent a construct validity examination, which demonstrated initial validity and reliability of the instrument. In addition, the reliability of the scale was supported through a Cronbach's $\alpha$ of .88 (McWhirter \& McWhirter, 2008). Statements from the FESA were adapted to measure what the participant believed families wanted for their future (e.g., reach my goals).

In addition to the statements from the FESA, questions regarding securing employment were added as family expectations have been found to be positively correlated with employment outcomes (Carter et al., 2012; Papay \& Bambara, 2011). Working in an inclusive setting (e.g., working with others without disabilities) was added as family expectations regarding preferred level of restriction of work setting were found to be affected by type of disability (Blacher et al., 2010). Attending college or university was added as it has been found that family expectations for postsecondary education for individuals with disabilities are significantly lower than the general population regardless of family education level (Cheatham et al., 2013). Previous research demonstrated that families voiced concern regarding individuals being involved in the community, having friendships, and living independently; therefore, questions were added to reflect these concerns (e.g., live on my own; Cheatham et al., 2013). 
The family expectations section of the environmental supports and barriers scale was comprised of three main subscales: general family support (e.g., My family is proud of me), family employment expectations (e.g., My family wants me to work), and family independence expectations (e.g., My family wants me to use public transportation). Separate items on the checklists were coded either " 0 " if it was not checked or " 1 " if it were. The three subscales had the following value ranges: general family support (0-5), family employment expectations (0-7), and family independence expectations (0-7). Please refer to the Appendix for the full survey.

\section{Community Resources.}

To examine the types of community resources accessed by the individuals, four subscales were derived from a review of the literature and validated by professionals in the field. As previously stated, the general community has a direct impact on future expectations for those with disabilities (Lehmann \& Roberto, 1996). Therefore, the checklist used for the study was created specifically for the South Florida community in which the participants reside. The content of the survey was validated by staff at the three non-profits providing access to participants, vocational rehabilitation staff, and key personnel in the local school district. In addition, potential environmental barriers were addressed in the checklists. For example, access to public transportation, to community resources, and programs that support individuals on the job have been cited as barriers to competitive employment (Gilson et al., 2018). The community resources section of the environmental supports and barriers scale was comprised of four subscales: transportation services (e.g., I have used a public bus), community programs (e.g., I have been part of Special Olympics), education programs (e.g., I have attended a college or university 
program), and community resources (e.g., I have used the public library to search for jobs). Separate items on the checklists were coded either "0" if it was not checked or "1" if it were. The four subscales had the following value ranges: transportation services (05), community programs (0-6), education programs (0-7), and community resources ( 0 3). The total value range for the environmental supports and barriers scale (family expectations and community resources) was 0-40 and reliability analysis of the environmental supports and barriers scale demonstrated a Cronbach's $\alpha$ of .721. Please refer to the Appendix for the full survey.

\section{Pilot Testing Procedures}

The survey instrument was pilot tested by all individuals on the Board prior to implementation through individualized meetings. This procedure ensured research integrity by including voices of the population and ensured content validity by assessing whether the items were comprehensive in reflecting the content relevant for the constructs being investigated in this research. In addition, this process ensured that the survey format, written and verbal instructions, and response options were understandable to the population with ID (Brod et al., 2009). Each Board member took the survey in the manner it would be administered in the field. During the pilot testing, each member was encouraged to use the "think-aloud" method and provide feedback as to how the answers were being determined and any missing information from the question (Charters, 2003). After the pilot testing was complete, the researcher requested feedback from each individual on the Board regarding comprehension, vocabulary level, and length of survey.

The feedback received during the pilot test was recorded and the following edits were made. The primary concern of the individuals on the Board was the length of the 
survey instrument. In all cases, the verbal feedback was provided in the middle of the personal attributes scale (the longest scale in the survey). It has been previously documented that lengthy research instruments lead to individuals with ID becoming tired, confused, or frustrated (McDonald, 2012). Thus, this concern was addressed by shortening the personal attributes section from 47 items to 29 items. Another concern of the Board was vocabulary used in the survey. To address this concern, vocabulary was adjusted to ensure ease of comprehension. For example, "long-range" was changed to "long-term" and "metro mover" was changed to "Metrorail or train." One Board member noted that the statements regarding feelings about oneself could be considered sensitive to some individuals (e.g., I accept my limitations). To address this concern, an edit was made to the instructions that the section may include some personal information. The survey was then tested once more with the Board before considered finalized.

\section{Data Collection Procedures}

After appropriate guidance by FIU's Institutional Review Board, a letter was sent to each of the non-profit locations explaining the purpose of the research study and anticipated benefits. A follow-up meeting was held with each non-profit organization explaining the procedure, identifying potential participants, and scheduling the dates and times of the data collection.

Prior to beginning the survey, the purpose of the study, benefits of the study, and confidentiality procedures were explained to each participant (Kitchin, 2000). The consent form was presented to each participant and explained to ensure comprehension. Each participant with ID in the study signed a consent form. Participants had the option to bring a natural support to assist with understanding of the consent form and survey. 
Proxy consent was only used for those individuals who did not have personal guardianship (McDonald \& Kidney, 2012). Only two participants requested a natural support to assist with comprehension of the survey. In alignment with best practices for the population, all participants were granted the right to leave a question blank, take a break, or withdraw from the study at any time (Hall, 2013).

The finalized survey was created using Qualtrics XM survey software and accessed through an anonymous survey link. The survey was administered to and completed by participants with ID via an iPad at the selected three different non-profit locations. Traveling to the location allowed for participants who did not have means of travel to participate (Perry, 2004). Participants completed the online survey individually with the researcher in a quiet area. Each question was read orally to participants and the participant selected the final answer on the iPad. Some participants requested that the researcher select the items on the iPad on their behalf. Participants asked for clarification and the researcher answered questions to ensure comprehension. The entire survey took approximately 15-45 minutes to complete, depending on the comprehension level of each participant. Participants were free to take breaks as needed and return to the survey if feeling fatigued (McDonald, 2012).

\section{Data Analysis}

To test the hypotheses, the study examined the relationships among four variables (three independent and one dependent) through a logistic regression analysis using the SPSS v.23.0 program: (a) environmental supports and barriers, (b) personal attributes, and (c) career behavior (independent variables), and (d) employment outcome (dependent variable). Logistic regression was selected for this study because it allows for robust 
examination of multiple independent variables' effect on variance on a single discrete dependent variable (Hosmer et al., 2013). Logistic regression modeling also allows for the consideration of contribution of each predictor variable by itself as well as combined with the other predictor variables (Tonidandel \& LeBreton, 2010).

To test for the first hypothesis, H1, a logistic regression was used to determine if the personal attribute of self-determination accounted for the performance attainment of employment. To test for the second hypothesis, $\mathrm{H} 2$, logistic regression was used to determine if participation in career behavior accounted for the performance attainment of employment. To test for the third hypothesis, $\mathrm{H} 3$, a logistic regression was used to determine if environmental factors of family expectations and available career related experiences in the community accounted for the performance attainment of employment. To test for the last hypothesis, $\mathrm{H} 4$, a hierarchical logistic regression controlling for environmental factors was used to determine if personal attributes and career behavior make unique contributions to performance attainment of employment.

\section{Summary}

This chapter detailed the research processes including the research design including, sampling and population, instrument development, ethical considerations, and procedures for data collection and analysis. Logistic regression analyses were used to determine the contributions of the independent variables (personal attributes, career behavior, environmental factors) to the outcome of employment. Chapter 4 presents the findings of the study, and Chapter 5 concludes the study with a summary, implications, and recommendations. 


\section{CHAPTER IV}

\section{RESULTS}

This chapter first examines the assumptions underlying the multicollinearity, normality, linearity, and homoscedasticity of the data, then presents the descriptive statistics, followed by testing the hypotheses through the logistical and hierarchical regression analyses.

\section{Data Screening}

The data were extracted from the Qualtrics XM survey software and uploaded into the SPSS v.23.0 program. Following this, the data were checked for any outliers or missing data. No missing data were recorded as all surveys were fully completed. To test for outliers, descriptive statistics and box plots were created. Any data point that is possibly illegitimate should be modified or deleted (Bakeman \& Robinson, 2005). In the generated box plots, no outliers were apparent. The descriptive statistics demonstrated $5 \%$ trim, which means nearly identical to original means. Thus, no outliers were reported.

\section{Examining Assumptions}

To run a logistical regression, the datasets must not violate the assumptions of multicollinearity, normality, linearity, or homoscedasticity. These assumptions were examined through a series of tests.

\section{Multicollinearity}

Multicollinearity occurs when two or more predictor variables are so highly correlated with each other that it interferes with the reliability of the variables as regression coefficients (Kim, 2019). Correlational coefficients of .90 or above should be removed or combined. As demonstrated in Table 3 and Table 4, none of the independent 
variables or subscales demonstrated a coefficient above the .90 threshold. In addition, a collinearity test using the variance inflation factor (VIF) was run in SPSS v23.0. A VIF lower than .2 or greater than 5 demonstrates that the correlation is severe enough to warrant a change or removal of the data (Harlow, 2014; Kim, 2019). The VIF values of the three independent variables were as follows: career behavior (1.615), personal attributes (1.706), and environmental supports and barriers (2.609). Therefore, the evidence suggests the lack of significant multicollinearity in the dataset.

\section{Homoscedasticity}

The test of homoscedasticity measures the variance of predictor variables around the regression line. To test the notion that the three variables do not violate that assumption, Levene's test for equality of variances was performed in SPSS v23.0. The Levene statistic demonstrated similarity in variance for the career behavior variable $(.147, p>.05)$ and the environmental supports and barriers variable (1.286, $p>.05)$. On the other hand, the personal attributes variable violated the assumption of homoscedasticity $(5.274, p<.05)$.

\section{Normality}

To test for normality, a histogram was created for each predictor variable and skewness and kurtosis were measured (Green \& Salkind, 2008). The histograms of both the career behavior variable and environmental supports and barriers variable demonstrated a relatively normal distribution with skewness of $.275(S E=.28)$ and .410 $(S E=.28)$, respectively. The histogram of personal attributes variable, however, demonstrated non-normality with skewness of -1.067 (SE =.28). 


\section{Linearity}

Inasmuch as logistic regression is a generalized linear model, it therefore requires an assumption of linearity in between the independent and dependent variables. To test for linearity, a normal probability scatter plot was created. The scatter plot was examined to determine if the data points created a linear relationship (Bakeman \& Robinson, 2005). The scatter plot demonstrated non-normality, which was expected due to the findings of the previous normality test for the personal attribute variable.

\section{Addressing Violations of Personal Attributes Variable}

The personal attributes variable violated the assumption of linearity, homoscedasticity, and normality. To address these violations, the personal attributes variable was first transformed using a $\log 10$ transformation to adjust for positive skewness. Performing a data transformation in conjunction with bootstrapping can adjust for skewness in a dataset (Hall, 1992). The transformed personal attributes variable was tested for normality, homoscedasticity, and linearity. The transformed personal attributes variable demonstrated normality with skewness of -.618 ( $\mathrm{SE}=.28)$. In addition, the transformed variable demonstrated linearity when examined in a normal probability scatter plot. However, the transformed variable violated the assumption of homoscedasticity $(5.314, p<.05)$. Heteroscedasticity in a dataset interferes with the standard error, a key component in measuring the significance in a regression model. To explore factors causing the violation, a principal component analysis with varimax rotation was run on the original personal attributes variable. Principal component analysis is a method for analyzing latent factors that affect variance (Bellmann, 2016). The initial scree plot was examined and demonstrated a break off point at three, which aligned with 
the total number of subscales in the personal attributes scale. The principal component analysis was then run with three forced components and the rotated data points (i.e., factor scores) were saved as three new variables that would be included in the subsequent correlational and logistic regression analyses.

\section{Descriptive Statistics and Intercorrelations}

Prior to running descriptive statistics on the research variables, the intercorrelations of all independent variable subscales were examined and are reported in Table 3. The strengths and direction of correlations between subscale scores were as expected from the literature. No correlation coefficients exceeded the .90 threshold; therefore, no subscales were combined or removed (Kim, 2019). Next, descriptive statistics were run on the dependent variable (employment outcome), and the independent variables (environmental factors, personal attributes, and career behavior). The three rotated factor scores (labeled as corresponding subscales) were used for the personal attributes variable making a total of five independent variables. The intercorrelations of the variables are reported in Table 4.

Correlation coefficients of .50 and above are interpreted as strong relationships (Harlow, 2014). There were two significant correlations between the independent variables: environmental supports and barriers and career behavior $(r=.60, p<.01)$ and environmental supports and barriers and the personal attributes rotated factor of acting on preferences, beliefs, interests, \& abilities $(r=.524, p<.01)$. On the other hand, the relationships between the five independent variables and the dependent variable of employment outcome were not statistically significant $(p s>.05)$. 


\section{Table 3}

\section{Intercorrelations of Independent Variables' Subscales}

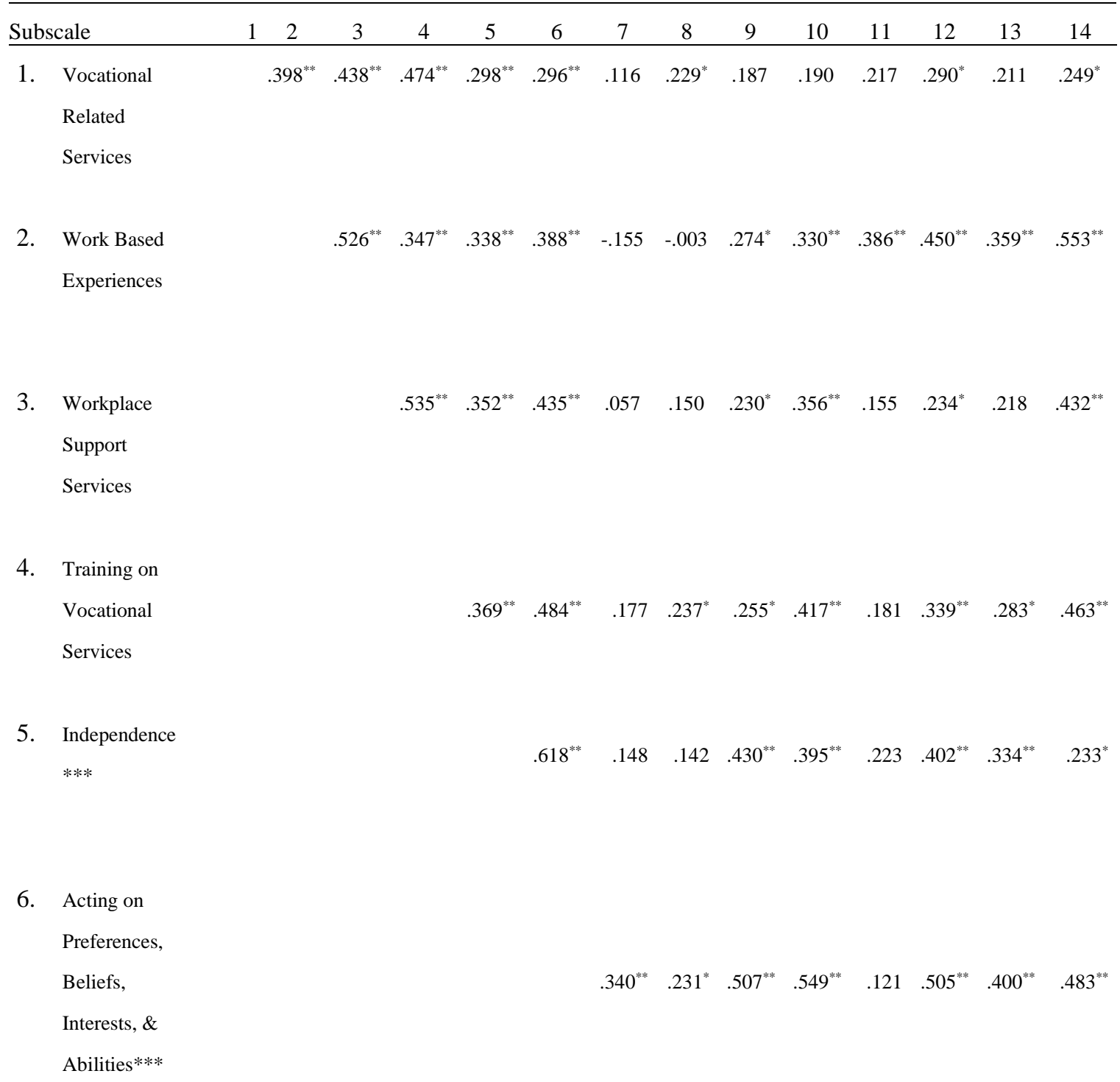

1. Vocational

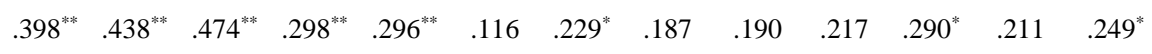

Related

Services

2. Work Based

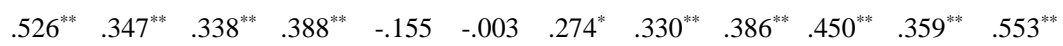

Experiences

3. Workplace

$\begin{array}{lllllllllll}.535^{* *} & .352^{* *} & .435^{* *} & .057 & .150 & .230^{*} & .356^{* *} & .155 & .234^{*} & .218 & .432^{* *}\end{array}$

Support

Services

4. Training on

Vocational

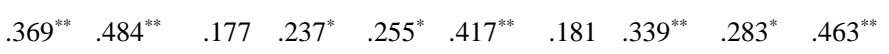

Services

5. Independence

$* * *$

$\begin{array}{lllllllll}.618^{* *} & .148 & .142 & .430^{* *} & .395^{* *} & .223 & .402^{* *} & .334^{* *} & .233^{*}\end{array}$

6. Acting on

Preferences,

Beliefs,

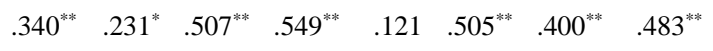

Interests, \&

Abilities***

7. Self-

Realization***

$\begin{array}{lllllll}.187 & .205 & .270^{*} & .006 & .174 & .089 & .099\end{array}$

8. General

Family

$\begin{array}{llllll}.219 & .286^{*} & -.008 & .193 & -.014 & .013\end{array}$

Support 
9. Family

Employment

$.509^{* *} .231^{*} .505^{* *} .358^{* *}$

.185

Expectations

10. Family

Independence

$.224 .364^{* *} .261^{*} \quad .378^{* *}$

Expectations

11. Transportation

Services

$.162 \quad .146$

.219

12. Community

$.468^{* *} \quad .452^{* *}$

Programs

13. Education

Programs

$.446^{* *}$

14. Other

Community

Resources

Note. $N=76$.

***Based on rotated factor scores.

$* * p<.01$.

$* p<.05$. 


\section{Table 4}

Intercorrelations of Research Variables

\begin{tabular}{lccc}
\hline & Employment & Career & $\begin{array}{c}\text { Environmental } \\
\text { Vupports \& }\end{array}$ \\
Butcome & Behavior & $\begin{array}{c}\text { Suples } \& \text { Subscales } \\
\text { Barriers }\end{array}$
\end{tabular}

1. Employment Outcome

2. Career Behavior

3. Environmental Supports

4. Personal Attributes***

a. Independence

b. Acting on Preferences, Beliefs, Interests, \& Abilities

c. Self-Realization
.122

.055

$.25 *$

Note. $N=76$.

*** Based on rotated factor scores.

$* * p<.01$.

$* p<.05$.

\section{Gender and Ethnicity Differences}

A two (gender) $\mathrm{X}$ three (ethnicity) ANOVA was run to test for possible gender and ethnicity group differences in the dependent variable (employment outcome). As for gender, the ANOVA revealed the lack of significant group differences in the dependent variable $F(2)=1.369, p>.05)$. Likewise, for ethnicity, the ANOVA revealed there were 
not significant differences by ethnic group $F(3)=1.478, p>.05$. Finally, the gender $\mathrm{X}$ ethnicity interaction was not statistically significant $F(5)=.526, p>.05$. Thus, these findings support not using gender and ethnicity as control variables in the forthcoming regression analyses.

\section{Logistic Regression Analysis}

Logistic regression analysis and hierarchical regression analysis were performed to test the hypothesized model. Logistic regression is used to assess if independent variables in a model are significantly related to an outcome variable (Hosmer et al., 2013). A logistic regression was performed to ascertain the effects of the three personal attributes variables, career behavior, and environmental supports and barriers on the likelihood that participants secure employment (see Tables 5 and 6). The model explained $22.3 \%$ (Nagelkerke $R^{2}$ ) of the variance in employment and correctly classified $77.6 \%$ of cases. The personal attributes rotated factor of acting on preferences, beliefs, interests, $\&$ abilities demonstrated a significant positive relationship to employment $(B=$ $.922, p<.05)$. According to the $\operatorname{Exp}(\mathrm{B})$ value, individuals reporting the personal attributes in this subscale were 2.515 times more likely to become employed. In contrast, the career behavior variable was found to have a significant negative relationship with the employment outcome $(B=-.171, p<.05)$. The environmental supports and barriers variable was not found to significantly impact the outcome of employment. 


\section{Table 5}

Classification Table of Logistic Regression Analysis

Observed Predicted

\begin{tabular}{lcccc}
\hline & & \multicolumn{2}{c}{ Do you have a job? } & Percentage Correct \\
Do you have a job? & Yes & 54 & No & 94.7 \\
& No & 14 & 5 & 26.3 \\
Overall Percentage & & & & 77.6 \\
\hline
\end{tabular}

Note. $N=76$. Cut value is .500 .

\section{Table 6}

Summary Results of Logistic Regression Analysis of Study Variables Predicting Employment Outcome

\begin{tabular}{|c|c|c|c|c|c|c|}
\hline & $B$ & $S E$ & Wald & $d f$ & Sig. & $\operatorname{Exp}(B)$ \\
\hline ESB & .012 & .072 & .029 & 1 & .865 & 1.012 \\
\hline $\mathrm{CB}$ & -.171 & .087 & 3.891 & 1 & .049 & .843 \\
\hline PA: Independence* & .549 & .487 & 1.268 & 1 & .260 & 1.731 \\
\hline \multicolumn{7}{|l|}{ PA: Acting on } \\
\hline Preferences, Beliefs, & & & & & & \\
\hline Interests, \& & .922 & .444 & 4.315 & 1 & .038 & 2.515 \\
\hline Abilities* & & & & & & \\
\hline PA: Self- & & & & & & \\
\hline Realization* & -.241 & .278 & .756 & 1 & .385 & .786 \\
\hline Constant & .078 & 1.354 & .003 & 1 & .954 & 1.081 \\
\hline
\end{tabular}


Note $. N=76 . \mathrm{ESB}=$ Environmental Supports and Barriers; $\mathrm{PA}=$ Personal Attributes; $\mathrm{CB}$ $=$ Career Behavior.

*Based on rotated factor scores.

\section{Hypothesis 1}

H1 stated that when working with individuals with ID, reports of higher selfdetermination will be positively linked to attaining employment. The three rotated personal attributes variables and the employment outcome variable were entered simultaneously into a logistic regression model. The rotated personal attributes variable of acting on preferences, beliefs, interests, and abilities demonstrated significance with a regression coefficient value of $B=.922, p<.05$ as demonstrated in Table 6 . Results demonstrated that participants with higher self-determination in the area of acting on preferences, beliefs, interests, and abilities as indicated by $\operatorname{Exp}(B)$ were 2.515 times more likely to be employed. Thus, the null hypothesis was rejected for $\mathrm{H} 1$ and personal attributes are positively linked to attaining employment.

\section{Hypothesis 2}

$\mathrm{H} 2$ stated when working with individuals with ID, reports of more engagement in career behavior will be positively linked to attaining employment. Entering the career behavior variable and employment outcome variable into a logistic regression model demonstrated a regression coefficient of $B=-.171, p<.05$ as demonstrated in Table 6 . However, the negative regression coefficient suggests that participants who reported more engagement in career behavior were .84 times less likely to be employed $(\operatorname{Exp}(B)=$ .84). Thus, the null hypothesis was not rejected for Hypothesis 2. Individuals with high engagement in career behavior were less likely to attain employment. 


\section{Hypothesis 3}

H3 stated when working with individuals with ID, reports of high family expectations and larger quantities of available community resources (e.g., educational programs) will be linked positively to attaining employment. Entering the environmental supports and barriers variable and the employment outcome variable into a logistic regression model demonstrated a regression coefficient of $B=.012, p>.05$ as shown in Table 6. Thus, the null hypothesis was not rejected for H3. Environmental supports and barriers were not significant predictors of employment attainment.

\section{Hierarchical Regression Analysis}

After the logistic regression was conducted, a hierarchical logistical regression was conducted by testing for the unique variance of both personal attributes and career behavior after controlling for environmental supports and barriers. Hierarchical regression is used in predictor variables when correlations occur between one or more of the variables. This type of regression is used as a statistical control typically based on theory or previous research (Pedhazur, 1997). As demonstrated in Table 4, the correlations between research variables aligned with previous research regarding environmental factors impacting both the personal attributes rotated factors $(r=.524, p<$ $.01 ; r=.25, p<.05)$ and career behavior $(r=.604, p<.01)$. Therefore, a hierarchical regression provides a platform to control for the environmental supports and barriers variable and examine the unique contributions of the other predictor variables to the model. The hierarchical regression model was run with a total of two blocks. Block 1 controlled for the environmental supports and barriers variable and Block 2 consisted of the personal attributes rotated factors and the career behavior variable. 
Block 1 demonstrated no contribution to variance in employment outcome which aligned with the fact that the environmental supports and barriers variable showed no significance to employment outcome on its own (refer to Table 8). Block 2 in the hierarchical logistical regression model accounted for $22.3 \%$ of the variance in employment outcome and correctly classified $76.3 \%$ of the cases (refer to Table $7 \&$ Table 8). Block 2 also demonstrated that after controlling for the environmental supports and barriers variable, the results of the hierarchical regression were similar to those in the former logistic regression model (refer to Table 8). The rotated personal attributes variable of acting on preferences, beliefs, interests, \& abilities was significant to employment outcome after controlling for environmental supports and barriers $(B=.799$, $p<.05)$. However, this model exhibited a slightly lower odds ratio for the personal attributes rotated factor $(\operatorname{Exp}(B)=2.224)$. Additionally, the hierarchical regression suggested a negative relationship between career behavior and employment outcome $(B=$ $-.158, p<.05)$ after controlling for environmental supports and barriers.

\section{Table 7}

Classification Table of Hierarchical Logistic Regression

Observed Predicted

Do you have a job?

Percentage Correct

Yes No

Block 1

Do you have a job? Yes

57

0

100.00

No

19

0

0.0

Overall Percentage

75.0 
Block 2

$\begin{array}{lllll}\text { Do you have a job? } & \text { Yes } & 56 & 1 & 98.2\end{array}$

$\begin{array}{llll}\text { No } & 17 & 2 & 10.5\end{array}$

Overall Percentage

76.3

Table 8

Summary Results of Hierarchical Logistical Regression Analysis of Study Variables

Predicting Employment Outcome

\begin{tabular}{|c|c|c|c|c|c|c|}
\hline & $B$ & $S E$ & Wald & $d f$ & Sig. & $\operatorname{Exp}(B)$ \\
\hline \multicolumn{7}{|l|}{ Block 1} \\
\hline ESB & .080 & .062 & 1.693 & 1 & .193 & 1.084 \\
\hline Constant & -1.141 & 1.001 & 1.300 & 1 & .254 & .319 \\
\hline \multicolumn{7}{|l|}{ Block 2} \\
\hline $\mathrm{CB}$ & -.158 & .079 & 4.028 & 1 & .045 & .853 \\
\hline PA: Independence* & .559 & .439 & 1.621 & 1 & .203 & 1.748 \\
\hline \multicolumn{7}{|l|}{ PA: Acting on } \\
\hline Preferences, & & & & & & \\
\hline Beliefs, Interests, \& & .799 & .433 & 3.404 & 1 & .045 & 2.224 \\
\hline Abilities* & & & & & & \\
\hline PA: Self- & & & & & & \\
\hline Realization* & -.375 & .272 & 1.904 & 1 & .168 & .687 \\
\hline Constant & .080 & 1.285 & .004 & 1 & .950 & .923 \\
\hline
\end{tabular}


Note. $N=76 . \mathrm{ESB}=$ Environmental Supports and Barriers; $\mathrm{PA}=$ Personal Attributes; $\mathrm{CB}$ $=$ Career Behavior.

$R^{2}$ explained in Block $1=0.00 \%(p<.05)$; Nagelkerke $R^{2}$ explained in Block $2=22.3 \%$, $p<.05$

*Based on rotated factor scores.

\section{Hypothesis 4}

H4 stated personal attributes and career behavior will make a unique contribution to employment outcome after controlling for environmental supports and barriers (i.e., family expectations and available community resources). The account of variance for the two variables after controlling for environmental supports and barriers remained the same. The rotated personal attributes variable of acting on preferences, beliefs, interests, and abilities remained significant to the outcome of employment after controlling for environmental supports and barriers although with a slightly smaller odds ratio (refer to Table 8). The career behavior variable also remained negatively significant to employment outcome after controlling for environmental supports and barriers (refer to Table 8). Thus, the null hypothesis was rejected for H4. After controlling for environmental supports and barriers, personal attributes and career behavior still made a unique contribution to employment attainment.

\section{Discussion of the Results}

The results of both the logistic regression and hierarchical logistic regression analyses demonstrated the research variables of environmental supports and barriers, personal attributes, and career behavior accounted for $22.3 \%$ of the variance in reported employment attainment. Thus, the proposed employment model demonstrated an effect 
on employment outcome. In both regression models, the career behavior variable was statistically significant, however, with a negative link to the employment outcome, suggesting that participation in career behavior adversely affected the chances of becoming employed. Further, in both models the rotated personal attributes variable of acting on preferences, beliefs, interests, and abilities was statistically significant to the employment outcome, indicating that personal attributes are a standalone positive predictor of employment outcome. The results of the hierarchical regression analysis suggested that controlling for environmental supports and barriers did not make a significant change in the contribution of personal attributes and career behavior to employment outcome. In conclusion, personal attributes (e.g., self-determination; positive effect) and career behavior (negative effect) were the only factors in the model found to be significant predictors of employment outcome. 


\section{CHAPTER V \\ DISCUSSION}

This chapter discusses the summary of the study followed by a discussion of the key findings and limitations. The theoretical, empirical, and practical implications are discussed. Finally, recommendations for practice and future research are presented.

\section{Summary of Results}

The results suggested that the hypothesized SCCT model for adults with intellectual disabilities was partially successful in predicting employment. First, the study identified personal attributes (e.g., self-determination) as a significant positive predictor of employment; in contrast, career behavior was a significant negative predictor. The correlational results revealed that most of the relationships among the research variables were in the strength and direction as predicted by SCCT theory and research for this adult population with ID. For example, strong correlations were found among the environmental supports and barriers, personal attributes, and career behavior variables.

Lent et al. (1994) postulated the cyclical nature of the elements of the SCCT, including self-efficacy and outcome expectations being continuously affected by environmental and behavioral influences. The results of this study demonstrated that in adults with ID, environmental factors (i.e., available resources; family support and expectations), personal attributes (e.g., self-determination), and career behavior were strongly linked with each other. These findings further noted the influence of these variables on individuals' career trajectories regardless of disability status, further confirming the applicability of the SCCT to diverse populations. 


\section{Limitations and Recommendations for Future Research}

The limitations of the study results and how they could be addressed in future research are discussed in terms of the three variables: personal attributes, environmental supports and barriers, and career behavior.

\section{Personal Attributes}

In this study, the original personal attributes variable was severely positively skewed. It is important to note that the participants of the study were selected from nonprofit organizations in the community. To participate in these organizations, an individual or corresponding support system (e.g., family member) would need to seek out the organization and demonstrate a desire to become involved. This process would require higher levels of personal attributes (e.g., self-determination) and/or higher levels of family support. The findings of this study suggested that personal attributes were strongly and positively correlated with environmental supports and barriers. Previous research on individuals with varying disabilities throughout the lifespan also demonstrated that selfdetermination characteristics, such as empowerment, enabled individuals to problemsolve and handle potential barriers to employment (Thoma \& Getzel, 2005). Similarly, Shogren et al. (2015) found self-determination to be a predictor of community access. Moreover, Lent et al. (1994) posited in the SCCT that environmental supports increased self-efficacy and decreased potential environmental barriers. Therefore, additional research on the relationship between personal attributes (e.g., self-determination) and environmental supports and barriers is needed to refine what we know about the relationships of these variables for the adult population with ID. One means to further this line of research would be to conduct a study with a larger sample of adults with ID, 
and using a sample from different parts of the U.S. to increase the study's

generalizability. To reduce the likelihood of skewness as it relates to personal attributes, future quantitative research should be designed where the proportional representation among those with both higher personal attributes levels and family support and lower levels of personal attributes and family support would be balanced.

In addition to being involved with non-profit organizations, supplementary findings in the dataset may have contributed to the initial skewness of the variable. For example, the majority of participants $(70 \%)$ in the sample received training on selfadvocacy. Self-advocacy is considered a component of self-determined behavior in which an individual demonstrates the ability to communicate, to lead, know individual rights, and know oneself (Shogren et al., 2017; Test et al., 2005). Receiving self-advocacy training among other self-determination trainings as an intervention was found to predict employment outcomes for individuals with varying disabilities transitioning from high school (Shogren et al., 2015). Shogren et al. (2015) also noted that research was needed as individuals moved further into adulthood, acknowledging that the timing of receiving such training could play a role in securing employment. Supplementary research on the timing of reported self-advocacy training could provide further insight on the relationship between the development of personal attributes and employment outcome. To overcome issues with skewness, future research should be designed where there is more balance as to the proportion of those who have received self-advocacy training and how much.

An additional factor potentially impacting the skewness of personal attributes variable was the $70 \%$ involvement of the Special Olympics participants. Special Olympics is an international program for youth and adults with intellectual disabilities in 
which individuals participate in a variety of sports. Preliminary studies have noted a correlation between personal attributes and participation in Special Olympics for people with and without disabilities (Casey et al., 2014). In a study by Weiss et al. (2003), for instance, the number of Special Olympics competitions individuals participated in were positively correlated with self-sufficiency and self-competence. However, results have been mixed in research on psychological development and participation in Special Olympics (Tint et al., 2017). Thus, further insight is required as to how and if participation in programs, such as Special Olympics, translate personal attributes (e.g., self-determination) into career behavior. The reduce possible skewness issues, future research could be designed where there is a balance between Special Olympics participants and non-participants.

\section{Principal Component Analysis}

The results demonstrated that the personal attributes rotated factor of acting on preferences, beliefs, interests, and abilities was a significant positive predictor of employment outcome. These findings align with previous conclusions in the literature that personal attributes (e.g., self-determination) are linked to employment attainment (Shogren et al., 2015; Wehmeyer \& Palmer, 2003). Nonetheless, there were limitations in using a principal component analysis with varimax rotation. Guided by SCCT theory and research, the three rotated factors were forced to be statistically independent from one another (this is the nature of using varimax rotation). Each factor was then examined as a predictor variable instead of the personal attributes variable as a whole. The results were constrained to a subscale of the personal attributes scale that were highly related to employment outcome, limiting the transferability of the entire personal attributes scale. 
This research should be replicated to determine if indeed the three-factor structure of the personal attributes scale is consistent, and if all three subscale scores, or just the one as was found in this research, might predict incremental variance in employment outcome.

\section{The ARC's Self-Determination Scale}

In this study, higher scores on one subscale of The Arc's Self-Determination Scale, acting on preferences, beliefs, interests, $\&$ abilities, were found to be a predictor of employment outcome. Interestingly, previous research using the full scale revealed similar results. Wehmeyer and Schwartz (1997) found the individuals with higher selfdetermination scores on The Arc's Self-Determination Scale were more likely to be employed than those with lower scores. The Arc's Self-Determination Scale was also used as one method of collecting data in a study by Shogren et al. (2015). Results demonstrated that self-determination levels were linked to employment attainment and job retention.

Another possible limitation includes the changes made to the original scale in this study. This study utilized a revised version of The Arc's Self-Determination Scale in which statements were presented in checklist format instead of Likert-scale format. This decision was made to (a) include a broad scope of individuals with mild ID and (b) eliminate the need for a pre-test to ensure that the individual possessed the ability to rank items from concrete to abstract (Cummins, 1997). In addition, based on feedback by the board of individuals with ID, the scale was shortened from the original. Though the reliability of the personal attributes scale demonstrated an acceptable Cronbach's $\alpha$ (.637;

Chretien, Nimon, Reio, \& Ellis, 2020), it is possible that the revisions to the scale may have interfered with the validity of the instrument. Future research should test the 
psychometric properties of the revised measure with a similar group of adults with ID to find additional reliability and validity evidence.

The use of self-reporting is another possible limitation in this study. The population with ID is not homogenous in terms of reading level or cognitive ability, making it difficult for an instrument to be valid for all individuals with ID (Finlay \& Lyons, 2001). In a recent study by Jones et al. (2018) examining predictors of selfdetermination with The Arc's Self-Determination Scale, there were noted limitations with self-reporting. There was an observed variance in the responses on the scale and Jones et al. (2018) stated the need for further research on supporting the use of self-reporting for the population with ID. In addition, Shogren et al. (2014), examined the NLTS-2, which included constructs of The Arc's Self-Determination Scale, and found race/ethnicity impacted self-reporting for self-determination, especially in Hispanic/Latino individuals. Thus, additional research with Hispanic/Latino populations is needed to refine our knowledge as to why and how race/ethnicity influences self-reporting. Qualitative case study research could be designed to explore self-report use among different ethnic and cultural groups to determine how and why belonging to these groups would be linked to self-reporting issues.

\section{Cultural Variance in Personal Attributes}

The sample of the study was representative of the demographics in Miami, Florida, where more than half of the population is of Hispanic/Latino descent (United States Census Bureau, 2019). The literature on personal attributes of individuals with ID has acknowledged that self-determination levels vary across cultural identities (Shogren, 2011). In an interview of seven Hispanic mothers of transition-aged young adults, the 
perceptions of self-determination demonstrated variance from mainstream selfdetermination practices (Shogren, 2012). It is possible that the results regarding employment and self-determination from previous studies may not reflect cultural variance due to underrepresentation of the Hispanic/Latino population. For example, in the self-determination study of 779 students by Shogren et al. (2015), 56.7\% of the sample was Caucasian and $18.7 \%$ were Hispanic. Similarly, in a study examining the constructs of the The Arc's Self-Determination Scale, the sample used was comprised of 65.83\% Caucasian and 6.67\% Hispanic individuals (Seo et al., 2015). In the present study, which is largely Hispanic/Latino, the cultural identity of the sample may have influenced the personal attributes variable and its correlation to employment in some unknown manner. Further research on the relationship between cultural identities, personal attributes such as self-determination, and employment would be beneficial to the population of adults with ID, specifically in the Hispanic/Latino community. Quantitative research (e.g., surveys) could be designed that includes each of the aforementioned variables with samples of Hispanics/Latino adults with ID.

\section{Environmental Supports and Barriers}

In this study, the environmental supports and barriers variable encompassed perceived family support and available community resources. The results suggested that this variable was not a significant predictor of employment, unlike the bulk of the prior research. Previous studies demonstrated that family expectations were correlated with employment, where high expectations led to more employment, (Timmons et al., 2011) and low family expectations limited options (Lindstrom et al., 2007). Previous research also noted that family members with limited education and work experiences sometimes 
inadvertently negatively affected children's work options (Lindstrom et al., 2007; Usinger, 2005). It is important to note that family's education level and family's employment status were not used as dependent variables in this study. Thus, future research designed to examine how family education level, family employment status, and family expectations as they relate to employment is needed.

Like family expectations, available community resources had a demonstrated impact on employment outcomes in previous literature, but not in this research. Wehman et al. (2015) cited that high levels of community involvement were correlated to employment outcomes. It is important to note that the type of community (e.g., rural) affected family expectations of employment (Blustein et al., 2016). In addition, both family involvement and availability of community services have been found to impact community involvement of individuals with ID (Verdonschot et al., 2009). Therefore, possible contributors to the discrepancy between results of this study and previous literature include both community and familial variances. Future replication research should be implemented to investigate whether the null findings in this research hold outside the sample examined in this research.

\section{Instrumentation}

An adapted version of Future Expectations Scale for Adolescents (FESA) was used to measure perceived support and expectations from families of individuals with ID (McWhirter \& McWhirter, 2008). This scale was originally created for at-risk youth; therefore, the vocabulary and sentence structure provided ease of comprehension (Hartley \& MacLean, 2006). For the purpose of this study, several revisions were made to the FESA scale, including asking about family expectations instead of personal expectations, 
removing parts of the scale that were not related to employment, and inserting supplemental topics prevalent in literature (e.g., inclusive work settings). Making significant changes to the scale could have impacted the validity of the family expectations portion of the survey. In addition, the original FESA had been used with varying disadvantaged youth (e.g., low SES) to examine perceived barriers to goals, selfefficacy, future goals, and career interests (Michael, 2019). However, it had not been examined as an employment predictor or in groups of individuals specifically with ID. Further research using this study's family expectations subscale with adults with ID is needed to build construct validity evidence.

Individuals with ID typically have deficits in the areas of critical thinking and reasoning, affecting the ability to grasp abstract concepts, such as perceived family expectations (Salvador-Carulla et al., 2018). For abstract questions or concepts (e.g., research using Likert-type scales), both Cummins (1997) and Perry (2004) suggest assessing conceptual understanding first to gauge participant ability. Inserting such an additional measure in this study would have required two data collection points per participant. Consequently, to avoid attrition, this study did not use a pre-screening instrument to assess the individuals prior to the survey. Replication of this study would be needed to gauge the reliability and validity of the measure. Future attempts to replicate the study also should include pre-screening measures, which would enable measuring test-retest reliability, to control for possible additional confounds (e.g. acquiescence bias, non-response bias).

In this study, the term "family" was used as an umbrella term to ensure that individuals across the lifespan could identify living family members when reflecting on 
family expectations. Therefore, the results of this study could include perceived expectations of additional family members (e.g., siblings). Previous research on family members and individuals with ID traditionally excluded other family members outside of the mother (Blacher \& Hatton, 2009). In addition, acquiescence bias could have impacted the results as participants might have been hesitant to share negative perceptions of family members. Future research might employ proxy reports to supplement data collected from individuals with ID as one solution to possible acquiescence bias (Perry, 2004).

\section{Family Expectations \& Culture}

Due to the Hispanic/Latino population composition of South Florida (U.S. Census Bureau, 2019), the possible cultural family dynamics that may impact the environmental supports and barriers variable must be explored. Previous literature has cited that family shapes career expectations for individuals with ID. Therefore, cultural values influence how a family defines career success and expectations (Geenen et al., 2001).

Hispanic/Latino families in the United States have been found to demonstrate the concept of familism, or interdependence between family members for support (Cohen et al., 2014; Magana, 1999). This aligns with research citing the key values of family, family support, and child rear bearing in Hispanic/Latino families (Cohen, 2013). The level or type of support provided to individuals with ID by Hispanic/Latino families may be significantly different, arguably making cross-cultural translations of previous research ineffective (Blacher \& Mink, 2004). These cultural considerations could account for the discrepancy between the previous research on family expectations and the results of the current study. Thus, further research on how Hispanic/Latino families view employment outcomes and 
the type of support provided to achieve those outcomes is needed. Case study research could explore this issue in great depth.

The family expectations subscale included 19 items. The results of the survey demonstrated a high level of family expectations $(M=14.43)$. It is possible that the concept of familism along with other cultural values impacted these results. For example, previous research found that mothers of Hispanic/Latino descent held a more positive view of their child with disabilities than Caucasian mothers (Blacher \& McIntrye, 2006). In additional, it was postulated that the role of familism has a moderating effect on quality of life for Hispanic mothers (Cohen et al., 2014), potentially indirectly affecting the expectations of the child. Further research is needed to determine if familism is related (directly or indirectly) to the level of support and expectations provided to individuals with ID.

\section{Community Resources}

The results of this study demonstrated that environmental supports and barriers were not a significant predictor of employment. These findings are contrary to previous research, which suggested that involvement in the community and access to communitybased training were positively correlated with future employment (Wehman et al., 2015; White \& Weiner, 2004). In previous studies (Wehman et al., 2015; White \& Weiner, 2004), community involvement and training were examined only during high school. In the current study, participants were asked what community programs were accessed at any time during the lifespan. It has been noted in the literature that community services for adults have less focus on gaining employment (Butterworth et al., 2017). It is possible that accessing community programs or training has a different effect on employment for 
high school-aged students than it does adults. Thus, further longitudinal research on the timing and context of community resources being accessed by individuals with ID and how it relates to employment across the lifespan is needed. In addition, a previous study by Wehman et al. (2015) measured overall community involvement rather than specific type. For example, an individual accessing one community activity was measured the same as an individual accessing multiple activities. In the study by White and Weiner (2004), the community-based training also included an employment training piece. Therefore, future research on specific types of community resources being accessed is needed to better determine the effects on employment.

Though the environmental supports and barriers variable was not a predictor for employment, the results found it was correlated with career behavior. One major theme prevalent in the literature is the relationship between access to community transportation and career behavior (Gilson et al., 2018; Ipsen \& Swicegood, 2015). The majority of participants in this study were employed (75\%) and reported having access to transportation training (53\%), as well as transportation services (85\%). However, it is important to note that access to the community and community services varies depending on the type of community (e.g., rural, urban; Blustein et al., 2016; Ispen \& Swicegood, 2015). Replication of this study in different community settings (e.g., rural, urban) is needed to examine the corresponding impacts of community and community services on career behavior to further validate these results.

\section{Career Behavior}

Contrary to previous studies, the results of the study found that the career behavior variable was a negative predictor for employment outcome. The career behavior 
variable in this model included an aggregate of career experiences (e.g., career exploration, on the job training, and paid work), job skills training, and job placement supports. The previous research on career behavior encompassed specific career development experiences that were predictors for future employment. For example, paid work experiences were found to predict future employment outcomes (Carter et al., 2012; Southward \& Kyzar, 2017) and vocational skills trainings predicted employment outcomes as well as job retention (Zhang et al., 2018). Further analysis is needed to identify if any specific career experiences affect employment outcome.

In addition, previous literature outlined the different aspects of career behavior that in conjunction with other variables increased the likelihood of employment. For example, career exploration experiences done in PSE programs were found to increase the likelihood of individuals receiving competitive employment (Qian et al., 2018). Additionally, having paid employment experiences in a PSE program increased the chances of paid employment upon program completion. Contrary to these findings, the results of this study demonstrated that participation in several types of career experiences in conjunction with environmental supports and barriers (e.g., accessing community resources such as PSE programs) did not account for an increase in likelihood to be employed.

Though career behavior was a negative predictor in this model, it was positively correlated with the environmental supports and barriers variable and the three rotated personal attributes variables. These findings align with previous literature on family expectations which suggest correlations between the variables bi-directionally. For example, high or low family expectations impact employment interests and options 
(Lindstrom et al., 2007; Timmons et al., 2011) and early access to hands on work experiences increase family expectations (Blustein et al., 2016). Similar findings were prevalent in the literature regarding personal attributes. Wehmeyer (1999) found that the level of self-determination an individual possessed affected the ways in which resources were accessed. Conversely, being involved in career experiences such as career exploration were found to increase self-determination skills (Stock et al., 2003). Further research is needed to determine if the specific relationships between environmental supports and barriers (e.g., family expectations), personal attributes (e.g., selfdetermination), and career behavior impact employment outcome.

\section{Availability of Career Experiences}

One limitation of this study was the availability of career experiences depending on the age of the participants. For example, the customized employment model was introduced by legislation passed in 2002 (Griffin et al., 2008), and PSE programs were introduced through legislation in 2008 (HEOA, 2008). Those who had aged out of high school before these two major legislative changes had fewer options than those attending high school later. Results of the study reflect this discrepancy as high school specific questions demonstrated significantly lower participation rates. For example, 55.3\% of participants reported completing a career assessment (available across the lifespan), whereas only $15.8 \%$ reported having paid employment experiences while in high school. Using stratified sampling for ages groups in future research on adults with ID could assist in analyzing the access to career experiences.

The range of responses on the career behavior scale $(n=22)$ demonstrated significant differences in availability of career experiences $(M=10.1, S D=4.77)$. Age is 
one potential factor affecting the variation in responses; however, other factors such as the community type (Ipsen \& Swicegood, 2015) and ethnicity (Pruchno \& McMullen, 2004) impact the availability of career experiences. The types of supports and academic supports provided by school districts have been identified as impacting post school success (Brigharm et al., 2006). Career services provided in schools vary in frequency and type (Joshi et al., 2012), ultimately impacting the types of career experiences that are accessible to the individual. Once the individual exits high school, the types of career experiences available depend on the services in the community (Retish \& Raiter, 1999). Ipsen and Swicegood (2015) found discrepancies in rehabilitation services depending on the type of community (e.g., urban, rural). In this sample, the data collected was representative of the Miami, Florida community, which is a large urban city. Therefore, the findings from this study may not be generalizable to other areas. Further research analyzing the types of career experiences available to adults in diverse types of communities is needed.

Additionally, ethnicity has also been found to impact the types of career experiences accessed. For example, Pruchno and McMullen (2004) found that minority groups were more likely to report unmet service needs by community providers. In this study, the ethnicity of the sample was not found to be significantly correlated to the career behavior variable. However, given the influences of culture on other variables (e.g., environmental supports and barriers, personal attributes), further research is needed on whether ethnicity influences participation in career behavior. 


\section{Implications for Theory and Research}

\section{Application to SCCT}

Though the proposed employment model was not fully validated, this study was one of few SCCT applied studies conducted on individuals with ID. Therefore, it is important to examine the results of this study, its alignment with the constructs of the SCCT, and its alignment with previous research. Lent et al. (2014) reviewed empirical research applying SCCT constructs to individuals with disabilities and found that selfefficacy and environmental supports and barriers were the most common constructs studied.

Self-efficacy was previously found to significantly predict career interests for those with ID (Nota et al., 2010) and impact career exploratory behavior for those with learning disabilities (Ochs \& Roessler, 2004). Career interests were not examined as a variable in this study; therefore, there is limited transferability of the results from the current study to the study on students with ID by Nota at al. (2010). However, there were some similarities between the results of this study and the study conducted by Ochs and Roessler (2004). The previous study found that career self-efficacy and career outcome expectations accounted for $22 \%$ of the variance of career exploratory behavior in high school students with learning disabilities (Ochs \& Roessler, 2004). The current study demonstrated that personal attributes were significantly correlated with engagement in career behavior $(r=.432, p<.01 ; r=.317, p<.01)$ and predicted employment outcome $(B=.922, p<.05)$. Though the study by Ochs and Roessler (2004) and the current study have several key differences (e.g., age group, disability type), the results of this study add 
to the body of literature that personal attributes (whether it be self-efficacy or selfdetermination) significantly impact career behavior in the population with disabilities.

Previous studies using the SCCT also demonstrated a strong correlation between environmental supports and barriers, career behavior, and personal attributes. Fabian et al. (2009) found that individuals with varying disabilities perceived barriers to receiving employment, receiving information about employment, and lacked career decisionmaking skills. Individuals who were employed perceived fewer barriers than those who had been out of the workforce. Similarly, Gibbons et al., (2016) found that environmental supports and barriers (caused by having an intellectual disability) impacted self-efficacy beliefs, self-determination, career interests, career goals, and college interests. The results of the current study also found correlations between environmental supports and barriers, career behavior, and personal attributes; adding to the body of research that the three constructs from the SCCT impact one another. It is important to note that further research is needed on the relationship between employment outcome and perceived supports and barriers for the population with ID. Despite the correlations found between the research variables, the current study demonstrated that environmental supports and barriers did not impact employment outcome alone or as a control variable.

The current study included a career behavior variable which examined what career experiences individuals with ID participated in. Though some experiences in the career behavior scale were related to career interests and setting goals, the constructs were not examined separately. The results of the current study found that participation in career behavior was a negative predictor to employment $(B=-.171, p<.05)$. Career behavior as a construct of the SCCT has not previously been examined on individuals 
with disabilities. Previous studies using the SCCT studied the relationships between the constructs of goal setting, the formation of career interests, and self-efficacy (Gibbons et al., 2016; Nota et al., 2010). The previous studies did not examine the relationship of the SCCT constructs to employment outcome. The SCCT posits that forming career interests and setting career goals leads to further career exposure by choice (career behavior), an increase in personal attributes (self-efficacy), and, ultimately, a positive employment outcome. The previous literature on the SCCT and individuals with disabilities has validated the relationship between the constructs yet has not examined the relationship of said constructs to employment outcome. Thus, the results of the current study demonstrate the need for further research examining the relationship between employment outcome and the constructs of the SCCT (e.g., career behavior, goal setting, and career interests).

The results of this study will add to the limited body of literature on the SCCT with people with ID. Like other studies, the constructs of environmental supports and barriers, personal attributes, and career behavior were correlated among each other. Though some constructs of the SCCT have been found to be predictors of employment for the population with ID (e.g., career behavior, personal attributes), the SCCT has not previously been used as a predictor model. This study demonstrated that for the sample of adults with ID from Miami, Florida, the SCCT constructs of environmental supports and barriers, personal attributes, and career behavior accounted for $22.3 \%$ of the variance in employment outcome. In addition, the results provided further insight on how the SCCT can be applied in future research with the population to understand variables affecting career choices throughout the lifespan. 


\section{Employment Predictors}

Previous empirical research on employment predictor variables for individuals with ID have included several variables with differing degrees of significance. For example, Test et al. (2009) examined 22 empirical studies and found 16 employment predictor categories with effect sizes ranging from .08 to .86 . In the current study the rotated personal attributes variable of acting on preferences, beliefs, interests, and abilities was a significant predictor of employment $(B=.922, p<.05 ; \operatorname{Exp}(B)=2.515)$. These findings align with previous literature suggesting that certain constructs of selfdetermination (e.g., psychological empowerment) were strong predictors of employment (Wehmeyer \& Schwartz, 1997). In contrast, the career behavior variable was found to be a significant negative predictor of employment $(B=-.171, p<.05 ; \operatorname{Exp}(B)=.84)$. These findings were incongruent with previous research suggesting that paid employment, vocational education, and work study were predictors of employment at varying degrees (Baer et al., 2003; Luecking \& Fabian, 2000; Rabren et al., 2002). The varying results of this study augmented insight on potential limitations in the previous literature on employment predictors.

\section{From High School to Adulthood}

First and foremost, this research study added to the limited body of research on employment predictors for adults with ID. Prior research on employment predictors have focused primarily on individuals transitioning from high school and the services provided while in school (Haber et al., 2016). Though there are benefits to researching high school-aged students, including access to larger sample sizes and readily available information provided by the corresponding school (e.g., school resources, curriculum), 
factors specifically impacting adults with ID tend to get overlooked. For example, job retention has been a noted obstacle in the literature on individuals with ID (Roessler, 2002). Follow-up studies after initial employment have indicated that individuals with ID lose employment over time (Spreat \& Convoy, 2015). Even if individuals secure employment upon completing high school, factors affecting the ability to retain the employment over time require further examination.

In addition, the correlation found in this study between environmental factors (e.g., community resources) and career behavior should be considered when comparing accessing employment during high school and accessing employment during adulthood. Once exiting high school, the availability of community programs decreases (Retish \& Raiter, 1999), which could impact employment outcomes including job retention rates. Therefore, the variables noted in previous research as predicting employment immediately following high school may not be as effective in predicting employment outcomes into adulthood. Further research on factors impacting employment for adults with ID would be needed to verify the results of this study.

\section{Demographic Variables}

A few limitations exist in previous research on employment predictors regarding demographic variables including the aggregation of ID with all other disability categories (e.g., learning disabilities). In previous studies predicting employment, individuals with ID were only a subset of the sample studied. For example, in a study by Shogren et al. (2015), individuals with ID only made up $29.9 \%$ of the sample and in a study by Baer et

al. (2003), individuals with ID only made up $21 \%$ of the sample. Though individuals with ID were included in these studies, it is difficult to generalize those findings to the greater 
population with ID. In addition, some research has noted a discrepancy in employment rates depending on the disability label. For example, Bush and Tassé (2017) noted that individuals with Down Syndrome were more likely to receive employment than individuals with ID or Autism. This study focused specifically on employment for adults with the disability label of ID and did not examine additional comorbidity variables (e.g., Down Syndrome, hearing impairment). In addition, only individuals with mild ID were included in this study. Thus, future studies on employment and career behavior only on the population with mild ID would add to the body of knowledge and determine generalizability of previous findings.

In addition to disability labels, previous research demonstrated mixed results regarding the impact of ethnicity on employment. This study surveyed participants in Miami, Florida, USA, where more than half of the sample identified as Hispanic/Latino. Previous research on employment predictor variables has been done on participants who were primarily White/Caucasian (Haber et al., 2016). In a number of previous studies, there was no Hispanic/Latino representation at all (e.g., Rabren et al, 2002; Shogren et al, 2015). In other cases, minorities were studied, but not specified in terms of ethnicity (e.g., Luecking \& Fabian, 2000; Baer et al., 2003), thus making it difficult to control for cultural variables. Some research has suggested that ethnicity, specifically the Hispanic/Latino ethnicity, influenced career behavior positively (Haber et al., 2016). In contrast, Kaya (2018) found that Hispanic/Latino and African American individuals with ID were less likely to be employed than those who were White/Caucasian. In a metaanalysis of 35 sources with 27 samples, Haber et al. (2016) noted that further research was needed that included substantial numbers of Hispanic/Latino individuals to consider 
the influence of culture on employment outcomes. The current study added to the limited body of research primarily on Hispanic/Latino individuals with ID. Follow-up studies would need to be conducted to examine what specific cultural variables in Hispanic/Latino populations may impact employment outcomes.

The demographic variable of gender has also produced mixed results in terms of predicting employment. Previous research demonstrated that gender could enhance or deter the chances of employment. Males with disabilities were found more likely to be employed than females even when provided the same vocational services (Capella, 2002; Coutinho et al., 2006). However, a study by Moore et al. (2002) found that gender did not significantly impact job placement. In the current study, gender was not included as an independent variable in the regression equations because significant differences were not found in employment outcome, supporting the Moore et al. (2002) study.

\section{Quantitative Research on Individuals with ID}

This study was conducted on the individual by self-reporting through a quantitative survey to test a proposed employment model. The body of literature on using quantitative methods with individuals with ID is limited; however, some issues have been addressed (e.g., comprehension, response bias, and self-reporting). Methods utilized in this study to increase validity and reliability are discussed with future implications of quantitative studies with the population with ID.

\section{Comprehension}

Previous literature has suggested the use of a comprehension assessment when administering self-reported surveys to ensure understanding (Cummins, 1997; Dagnan et 
al., 2008). Instead of using a comprehension assessment in this study, the sample was limited to individuals with mild ID who could complete a 30-minute survey in its entirety. Individuals were identified by intermediaries at non-profit organizations who were familiar with comprehension levels of the respondents. This method was considered effective as all participants were able to successfully complete the survey. However, it is important to note that service providers may underestimate the ability or willingness of participation (McDonald, Conroy, \& Olick, 2017).

In addition to comprehension assessments, previous literature suggested the use of pictures or other media to assist with self-report surveys (Finlay \& Lyons, 2002; Hartley $\&$ MacLean, 2006). The use of pictures in self-reporting research has been found most effective in reducing non-response error in Likert-scale questions relating to emotions or other abstract concepts. Morever, pictures and symbols are widely used as a communication strategy with individuals with severe ID (Beukelman \& Mirenda, 2013; Stephenson, 2016). Preliminary research has determined that reading text aloud and providing responses that include pictures increases comprehension levels with individuals with ID (Cox-Magno, et al., 2018; Shurr \& Taber-Doughty, 2017). Thus, the use of pictures or other media in future replication of this survey would assist with comprehension and potentially include individuals with varying levels of ID.

Finlay and Lyons (2001) noted that when administering a survey, the researcher must be flexible enough in the approach to allow for rephrasing, probing, and delayed responses. In this study, the researcher brought in prior practical and empirical knowledge of the population with ID. Thus, the survey was created with the intent of using definitions and alternative phrases. Probes were used when necessary to ensure 
comprehension. For example, 'Would you like a definition for that word?' In addition, probes were used to maintain respect for response time. For example, 'Would you like some time to think about the question?' The use of intermediaries supplemented this process as information was provided ahead of time regarding comprehension and response time. Having brief introductions to the sample being surveyed as well as the intermediaries prior to the survey administration had demonstrated positive effects on ease of the survey process.

\section{Response Bias}

Response bias has been found to be negatively correlated with intellectual functioning (Perkins, 2007). To control for these types of bias, methods were put into place. For example, the use of multiple-choice questions was limited and rating scales eliminated (Hartley \& MacLean, 2006). In the few multiple-choice questions, a “Don't Know" option was added that would not be scored (Ramirez \& Lukenbill, 2008). A checklist format was used to avoid using "yes" or "no" questions to reduce acquiescence bias (Perry, 2004). However, parts of the survey involved topics that were not concrete (e.g., family expectations), limiting this survey to individuals with mild ID. Replication of this study could provide further insight on the test-retest reliability of the survey for individuals with mild ID as well as identify emergence of any response bias.

The addition of proxy reporting has been noted as one way to reduce potential response bias (Perry, 2004). However, the research on self-reporting measures versus proxy reporting have been mixed. For example, in a study by Claes et al. (2012) individuals with ID who self-reported on a quality of life scale reported higher scores than those of a proxy report. In studies about emotions (e.g., anxiety), self-report 
measures were more reliable than those done by proxy (Ramirez \& Lukenbill, 2008).

Parts of the survey in this study were subjective (e.g., family expectations), making it difficult to confirm results through proxy (Perkins, 2007). However, the concrete portions of the survey (e.g., services accessed) have a higher chance of being validated. Replication of this study including proxy reporting could verify if the self-reported data aligned with those of family members or other support systems as well as identify any discrepancies due to response bias.

\section{Self-Reporting Measures}

Ethical considerations regarding accuracy of self-reported data have been noted in the literature. To fully respect the perspective of the individual with a disability, one must assume the communication provided by the participant is accurate within their own frame of reference (Goodley \& Runswick-Cole, 2016). Perry (2004) noted that formal interview processes are not always practical as some individuals with ID best convey information through conversation or stories. For example, individuals who have difficulty communicating may provide information in how the data are presented. One way this barrier was circumvented was to keep the survey in a natural setting. The researcher physically went to each non-profit location to conduct the surveys. Survey implementation took place in an area that the individual would typically be in during the time at the organization.

Through the surveying process, many participants desired to share additional information that could not be used in this study. Follow-up studies on the same participants could provide additional insight that was not captured in the dataset. In addition, the desire to share experiences suggests that follow-up studies on social 
cognitive factors impacting employment could use mixed methodologies or methodological pluralism. Supplementing quantitative methods with qualitative research methods could inform about the experiences and lives of people with ID (Beail \& Williams, 2014). Additionally, using methodological pluralism or multiple methods of collecting data (e.g., self-report and observation) could assist in validating self-report results (Claes et al., 2012; Finlay \& Lyons, 2001).

\section{Accessing the Population}

Though individuals are willing to participate in research studies, accessing and identifying the population of adults with ID is a known obstacle (Fujiura, 2003). The success acquiring the sample in this study was due to the assistance of intermediaries at each non-profit organization. One limitation of the sample in the current study was the potential influence of involvement in non-profit organizations where the research was conducted on employment outcomes. The sample only included individuals already participating in organizations which provided employment training. There is a large population of individuals with ID not involved in community programs and never employed. For example, Siperstein et al. (2013) found that $28 \%$ of a sample of 1,107 individuals with ID had never been in the workforce. One method to reach isolated groups is by using snowball sampling where one individual provides access to another (Atkinson \& Flint, 2001). Future studies including snowball sampling methods to increase the number of participants not accessing community resources are needed to validate the results of this study. 


\section{COVID-19 and Future Research}

The data collection from this study was completed before the COVID-19 pandemic began in the United States. However, moving forward research with adults with ID may be impacted by the pandemic due to health concerns. Instead of administering surveys face-to-face, researchers might conduct telephone interviews or use an online platform such as Zoom. If using an online platform, researchers will need to develop a plan to guarantee privacy. It is the responsibility of the researcher to ensure that both the researcher and participants are in private, quiet rooms when conducting the survey. In addition, researchers using online platforms (e.g., Zoom) should use a password to protect the online session. Conducting telephone surveys increases the amount of survey participants as not all individuals with ID may have a reliable internet connection. Regardless of communication method used to administer the survey, researchers will need to schedule the interviews in advance to ensure that: (a) the individual has time to complete the survey and (b) the participants have a copy of the survey instrument in front of them during the process.

\section{Implications for Practice}

\section{Implications for Service Providers}

\section{Promoting Awareness of Community Resources}

The results of this study revealed that personal attributes were correlated with environmental supports and barriers and career behavior. These symbiotic relationships demonstrate the need for individuals to continue to learn about the vocational supports available in the community as well as how to navigate the resources that are available. 
Though self-determination was correlated to removing environmental barriers and accessing services in previous studies (Shogren et al., 2015; Thoma \& Getzel, 2005), it cannot be generalized to the entire population with ID. Despite the high levels of selfdetermination noted in the study sample as well as participation in non-profit organizations, individuals were still not accessing many of the available vocational resources in the community. Out of 21 possible community services, the average respondent in this study accessed around seven services with some respondents reporting as low as two services accessed. In addition, only half of the participants (52.6\%) indicated using a vocational rehabilitation service, a state-run service to assist with job placement and retention. Receiving job placement assistance from vocational rehabilitation services specifically have been shown to increase the chance of employment by 3.15 times (Kaya, 2018). Considering the relatively low community participation rate in the sample accessing non-profit organizations, communication about available resources is key especially for those individuals not participating in any organizations or employment. Evaluating the methods of communication and strategies used to provide information to homebound adults with ID could be beneficial to service providers.

Promoting community resources is especially important for individuals within minority ethnic groups. Minority ethnic groups were found to report more unmet needs in terms of community services and supports particularly in vocational training (Pruchno \& McMullen, 2004). In addition, Black and Hispanic/Latino households were less likely to access formal services in the community (Hasnain \& Balcazar, 2009). Given the correlation between use of community resources and career behavior (Hasnain \& 
Balcazar, 2009; Kaya, 2018) receiving support from community resources plays an important role in the equity of employment for minorities with ID. Therefore, efforts to promote community resources must be strategic in marketing to minority populations.

One community service that was well accessed in the current sample was transportation. Previous research has found transportation to be a cited barrier to career behavior and employment (Gilson et al., 2018). In contrast, the results of this study found about half of the participants accessed transportation training (53\%) and the large majority utilized transportation services provided by the county (85\%). Additionally, all participants accessed at least one mode of transportation listed on the survey. It is important to note that the location of Miami, Florida, USA, is an urban city with multiple existing modes of transportation. The introduction of ride sharing apps such as Uber and Lyft provided added methods of travel. Close to half of the sample (44.7\%) identified the use of Uber or Lyft at least once. However, those with physical disabilities requiring accessibility may not view ride sharing as a feasible option (Reed, 2016). Emphasis on transportation options and training services should continue as it is a key component of gaining employment.

\section{SCCT Theory to Practice}

The SCCT provides a theoretical basis for the development of career behavior for diverse groups of individuals (Lent et al., 1994). Implementing the SCCT framework into all aspects of career planning could improve the understanding of the career behavior of adults with ID (Fabian, 2000). The findings from this study, along with other SCCT studies on individuals with ID, should be taken into consideration by service providers. For example, PSE programs implement strategies to set goals through a person-centered 
planning process (Hart et al., 2010). However, the results of previous SCCT studies have demonstrated a correlation between environmental supports and barriers, personal attributes, and goal setting (Gibbons et al., 2016). Therefore, examining the impact outside factors (e.g., family support) may have on achieving goals would be necessary to ensure success in goal setting.

Future career assessments or intakes should first identify potential supports and barriers in the individual's environment. This study informed the following familial variables: family structure, level of family involvement, family vocational expectations, and cultural contexts. In addition, the community variables should be assessed including transportation options, availability of services located near the individual, and availability of school services. Examining this information supplements the goal setting process. For example, an individual striving for a goal of full-time employment may be impeded by a family member who expects the individual to be home to assist other family members.

Next, career behavior the individual has engaged in previously should be identified. According to the SCCT and the results of this study, engagement in career behavior affects personal attributes (Lent et al., 1994). Therefore, the outcome of the experience is equally as important as the engagement in career behavior. This study informed the following career variables: vocational training in high school, vocational training outside of high school, internships, and paid employment. Gathering this information can inform future goal setting by also incorporating past career goals that were or were not achieved.

Finally, future career assessments and intakes should identify the steps the individual has taken to secure employment. The results of this study demonstrated that 
personal attributes such as self-determination were interrelated with career behavior and environmental supports and barriers. In addition, personal attributes such as selfdetermination were found to predict employment outcome. Therefore, assessing personal attributes such as self-determination provides integral information on the individual in terms of employment. This study informed the following personal attribute variables: job searching, securing supports, self-advocacy, and self-determination. Information gathered from all SCCT constructs should be aggregated and considered when assisting with goal setting.

\section{Implications for HRD Professionals}

Much of the literature on employment for the population with ID focuses on employers or support system perspectives. Thus, the perspectives of employees with ID have been underrepresented (Ellenkamp et al., 2016). In this study, the majority (75\%) of the sample reported having a job. Therefore, findings in the dataset can provide insight for HRD professionals.

\section{Promoting Self-Determination}

The results of this study found that personal attributes such as self-determination were a strong predictor of employment. This aligns with previous research that demonstrated a relationship between self-determination and employment outcomes (Shogren et al., 2015; Wehmeyer \& Schwartz, 1997). Individuals with ID are less likely to look for a higher salary or a promotion (Ali et al., 2011); therefore, retaining an employee with ID may be more related to personal benefits and quality of life factors than monetary value. The promotion of self-determination at work is related to initiation 
of new tasks, improvement in overall job performance, and adaptation to work changes (Spreitzer \& Porath, 2014). Promotion of self-determination does not have to be conducted formally; rather, it can be fostered by encouraging decision-making, developing trust, and providing ongoing feedback. One main tenant of the SCCT is the relationship between receiving feedback and developing belief in oneself of completing the job task (Lent et al., 1994). Therefore, providing ongoing feedback strengthens the personal attributes of the individual, ultimately leading to more work autonomy.

\section{On the Job Support}

Previous research illustrated the importance of work support systems and assistance in the workplace in terms of job attainment (Ellenkamp et al., 2016). Kaya (2018) found that individuals with on the job support were 2.78 times more likely to gain employment. Though the career behavior variable was a negative predictor of employment, the majority (75\%) of participants in the study were employed. Of the 76 respondents, $61.8 \%$ had access to a job coach and $68.4 \%$ reported having access to natural supports on the job, highlighting the prevalence of on the job supports in the adult population of ID. Natural supports include any person in the work environment that assists the individual with a disability (Wehman \& Hill, 1985). Natural supports can be assigned or selected naturally by the individual. The use of natural supports ensures the individual always has a support system when in the workplace and not just when a job coach is present. Considering that participation in career behavior (e.g., internship) negatively impacted employment outcomes, individuals with ID may need continuous employment training. The implications of these findings denote that individuals with ID require accommodations to allow for additional support or training during work hours. 
Individuals with ID have stated in previous studies that a preferred employer would provide accommodations to all employees as to not single out the individual (Gilbride et al., 2003). Most importantly, all conversations regarding accommodations and support should always include the individual.

\section{Employment Partnerships}

Individuals with ID face many barriers to obtaining employment. Without proper support or self-determination, the process of applying for jobs presents a challenge (Ali et al., 2011). The results of this study indicated that $75 \%$ of the respondents involved in non-profit organizations were employed. This finding denotes the importance of ongoing employment partnerships between community vocational programs and employers. As previously stated, access to community resources was considerably low for the respondents, making the continuation of partnerships significant. A low-cost option to creating a community partnership is to offer internship options that eventually lead to jobs (Gilbride et al., 2003). Internships have demonstrated benefits in the literature such as promoting work skills for individuals with ID (Luecking \& Fabian, 2000). Due to the results of this study demonstrating a negative relationship between career behavior and employment outcome, ensuring a pipeline from internship to employment could close that gap. The internship process for individuals with ID is comparable to that of nondisabled interns. Montague and Violette (2017) outlined sound internship practices including an initial training period and matching the intern with a mentor or natural support who provides feedback. These practices align with the aforementioned SCCT tenant of ongoing feedback as well as the use of natural supports. Though it may not be

feasible for all internships to lead to employment at the place of business, individuals will 
have access to job training that could lead to setting future employment goals and increasing personal attributes such as self-determination.

\section{Conclusion}

Personal attributes such as self-determination were validated in this study as a positive predictor to employment outcome for adults with ID. Promotion of selfdetermination constructs should be continued by service providers as well as family supports throughout the lifespan to ensure ongoing positive employment outcomes. Career behavior on the other hand was found to be a negative predictor to employment outcome. This finding highlights the need for continued research on the types of career building opportunities provided into adulthood for the population with ID and subsequent effects on employment.

The constructs of the SCCT including environmental supports and barriers, personal attributes, and career behavior were found to be correlated among each other in this study. This finding validates the cyclical nature of the SCCT throughout the lifespan, highlighting the importance of continued focus on social cognitive factors in service structure and support for adults with ID. In conclusion, this study added to the limited body of literature on adults with ID in terms of employment. Various gaps in literature still exist on the social cognitive influences (e.g., family expectations, community resources) on career trajectories in adults with ID to inform best practices for employment attainment. 


\section{References}

Agran, M., \& Krupp, M. (2011). Providing choice making in employment programs: The beginning or end of self-determination? Education \& Training in Autism \& Developmental Disabilities, 46, 565-575.

Agran, M., Spooner, F., Brown, F., Morningstar, M., Singer, G. H. S., \& Wehman, P. (2018). Perspectives on the state of the art (and science) of selected life-span services. Research \& Practice for Persons with Severe Disabilities, 43, 67-81. https://doi.org/10.1177/1540796918769566

Ali, M., Schur, L., \& Blanck, P. (2011). What types of jobs do people with disabilities want? Journal of Occupational Rehabilitation, 21(2), 199-210. https://doi.org/10.1007/s10926-010-9266-0

Akkerman, A., Janssen, C. G. C., Kef, S., \& Meininger, H. P. (2014). Perspectives of employees with intellectual disabilities on themes relevant to their job satisfaction. An explorative study using photovoice. Journal of Applied Research in Intellectual Disabilities, 27(6), 542-554. https://doiorg.ezproxy.fiu.edu/10.1111/jar.12092

Atkinson, R., \& Flint, J. (2001). Accessing hidden and hard-to-reach populations: snowball research strategies. Social Research Update, 33, 1-8.

Baer, R. M., Daviso III, A. W., Flexer, R. W., McMahan Queen, R., \& Meindl, R. S. (2011). Students with intellectual disabilities: Predictors of transition outcomes. Career Development for Exceptional Individuals, 34, 132-141. https://doi.org/10.1177/0885728811399090

Baer, R. M., Flexer, R. W., Beck, S., Amstutz, N., Hoffman, L., Brothers, J., et al. (2003). A collaborative followup study on transition service utilization and post-school outcomes. Career Development for Exceptional Individuals, 26, 7-25.

Bakeman, R., \& Robinson, B. F. (2005). Understanding statistics in the behavioral sciences. Psychology Press.

Bandura, A. (1986). Social foundations of thought and action: A social cognitive theory. Prentice-Hall.

Bandura, A. (1999). Social cognitive theory: An agentic perspective. Asian Journal of Social Psychology, 2, 21-41.

Beail, N., \& Williams, K. (2014). Using qualitative methods in research with people who have intellectual disabilities. Journal of Applied Research in Intellectual Disabilities, 27(2), 85-96. https://doi-org.ezproxy.fiu.edu/10.1111/jar.12088 
Bellmann, M. (2016). Factor analysis of geometric figures with four attributes: A comparison of PCA, varimax and varimin. Personality and Individual Differences, 90, 326-331. https://doi.org/10.1016/j.paid.2015.11.032

Berry, J. O. \& Hardman, M. L. (1998). Lifespan perspectives on the family and disability. Allyn and Bacon.

Betz, N. E. (2007). Career self-efficacy: Exemplary recent research and emerging directions. Journal of Career Assessment, 15, 403-422. https://doi.org/10.1177/1069072707305759

Beukelman, D., \& Mirenda, P. (2013). Augmentative and alternative communication: Supporting children and adults with complex communication needs (4th ed.). Brookes.

Blacher, J., \& Hatton, C. (2009). Families in context: influences on coping and adaptation. In S.L. Odom, R.H. Horner, \& M.E. Snell, (Eds.). Handbook of developmental disabilities (pp. 531-551). Guilford Press.

Blacher, J., Kraemer, B. R., \& Howell, E. J. (2010). Family expectations and transition experiences for young adults with severe disabilities: Does syndrome matter? Advances in Mental Health and Learning Disabilities, 4, 3-16. https://doi.org/10.5042/ amhld.2010.0052

Blacher J., \& McIntyre L. L. (2006). Syndrome specificity and behavioural disorders in young adults with intellectual disability: cultural differences in family impact. Journal of Intellectual Disability Research, 50(3), 184-198. https://doi,org/10.1111/j.1365-2788.2005.00768

Blacher, J., \& Mink, I. T. (2004). Interviewing family members and care providers: Concepts, methodologies, and cultures. In E. Emerson, C. Hatton, T. Thompson, \& T. Parmenter (Eds.), International handbook of applied research in intellectual disabilities (pp. 133-159). Wiley.

Black, B. J. (1992). A kind word for sheltered work. Psychosocial Rehabilitation Journal, 15, 87-89.

Blackorby, J., \& Wagner, M. (1996). Longitudinal postschool outcomes of youth with disabilities: Findings from the National Longitudinal Transition Study.

Exceptional children, 62(5), 399-413. https://doi.org/10.1177/001440299606200502

Blustein, C. L., Carter, E. W., \& McMillan, E. D. (2016). The voices of parents: posthigh school expectations, priorities, and concerns for children with intellectual and developmental disabilities. Journal of Special Education, 50(3), 164-177. 
Boeltzig, H., Timmons, J. C., \& Butterworth, J. (2008). Entering work: Employment outcomes of people with developmental disabilities. International Journal of Rehabilitation Research, 31, 217-223.

Bouck, E. C., \& Joshi, G. S. (2014). Transition and students with mild intellectual disability: Findings from the National Longitudinal Transition Study-2. Career Development and Transition for Exceptional Individuals, 39(3), 154-163. https://doi.org/10.1177/2165143414551408

Brigharm, N., Morocco, C. C., Clay, K., \& Zigmond, N. (2006). What makes a high school a good high school for students with disabilities. Learning Disabilities Research \& Practice, 21, 184-190. https://doi.org/10.1111/j.1540$\underline{\text { 5826.2006.00217.x }}$

Brod, M., Tesler, L. E., \& Christensen, T. L. (2009). Qualitative research and content validity: developing best practices based on science and experience. Quality of Life Research, 18, 1263-1278. https://doi.org/10.1007/s11136-009-9540-9

Burge, P., Ouellette-Kuntz, H., \& Lysaght, R. (2007). Public views on employment of people with intellectual disabilities. Journal of Vocational Rehabilitation, 26, 29-37.

Bush, K. L. \& Tassé, M. J. (2017). Employment and choice-making for adults with intellectual disability, Autism, and Down Syndrome. Research in Developmental Disabilities, 65, 23-34. https://doi.org/10.1016/j.ridd.2017.04.004

Butterworth, J., Christensen, J., \& Flippo, K. (2017). Partnerships in employment: Building strong coalitions to facilitate systems change for youth and young adults. Journal of Vocational Rehabilitation, 47(3), 265-276. https://doiorg.ezproxy.fiu.edu/10.3233/JVR-170901

Butterworth, J., Hagner, D., Helm, D. T., \& Whelley, T. A. (2000). Workplace culture, social interactions, and supports for transition-age young adults. Mental Retardation, 38(4), 342-353. https://doi.org/10.1352/00476765(2000)038<0342:WCSIAS >2.0.CO;2

Butterworth, J., Hall, A. C., Smith, F. A., Migliore, A., Winsor, J., Timmons, J., \& Domin, D. (2011). StateData: The national report on employment services and outcomes. Boston, MA: University of Massachusetts Boston, Institute for Community Inclusion.

Butterworth, J., Migliore, A., Nord, D., \& Gelb, A. (2012). Improving the employment outcomes of job seekers with intellectual and developmental disabilities: A training and mentoring intervention for employment consultants. Journal of Rehabilitation, 78, 20-29. 
Callahan, M., Griffin, C., \& Hammis, D. (2011). Twenty years of employment for persons with significant disabilities: A retrospective. Journal of Vocational Rehabilitation, 35, 163-172. https://doi.org/10.3233/JVR-2011-0565

Cameto, R., Levine, P., \& Wagner, M. (2004). Transition planning for students with disabilities: a special topic report of findings from the National Longitudinal Transition Study-2 (NLTS2). Menlo Park, CA: SRI International. Retrieved from http://www.nlts2.org/reports/2004_11/nlts2_report_2004_11_execsum.pdf

Capella M.E. (2002). Inequities in the VR system: do they still exist? Rehabilitation Counseling Bulletin, 45(3), 143-192.

Carter, E. W., Austin, D., \& Trainor, A. (2011). Factors associated with the early work experiences of adolescents with severe disabilities. Intellectual and Developmental Disabilities, 49(4), 233-247. https://doi.org/10.1352/1934-9556$\underline{49.4 .233}$

Carter, E. W., Austin, D., \& Trainor, A. (2012). Predictors of post-school employment outcomes for young adults with severe disabilities. Journal of Disability Policy Studies, 23, 50-63. https://.doi.org10.1177/1044207311414680

Carter, E. W., Ditchman, N., Sun, Y., Trainor, A. A., Swedeen, B., \& Owens, L. (2010). Summer employment and community experiences of transition-age youth with severe disabilities. Exceptional Children, 76, 194-212. https://doi.org/10.1177/001440291007600204

Carter, E.W., Kleinert, H.L., LoBianco, T.F., Sheppard-Jones, K., Butler, L.N., \& Tyree, M.S. (2015). Congregational participation of a national sample of adults with intellectual and developmental disabilities. Intellectual and Developmental Disabilities, 53(6), 381-393. doi: 10.1352/1934-9556-53.6.381

Carter, E. W., Trainor, A. A., Cakiroglu, O., Swedeen, B., \& Owens, L. A. (2010). Availability of and access to career development activities for transition-age youth with disabilities. Career Development for Exceptional Individuals, 33, 1324. https://doi.org/10.1177/0885728809344332

Casey, A. F., Wang, X., \& Boucher, J. (2014). Test of self-determination theory in swimmers with and without Down Syndrome. Inclusion, 2(1), 54-64.

Cease-Cook, J., Fowler, C., \& Test, D. W. (2015). Strategies for creating work-based learning experiences in schools for secondary students with disabilities. Teaching Exceptional Children, 47, 352-358. https://doi.org/10.1177/0040059915580033

Chachamovich E., Fleck M. P. \& Power M. (2009) Literacy affected ability to adequately discriminate among categories in multipoint Likert Scales. Journal of Clinical Epidemiology 62, 37-46. 
Chadsey-Rusch, J., \& Gonzalez, P. (1996). Analysis of directions, responses, and consequences involving persons with mental retardation in employment and vocational training settings. American Journal on Mental Retardation, 100, 481592.

Chadsey-Rusch, J. C., Rusch, F. R., \& O'Reilly, M. F. (1991). Transition from school to integrated communities. Remedial and Special Education, 12, 23-33. https://doi.org/10.1177/074193259101200605

Chapman, C., Laird, J., and KewalRamani, A. (2010). Trends in high school dropout and completion rates in the United States: 1972-2008 (NCES 2011-012). National Center for Education Statistics, Institute of Education Sciences, U.S. Department of Education. Washington, DC.

Charters, E. (2003). The use of think-aloud methods in qualitative research. An introduction to think-aloud methods. Brock Education, 12, 68-82.

Cheatham, G. A., Smith, S. J., Elliott, W., \& Friedline, T. (2013). Family assets, postsecondary education, and students with disabilities: Building on progress and overcoming challenges. Children and Youth Services Review, 35(7), 1078-1086. https://doi.org/10.1016/j.childyouth.2013.04.019

Chretien, J., Nimon, K., Reio, T. G., Jr., \& Ellis, J. (2020). Responding to low coefficient alpha: Potential alternatives to the file drawer. Human Resource Development Review, 19, 215-239. https://doi.org/10.1177/1534484320924151

Claes, C., Vandevelde, S., Van Hove, G., Van Loon, J., Verschelden, G., \& Schalock, R. (2012). Relationship between self-report and proxy ratings on assessed personal quality of life-related outcomes. Journal of Policy \& Practice in Intellectual Disabilities, 9(3), 159-165. https://doi-org.ezproxy.fiu.edu/10.1111/j.17411130.2012.00353.x

Cohen, S. R. (2013). Advocacy for the "abandonados": Harnessing cultural beliefs for Latino families and their children with intellectual disabilities. Journal of Policy and Practice in Intellectual Disabilities, 10(1), 71-78.

Cohen, S. R., Holloway, S. D., Dominguez-Pareto, I. \& Kuppermann, M. (2014). Receiving or believing in family support? Contributors to the life quality of Latino and non-Latino families of children with intellectual disability. Journal of Intellectual Disability Research, 58(4), 333-345. https://doi.org/10.1111/jir.12016

Coutinho, M. J., Oswald, D. P., \& Best, A. M. (2006). Differences in outcomes for female and male students in special education. Career Development for

Exceptional Individuals, 29(1), 48-59. https://doiorg.ezproxy.fiu.edu/10.1177/08857288060290010401 
Cox-Magno, N., Ross, P., Dimino, K., \& Wilson, A. (2018). Metacognitive reading strategy and emerging reading comprehension in students with intellectual disabilities. Journal of Educational Research \& Practice, 8(1), 195-209. https://doi-org/10.5590/jerap.2018.08.1.14

Cummins, R. A. (1997). The comprehensive quality of life scale: Intellectual disability (5th ed.). Melbourne: Deakin University.

Dagnan, D., Jahoda, A., McDowell, K., Masson, J., Banks, P., \& Hare, D. (2008). The psychometric properties of the hospital anxiety and depressions scale adapted for use with people with intellectual disabilities. Journal of Intellectual Disability Research, 52(11), 942-949. https://doi-org.ezproxy.fiu.edu/10.1111/j.13652788.2008.01053.x

Dalton, A. J., \& McVilly, K. R. (2004). Ethics guidelines for international, multicenter research involving people with intellectual disabilities. Journal of Policy and Practice in Intellectual Disabilities, 1(2), 57-70.

Dillman, D. A. (2007). Mail and internet surveys: the tailored design method. Wiley.

Dixon, R. M., \& Reddacliff, C. A. (2001). Family contribution to the vocational lives of vocationally competent young adults with intellectual disabilities. International Journal of Disability, Development \& Education, 48, 193-206. https://doi.org/10.1080/10349120120053667

Domin, D., \& Butterworth, J. (2013). The role of community rehabilitation providers in employment for persons with intellectual and developmental disabilities: results of the 2010-2011 national survey. Intellectual and Developmental Disabilities, 51, 215-225. https://doi.org/10.1352/1934-9556-51.4.215

Donnay, D., \& Borgen, F. (1999). The incremental validity of vocational self-efficacy: An examination of interest, self-efficacy, and occupation. Journal of Counseling Psychology, 46, 432-447.

Doren, B., \& Benz, M. R. (1998). Employment inequality revisited: Predictors of better employment outcomes for young women with disabilities in transition. Journal of Special Education, 31, 425-442. https://doi.org/10.1177/002246699803100402

Doren, B., Gau, J.M., \& Lindstrom, L. (2010). The role of gender in the long-term employment outcomes of young adults with disabilities. Journal of Vocational Rehabilitation, 34, 35-42. https://doi.org/10.3233/JVR-2010-0532

Dotson, W. H., Richman, D. M., Abby, L., Thompson, S., \& Plotner, A. (2013). Teaching skills related to self-employment to adults with developmental disabilities: An analog analysis. Research in Developmental Disabilities, 34, 2336-2350. https://doi.org/10.1016/j.ridd.2013.04.009 
Ellenkamp, J., Brouwers, E., Embregts, P., Joosen, M., \& Weeghel, J. (2016). Work environment-related factors in obtaining and maintaining work in a competitive employment setting for employees with intellectual disabilities: a systematic review. Journal of Occupational Rehabilitation, 26(1), 56-69.

Epler, P. L., \& Ross, R. (2015). Models for effective service delivery in special education programs. IGI Global.

Erickson, W., Lee, C., \& von Schrader, S. (2012). Disability Statistics from the 2010 American Community Survey (ACS). Ithaca, NY: Cornell University Employment and Disability Institute (EDI). Retrieved from www.disabilitystatistics.org

Fabian, E. S. (2000). Social cognitive theory of careers and individuals with serious mental health disorders: Implications for psychiatric rehabilitation programs. Psychiatric Rehabilitation Journal, 23, 262-269.

Fabian, E. S., Ethridge, G., \& Beveridge, S. (2009). Differences in perceptions of career barriers and supports for people with disabilities by demographic, background and case status factors. Journal of Rehabilitation, 75(1), 41-49.

Feerasta, J. (2017). Individuals with intellectual disabilities in the restaurant business: An exploratory study of attributes for success. Journal of Human Resources in Hospitality \& Tourism, 16, 22-38. https://doi.org/10.1080/15332845.2016.1202047

Field, S. (1996). Self-determination instructional strategies for youth with learning disabilities. Journal of Learning Disabilities, 29, 40-52. https://doi.org/10.1177/002221949602900107

Field, S., Martin, J., Miller, R., Ward, M., \& Wehmeyer, M. (1998). Self-determination in career and transition programming: A position statement of the division on career development and transition. Career Development for Exceptional Individuals, 21, 113-128.

Finlay, W. M. \& Lyons, E. (2001). Methodological issues in interviewing and using selfreport questionnaires with people with mental retardation. Psychological Assessment, 13(3), 319-335. https://doi-org.ezproxy.fiu.edu/10.1037/1040$\underline{3590.13 .3 .319}$

Flexer, R. W., Daviso, A. W., III, Baer, R. M., Queen, R. M., \& Meindl, R. S. (2011). An epidemiological model of transition and postschool outcomes. Career

Development for Exceptional Individuals, 34, 83-94. https://doi.org/10.1177/0885728810387922 
Flippo, K. F., \& Gardner, J. F. (2011). Employment: It is everybody's business. Intellectual and Developmental Disabilities, 49, 305-309. https://doi.org/10.1352/1934-9556-49.4.305

Francis, L. P. (2004). Employment and intellectual disability. The Journal of Gender, Race, and Justice, 8, 299-325.

Fujiura, G. T. (2003). Continuum of intellectual disability: Demographic evidence for the "forgotten generation." Mental Retardation, 41(6), 420-429.

Gadbow, N. F., \& Du Bois, D. A. (1998). Adult learners with special needs: Strategies and resources for postsecondary education and workplace training. Krieger Publishing Company.

Geenen, S., Powers, L. E., \& Lopez-Vasquez, A. (2001). Multicultural aspects of parent involvement in transition planning. Exceptional Children, 67(2), 265. https://doiorg.ezproxy.fiu.edu/10.1177/001440290106700209

Gibbons, M. M., Hyfantis, J., Cihak, D. F., Wright, R., \& Mynatt, B. (2016). A socialcognitive exploration of the career and college understanding of young adults with intellectual disabilities. Professional School Counseling, 19, 80-91. https://doi.org/10.5330/1096-2409-19.1.80

Gilbride, D., Stensrud, R., \& Vandergoot, D. (2003). Identification of the characteristics of work environments and employers open to hiring and accommodating people with disabilities. Rehabilitation Counseling Bulletin, 46(3), 130. https://doiorg.ezproxy.fiu.edu/10.1177/00343552030460030101

Gilson, C. B., Carter, E. W., Bumble, J. L., \& McMillan, E. D. (2018). Family perspectives on integrated employment for adults with intellectual and developmental disabilities. Research and Practice for Persons with Severe Disabilities, 43, 20-37.

Goodley, D., \& Runswick-Cole, K. (2016). Becoming dishuman: thinking about the human through dis/ability. Discourse: Studies in the Cultural Politics of Education, 37(1), 1-15. https://doi.org10.1080/01596306.2014.930021

Green, S. B. (1991). How many subjects does it take to do a regression analysis? Multivariate Behavioral Research, 26, 449-510.

Green, S. B., \& Salkind, N. J. (2008). Using SPSS for Windows and Macintosh: analyzing and understanding data (5th ed.). Pearson/Prentice Hall.

Griffin, G., Hammis, D., Geary, T., \& Sullivan, M. (2008). Customized employment: Where we are, where we're headed. Journal of Vocational Rehabilitation 28, $135-139$. 
Grigal, M., Hart, D., \& Migliore, A. (2011). Comparing the transition planning, postsecondary education, and employment outcomes of students with intellectual and other disabilities. Career Development and Transition for Exceptional Individuals, 34, 4-17. https://doi.org10.1177/0885728811399091

Grigal, M., Hart, D., \& Weir, C. (2012). A survey of postsecondary education programs for students with intellectual disabilities in the United States. Journal of Policy and Practice in Intellectual Disabilities, 9, 223-233. https://doi.org/10.1111/jppi.12012'

Grigal, M., \& Neubert, D. A. (2004). Parents' in-school values and post-school expectations for transition aged youth with disabilities. Career Development for Exceptional Individuals, 27, 65-85. https://doi.org/10.1177/088572880402700105

Grigal, M., Papay, C., Smith, F., Hart, D., \& Verbeck, R. (2019). Experiences that predict employment for students with intellectual and developmental disabilities in federally funded higher education programs. Career Development and Transition for Exceptional Individuals, 42, 17-28.

Gonzalez, R., Rosenthal, D. A., \& Kim, J. H. (2011). Predicting vocational rehabilitation outcomes of young adults with specific learning disabilities: Transitioning from school to work. Journal of Vocational Rehabilitation, 34, 163-172. https://doi.org/10.3233/JVR-2011-0544

Haber, M. G., Mazzotti, V. L., Mustian, A. L., Rowe, D. A., Bartholomew, A. L., Test, D.W., \& Fowler, C. H. (2016). What works, when, for whom, and with whom: a meta-analytic review of predictors of postsecondary success for students with disabilities. Review of Educational Research, 86(1), 123-162. https://doi.org/10.3102/0034654315583135

Hall, P. (1992). On the removal of skewness by transformation. Journal of the Royal Statistical Society. Series B (Methodological), 54(1), 221-228.

Hall, S. A. (2013). Including people with intellectual disabilities in qualitative research. Journal of Ethnographic \& Qualitative Research, 7(3), 128-142.

Harlow, L. L. (2014). Multivariate applications series. The essence of multivariate thinking: Basic themes and methods (2nd ed.). Routledge/Taylor \& Francis Group.

Hartley S. L. \& Maclean W. E. (2006) A review of the reliability and validity of Likerttype scales for people with intellectual disability. Journal of Intellectual Disability Research 50, 813-27.

Harvey, M. W. (2002). Comparison and postsecondary transitional outcomes between students with and without disabilities by secondary vocational education 
participation: Findings from the National Education Longitudinal Study. Career Development for Exceptional Individuals, 25, 99-122. https://doi.org/10.1177/088572880202500202

Hart, D., Grigal, M., \& Weir, C. (2010). Expanding the paradigm: postsecondary education for individuals with autism spectrum disorder and intellectual disabilities. Focus on Autism and Other Developmental Disabilities, 25, 134-150. https://doi.org/10.1177/1088357610373759

Hasnain R., \& Balcazar F. (2009). Predicting community- versus facility-based employment for transition-aged young adults with disabilities: the role of race, ethnicity, and support systems. Journal of Vocational Rehabilitation, 31(3), 175188. https://doi-org.ezproxy.fiu.edu/10.3233/JVR-2009-0487

Heal, L. W., \& Sigelman, C. K. (1995). Response biases in interviews of individuals with limited mental ability. Journal of Intellectual Disability Research, 39(4), 331340. https://doi.org/10.1111/j.1365-2788.1995.tb00525.x

Higher Education Opportunity Act (HEOA), 20 U.S.C. $\S \S 1001-1161$. (2008).

Hosmer, D. W., Lemeshow, S., \& Sturdivant, R. X. (2013). Applied logistic regression. Wiley.

Individuals with Disabilities Education Act (IDEA) of 1989, Pub. L. No. 101-476, 104 Stat. 1142 (1990).

Ipsen, C., \& Swicegood, G. (2015). Rural and urban case differences in vocational rehabilitation case mix, delivery practices, and employment outcomes.

Rehabilitation, Research, Policy, and Education, 29, 349-370. https://doi.org/10.1891/2168-6653.29.4.349

Jahoda, M. (1981). Work, employment and unemployment: Values, theories and approaches in social research. American Psychologist, 36, 184-191.

Jones, J. L., Vierling, K. L., Gallus, K. L., Shogren, K. A., Grandfield, E. M., \& Shaw, L. A. (2018). Examining predictors of self-determination in adults with intellectual and developmental disabilities. Journal of Developmental \& Physical Disabilities, 30(5), 601-614. https://doi-org.ezproxy.fiu.edu/10.1007/s10882-018-9607-z

Joseph, M. M., Osmanu, K., \& Moss, K. (2017). Ethical considerations for working with transition aged youth and students with disabilities given the implications of WIOA. Journal of Applied Rehabilitation Counseling, 48, 42-47.

Joshi, G. S., Bouck, E. C., \& Maeda, Y. (2012). Exploring employment preparation and postschool outcomes for students with mild intellectual disability. Career 
Development and Transition for Exceptional Individuals, 35, 97-107. https://doi.org/10.1177/0885728811433822

Kaya, C. (2018). Demographic variables, vocational rehabilitation services, and employment outcomes for transition-age youth with intellectual disabilities. Journal of Policy and Practice in Intellectual Disabilities, 15, 226-236. https://doi.org/10.1111/jppi.12249

Kiernan, W. E. (2000). Where are we now: Perspectives on employment of persons with mental retardation. Focus on Autism and Other Developmental Disabilities, 15, 90-96. https://doi.org/10.1177/108835760001500204

Kiernan, W. E., Hoff, D., Freeze, S., \& Mank, D. M. (2011). Employment first: A beginning not an end. Intellectual and Developmental Disabilities, 49, 300-304. https://doi.org/10.1352/1934-9556-49.4.300

Kim, J. H. (2019). Multicollinearity and misleading statistical results. Korean Journal of Anesthesiology, 72(6), 558-569. https://doi-org.ezproxy.fiu.edu/10.4097/kja.19087

Kitchin, R. (2000). The researched opinions on the researched: Disabled people and disability research. Disability \& Society, 15(1), 25-47. https://doi.org/10.1080/09687590025757

Kleinert, H. L., Jones, M. M., Sheppard-Jones, K., Harp, B., \& Harrison, E. M. (2012). Students with intellectual disabilities going to college? Absolutely! Teaching Exceptional Children, 44, 26-35.

Kluesner, B., Taylor, D., \& Bordieri, J. (2005). An investigation of the job tasks and functions of providers of job placement activities. Journal of Rehabilitation, 71, 26-35.

Kocman, A., Fischer, L., \& Weber, G. (2018). The employers' perspective on barriers and facilitators to employment of people with intellectual disability: A differential mixed-method approach. Journal of Applied Research in Intellectual Disabilities, 31, 120-131. https://doi.org/10.1111/jar.12375

Kohler, P. D., \& Field, S. (2003). Transition-focused education: Foundation for the future. Journal of Special Education, 37, 174-183. https://doi.org/10.1177/00224669030370030701

Lapan, R. T., Hinkelman, J. M., Adams, A., \& Turner, S. (1999). Understanding rural adolescents' interests, values, and efficacy expectations. Journal of Career Development, 26, 107-124. 
Lee, Y., Wehmeyer, M. L., Palmer, S. B., Williams-Diehm, K., Davies, D. K., \& Stock, S. E. (2012). Examining individual and instruction-related predictors of the selfdetermination of students with disabilities: Multiple regression analyses.

Remedial and Special Education, 33, 150-161.

https://doi.org/10.1177/0741932510392053

Lehmann, J. P., \& Roberto, K. A. (1996). Comparison of factors influencing mothers' perceptions about the futures of their adolescent children with and without disabilities. Mental Retardation, 34(1), 27-38.

Lent, R. W., Brown, S. D., \& Hackett, G. (1994). Toward a unifying social cognitive theory of career and academic interest, choice, and performance. Journal of Vocational Behavior, 45, 79-122. https://doi.org/10.1006/jvbe.1994.1027

Lent, R. W., Brown, S. D., Sheu, H-B., Schmidt, J., Brenner, B., Gloster, C. S., Wilkins, G., Schmidt, L.C., Lyons, H., \& Treistman, D. (2005). Social cognitive predictors of academic interests and goals in engineering: Utility for women and students at historically black universities. Journal of Counseling Psychology, 52, 84-92. https://doi.org/10.1037/0022-0167.52.1.84

Lent, R. W., Morrison, A., \& Ezeofor, I. (2014). The career development of people with disabilities: A social cognitive perspective. In D.R. Strauser (Ed.), Career development, employment, and disability in rehabilitation: From theory to practice (pp. 113-124). Springer.

Lennox, N., Taylor M., Rey-Conde, T., Bain, C., Purdie, D. M., \& Boyle, F. (2005). Beating the barriers: recruitment of people with intellectual disability to participate in research. Journal of Intellectual Disability Research, 49(4), 296305.

Lindstrom, L., E., \& Benz, M. R. (2002). Phases of career development: Case studies of young women with learning disabilities. Exceptional Children, 69, 67-83. https://doi.org/10.1177/001440290206900105

Lindstrom, L. E., Doren, B., Metheny, J., Johnson, P., \& Zane, C. (2007). Transition to employment: Role of family in career development. Exceptional Children, 73, 348-366. https://doi.org/10.1177/001440290707300305

Linker, B. (2013). On the borderland of medical and disability history: A survey of the fields. Bulletin of the History of Medicine 87, 499-535.

Luckasson, R., \& Schalock, R. L. (2013). Defining and applying a functionality approach to intellectual disability. Journal of Intellectual Disability Research, 57, 657-668. https://doi.org/10.1111/j.1365-2788.2012.01575.x 
Luecking, R. G. (2009). The way to work: How to facilitate work experiences for youth in transition. Brookes Publishing Company.

Luecking, R. G., \& Fabian, E. S. (2000). Paid internships and employment success for youth in transition. Career Development for Exceptional Individuals, 23, 205-221. https://doi.org/10.1177/088572880002300207

Lysaght, R., Cobigo, V., \& Hamilton, K. (2012). Inclusion as a focus of employmentrelated research in intellectual disability from 2000 to 2010: A scoping review. Disability \& Rehabilitation, 34, 1339-1350. https://doi.org/10.3109/09638288.2011.644023

Lysaght R., Ouellette-Kuntz H., \& Morrison C. (2009). The meaning and value of productivity to adults with intellectual disabilities. Intellectual and Developmental Disabilities, 47, 413-424. https://doi.org/10.1352/1934-9556-47.6.413

Madaus, J. W., Gelbar, N. W., Dukes, L. L., III., Faggella-Luby, M., Lalor, A. R., \& Kowitt, J. S. (2013). Thirty-five years of transition topics: A review of CDTEI issues from 1978 to 2012. Career Development and Transition for Exceptional Individuals, 36, 7-14. https://doi.org/10.1177/2165143413476734

Magana, S. (1999). Puerto Rican families caring for an adult with mental retardation: The role of familism. American Journal on Mental Retardation, 104, 466-482.

Mamun, A. A., Carter, E. W., Fraker, T. M., \& Timmins, L. L. (2018). Impact of early work experiences on subsequent paid employment for young adults with disabilities. Career Development and Transition for Exceptional Individuals, 41, 212-222. https://doi.org/10.1177/2165143417726302

Mann, D. R., \& Honeycutt, T. (2016). Understanding the disability dynamics of youth: health condition and limitation changes for youth and their influence on longitudinal survey attrition. Demography, 53(3), 749-776.

Manning, J. P., \& Gaudelli, W. (2006). What teacher educators should know about poverty and special education. Teacher Education and Special Education, 29, 2835. https://doi.org/10.1177/088840640602900404

Martinez, K. (2012). Integrated employment, EmploymentFirst, and U.S. federal policy. Journal of Vocational Rehabilitation, 38, 165-168. https://doi.org/10.3233/JVR$\underline{130631}$

Maulik, P. K., Mascarenhas, M. N., Mathers, C. D., Dua, T., \& Saxena, S. (2011). Prevalence of intellectual disability: A meta-analysis of population-based studies. Research in Developmental Disabilities, 32, 419-436.

https://doi.org/10.1016/j.ridd.2010.12.018 
Mazzotti, V. L., Test, D. W., \& Mustian, A. L. (2014). Secondary transition evidencebased practices and predictors: Implications for policymakers. Journal of Disability Policy Studies, 25, 5-18. https://doi.org/10.1177/1044207312460888

McConnell, A. E., Martin, J. E., Juan, C. Y., Hennessey, M. N., Terry, R. A., el-Kazimi, N .A., Pannells, T. C., \& Willis, D. M. (2012). Identifying nonacademic behaviors associated with post-school employment and education. Career Development and Transition for Exceptional Individuals, 36, 174-187. https://doi.org/10.1177/2165143412468147

McConnell, A. E., Osmani, K. J., Williams-Diehm, K. L., \& Pulos, J. M. (2018). iJobs summer work experience: A pilot transition program to enhance job-readiness skills using evidence-based practices, Inclusion, 6, 208-223. https://doi.org/10.1352/2326-6988-6.3.208

McDermott, S., Durkin, M.S., Schupf, N., \& Stein, Z.A. (2007). Epidemiology and etiology of mental retardation. In J.W. Jacobson, J.A. Mulick, J. Rojahn (Eds.), Handbook of intellectual and developmental disabilities (pp. 3-40). Springer.

McDonald, K. E. (2012). “We want respect": Adults with intellectual and developmental disabilities address respect in research. American Journal on Intellectual and Developmental Disabilities, 117(4), 263-274.

McDonald, K. E., Conroy, N. E., \& Olick, R. S. (2017). What's the harm? Harms in research with adults with intellectual disability. American Journal on Intellectual and Developmental Disabilities, 122(1), 78-92.

McDonald, K. E., \& Kidney, C. A. (2012). What is right? Ethics in intellectual disabilities research. Journal of Policy and Practice in Intellectual Disabilities, 9(1), 27-39.

McWhirter, E. H., \& McWhirter, B. T. (2008). Adolescent future expectations of work, education, family, and community development of a new measure. Youth \& Society, 40(2), 182-202. https://doi.org/10.1177/0044118X08314257

Michael, R. (2019). Self-efficacy and future career expectations of at-risk adolescents: The contribution of a tutoring program. Journal of Community Psychology, 47(4), 913-923. https://doi.org/10.1002/jcop.22163

Montague, N., \& Violette, G. (2017). The millennial internship experience: balancing technical training with soft skills. CPA Journal, 87(12), 42-46.

Moore, C. L., Feist-Price, S., \& Alston, R. J. (2002). Competitive employment and mental retardation: Interplay among gender, race, secondary psychiatric disability, and rehabilitation services. Journal of Rehabilitation, 68(1), 14-19. 
Morningstar, M. E. (1997). Critical issues in career development and employment preparation for adolescents with disabilities. Remedial and Special Education, 18, 307-320. https://doi.org/10.1177/074193259701800506

Murray, C. (2003). Risk factors, protective factors, vulnerability, and resilience: A framework for understanding and supporting the adult transitions of youth with high-incidence disabilities. Remedial and Special Education, 24, 16-26. https://doi.org/10.1177/074193250302400102

Nazarov, Z. E., Golden, T. P., \& Schrader, S. V. (2012). Prevocational services and supported employment wages. Journal of Vocational Rehabilitation, 37, 119-129. https://doi.org/10.3233/JVR-2012-0605

Neubert, D. A., \& Leconte, P. J. (2013). Age-Appropriate transition assessment: The position of the division on career development and transition. Career Development and Transition for Exceptional Individuals, 36, 72-83. https://doi.org/10.1177/2165143413487768

Nicholson, L., Colyer, M., \& Cooper, S. A. (2013). Recruitment to intellectual disability research: a qualitative study. Journal of Intellectual Disability Research, 57(7), 647-656. https://doi.org/10.1111/j.1365-2788.2012.01573.x

Niemiec, B., Lavin, D., \& Owens, L.A. (2009). Establishing a national employment first agenda. Journal of Vocational Rehabilitation, 31, 139-144. https://doi.org/10.3233/JVR-2009-0483

Nord, D., Hamre, K., Pettingell, S., \& Magiera, L. (2018). Employment goals and settings: Effects of individual and systemic factors. Research and Practice for Persons with Severe Disabilities, 43, 194-206. https://doi.org/10.1177/1540796918785352

Nord, D., Luecking, R., Mank, D., Kiernan, W., \& Wray, C. (2013). The state of the science of employment and economic self-sufficiency for people with intellectual and developmental disabilities. Intellectual and Developmental Disabilities, 51, 376-384. https://doi.org/10.1352/1934-9556-51.5.376

Nota, L., Ginevra, M.C., \& Carrieri, L. (2010) Career interests and self-efficacy beliefs among young adults with an intellectual disability. Journal of Policy \& Practice in Intellectual Disabilities, 7, 250-260. https://doi.org/10.1111/j.1741$\underline{1130.2010 .00274 . x}$

Novak, J. (2015). Raising expectations for U.S. youth with disabilities: Federal Disability policy advances integrated employment. Center for Educational Policy Studies Journal, 5, 91-110. 
Ochs, L. A., \& Roessler, R. T. (2004). Predictors of career exploration intentions: A social cognitive career theory perspective. Rehabilitation Counseling Bulletin, 47, 224-233. http://dx.doi.org/10.1177/00343552040470040401

O’Sullivan, D., Strauser, D. R., \& Wong, A. W. K. (2012). Five-factor Model of personality, work behavior self-efficacy, and length of prior employment for individuals with disabilities: An exploratory analysis. Rehabilitation Counseling Bulletin, 55, 156-165. https://doi.org/10.1177/0034355212437046

Panagos, R. J. \& DuBois, D. L. (1999). Career self-efficacy development and students with learning disabilities. Learning Disabilities Research and Practice, 14, 25-34.

Park, J. \& Bouck, E. (2018). In-school service predictors of employment for individuals with intellectual disability. Research in Developmental Disabilities, 77, 68-75. https://doi.org/10.1016/j.ridd.2018.03.014

Papay, C. K., Bambara, L. M. (2011). Postsecondary education for transition-age students with intellectual and other developmental disabilities: A national survey. Education and Training in Autism and Developmental Disabilities, 46, 78-93.

Pedhazur, E. J. (1997). Multiple regression in behavioral research (3rd ed.). Harcourt Brace.

Perkins, E. A. (2007). Self and proxy reports across three populations: older adults, persons with Alzheimer's disease, and persons with intellectual disabilities. Journal of Policy \& Practice in Intellectual Disabilities, 4(1), 1-10. https://doiorg.ezproxy.fiu.edu/10.1111/j.1741-1130.2006.00092.x

Perry, J. (2004). Interviewing people with intellectual disabilities. In E. Emerson (Ed.), International handbook of applied research in intellectual disabilities (pp. 115131). Wiley.

Petcu, S. D., Chezan, L. C., \& Van Horn, M. L. (2015). Employment support services for students with intellectual and developmental disabilities attending postsecondary education programs. Journal of Postsecondary Education and Disability, 28, 359374.

Prohn, S. M., Kelley, K. R., \& Westling, D. L. (2018). Students with intellectual disability going to college: What are the outcomes? A pilot study. Journal of Vocational Rehabilitation, 48(1), 127-132.

Pruchno, R. A., \& McMullen, W. F. (2004). Patterns of service utilization by adults with a developmental disability: Type of service makes a difference. American Journal on Mental Retardation, 109, 362-378. 
Qian, X., Johnson, D. R., Smith, F. A., \& Papay, C. K. (2018). Predictors associated with paid employment status of community and technical college students with intellectual disability. American Journal on Intellectual and Developmental Disabilities, 123, 329-343. https://doi.org/10.1352/1944-7558-123.4.329

Rabren, K., Dunn, C., \& Chambers, D. (2002). Predictors of post-high school employment among young adults with disabilities. Career Development for Exceptional Individuals, 25, 25-40. https://doi.org/10.1177/088572880202500103

Ramirez, S., \& Lukenbill, J. (2008). Psychometric properties of the Zung Self-Rating Anxiety Scale for adults with intellectual disabilities (SAS-ID). Journal of Developmental \& Physical Disabilities, 20(6), 573-580. https://doiorg.ezproxy.fiu.edu/10.1007/s10882-008-9120-x

Reed, R. (2016). Disability Rights in the Age of Uber: Applying the Americans with Disabilities Act of 1990 to transportation network companies. Georgia State University Law Review, 33(2), 517-v.

The Rehabilitation Act of 1973, Pub. L. 93-112, 29 U.S.C. § 701 et seq (1973).

Reid, P. M., \& Bray, A. (1997). Paid work and intellectual disability. Journal of Intellectual and Developmental Disability, 22, 87-96. https://doi.org/10.1080/13668259700033321

Retish, P., \& Raiter, S. (1999). Adults with disabilities: International perspectives in the community. Routledge.

Riesen, T., Morgan, R. L., \& Griffin, C. (2015). Customized employment: A review of the literature. Journal of Vocational Rehabilitation, 43, 183-193. https://doi.org/10.3233/JVR-150768

Roessler, R. T., Brolin, D. E., \& Johnson, J. M. (1990). Factors affecting employment success and quality of life: A one year follow-up of students in special education. Career Development for Exceptional Individuals, 13, 95-107. https://doi.org/10.1177/088572889001300201

Salvador-Carulla, L., Bertelli, M. \& Martinez-Leal, R. (2018). The road to 11th edition of the International Classification of Diseases. Current Opinion in Psychiatry, 31(2), 79-87. https://doi.org/10.1097/YCO.0000000000000396

Scotch, R. K. (2000). Disability policy: An eclectic overview. Journal of Disability Policy Studies, 11, 6-11. https://doi.org/10.1177/104420730001100104

Schalock, R. L. \& Luckasson, R. (2013). Clinical judgment (2nd ed). Washington, D.C.: American Association on Intellectual and Developmental Disabilities (AAIDD). 
Seo, H., Wehmeyer, M. L., Palmer, S.B., \& Little, T.D. (2015). A two-group confirmatory factor analysis of The Arc's Self-Determination Scale with students with emotional/behavioral disorders or learning disabilities. Journal of Emotional and Behavioral Disorders, 23(1), 17-27. https://doi.org/10.1177/1063426613503496

Shandra, C. L. \& Hogan, D. P. (2008). School-to-work program participation and the post-high school employment of young adults with disabilities. Journal of Vocational Rehabilitation, 29, 117-130.

Shogren, K.A. (2011). Culture and self-determination: A synthesis of the literature and directions for future research and practice. Career Development for Exceptional Individuals, 34(2) 115-127.

Shogren, K.A. (2012). Hispanic mothers' perceptions of self-determination. Research \& Practice for Persons with Severe Disabilities, 37(3), 170-184.

Shogren, K. A., Burke, K. M., Anderson, M. H., Antosh, A. A., Wehmeyer, M. L., LaPlante, T., \& Shaw, L. A. (2018). Evaluating the differential impact of interventions to promote self-determination and goal attainment for transition-age youth with intellectual disability. Research \& Practice for Persons with Severe Disabilities, 43, 165-180. https://doi.org/10.1177/1540796918779775

Shogren, K. A., Garnier Villarreal, M., Lang, K., \& Seo, H. (2017). Mediating role of self-determination constructs in explaining the relationship between school factors and postschool outcomes. Exceptional Children, 83, 165-180.

Shogren, K. A., Kennedy, W., Dowsett, C., Garnier Villarreal, M., \& Little, T. D. (2014). Exploring essential characteristics of self-determination for diverse students using data from NLTS2. Career Development and Transition for Exceptional Individuals, 37(3), 168-176.

Shogren, K.A., \& Plotner, A.J. (2012). Transition planning for students with intellectual disability, autism, or other disabilities: Data from the National Longitudinal Transition Study-2. Intellectual and Developmental Disabilities, 50, 16-30. https://doi.org/10.1352/1934-9556-50.1.16

Shogren, K. A., Wehmeyer, M. L., Palmer, S. B., Rifenbark, G.G., \& Little, T. D. (2015). Relationships between self-determination and postschool outcomes for youth with disabilities. The Journal of Special Education, 48, 245-267. https://doi.org/10.1177/0022466913489733

Shogren, K. A., Wehmeyer, M. L., Palmer, S. B., Soukup, J. H., Little, T. D., Garner, N., \& Lawrence, M. (2008). Understanding the construct of self-determination: Examining the relationship between the Arc's Self-Determination Scale and the 
American Institutes for Research Self-Determination Scale. Assessment for Effective Intervention, 33(2), 94-107.

Shurr, J. \& Taber-Doughty, T. (2017). The picture plus discussion intervention:

Text access for high school students with moderate intellectual disability. Focus on Autism and Other Developmental Disabilities, 32(3), 198-208. http://doi.org/10.1177/1088357615625056

Shyman, E. (2013). The Path of Access: Exploring the vacillating histories of individuals with physical and developmental disabilities in the United States. Journal of Educational Thought, 46(2), 87-106.

Silverstein, R. (2010). Anatomy of change: The need for effective disability policy change agents. Archives of Physical Medicine \& Rehabilitation, 91, 173-177.

Sima, A. P., Wehman, P. H., Chan, F., West, M. D., \& Luecking, R. G. (2015). An evaluation of risk factors related to employment outcomes for youth with disabilities. Career Development and Transition for Exceptional Individuals, 38, 89-100. https://doi.org/10.1177/2165143414534887

Simonsen, M. L., \& Neubert, D. A. (2013). Transitioning youth with intellectual and other developmental disabilities: Predicting community employment outcomes. Career Development and Transition for Exceptional Individuals, 36, 188-198. https://doi.org/10.1177/2165143412469399

Siperstein, G. N., Parker, R. C., \& Drascher, M. (2013). National snapshot of adults with intellectual disabilities in the labor force. Journal of Vocational Rehabilitation, 39, 157-165. https://doi.org/10.3233/JVR-130658

Smith, P., \& Fouad, N. (1999). Subject matter specificity of self-efficacy, outcome expectations, interests and goals: Implications for the social cognitive model. Journal of Counseling Psychology, 46, 461-471. https://doi.org/10.1037/0022$\underline{0167.46 .4 .461}$

Southward, J. D., \& Kyzar, K. (2017). Predictors of competitive employment for students with intellectual and/or developmental disabilities. Education and Training in Autism and Developmental Disabilities, 52, 26-37.

Spreat, S., \& Conroy, J.W. (2015). Longitudinal investigation of vocational engagement. Journal of Policy and Practice in Intellectual Disabilities, 12, 266-271. https://doi.org/10.1111/jppi.1213

Spreitzer, G.M., \& Porath, C. (2014). Self-determination as a nutriment for thriving: building an integrative model of human growth at work. In M. Gagné (Ed.), The Oxford Handbook of Work Engagement, Motivation, and Self-Determination Theory (pp. 245-258). Oxford University Press. 
Stajkovic, A. D., \& Luthans, F. (1998). Self-efficacy and work-related performance: A meta-analysis. Psychological Bulletin, 124, 240-261. https://doi.org/10.1037/0033-2909.124.2.240

Stephenson, J. (2016). Using the Choiceboard Creator ${ }^{\mathrm{TM}}$ app on an $\mathrm{iPad}(\mathrm{C}$ to teach choice making to a student with severe disabilities. AAC: Augmentative \& Alternative Communication, 32(1), 49-57. https://doi-org/10.3109/07434618.2015.1136688

Stock, S. E., Davies, D. K., Secor, R. R., \& Wehmeyer, M. L. (2003). Self-directed career preference selection for individuals with intellectual disabilities: using computer technology to enhance self-determination. Journal of Vocational Rehabilitation, $19,95-103$.

Sung, C., \& Connor, A. (2017). Social-cognitive predictors of vocational outcomes in transition youth with epilepsy: application of social cognitive career theory. Rehabilitation Psychology, 62, 276-289. https://doi.org/10.1037/rep0000161

Super, D. E., (1983). Assessment in career guidance: Toward truly developmental counseling. The Personnel and Guidance Journal, 61, 555-561. https://doi.org/10.1111/j.2164-4918.1983.tb00099.x

Test, D. W., Flowers, C., \& Hewitt, A. (2004). Training needs of direct support staff. Mental Retardation, 42, 327-37. https://doi.org/10.1352/0047-6765(2004)42<327:TNODSS>2.0.CO;2

Test, D. W., Mazzotti, V., Mustian, A., Fowler, C. H., Kortering, L., \& Kohler, P. (2009). Evidence-based secondary transition predictors for improving postschool outcomes for students with disabilities. Career Development for Exceptional Individuals, 32, 160-181. https://doi.org/10.1177/0885728809346960

Thoma, C. A. \& Getzel, E. E. (2005). "Self-determination is what it's all about": What Post-secondary students with disabilities tell us are important considerations for success. Education and Training in Developmental Disabilities, 40, 234-242.

Tierney, P., \& Farmer, S. M. (2002). Creative self-efficacy: Its potential antecedents and relationship to creative performance. Academy of Management Journal, 45, 11371148. https://doi.org/10.5465/3069429

Timmons, J. C., Hall, A. C., Bose, J., Wolfe, A., \& Winsor, J. (2011). Choosing employment: Factors that impact employment decisions for individuals with intellectual disability. American Association on Intellectual and Developmental Disabilities, 49, 285-299. https://doi.org/10.1352/1934-9556-49.4.285

Tint, A., Thomson, K., \& Weiss, J. A. (2017). A systematic literature review of the physical and psychosocial correlates of Special Olympics participation among 
individuals with intellectual disability. Journal of Intellectual Disability Research, 61(4), 301-324. https://doi-org.ezproxy.fiu.edu/10.1111/jir.12295

Tonidandel, S., \& LeBreton, J. M. (2010). Determining the relative importance of predictors in logistic regression: An extension of relative weight analysis. Organizational Research Methods, 13(4), 767-781. https://doi.org/10.1177/1094428109341993

Trainor, A. A. (2017). Transition by design: Improving equity and outcomes for adolescents with disabilities. Teachers College Press.

Trembath, D., Balandin, S., Stancliffe, R. J., \& Togher, L. (2010). Employment and volunteering for adults with intellectual disability. Journal of Policy \& Practice in Intellectual Disabilities, 7, 235-238. https://doi.org/10.1111/j.1741$\underline{1130.2010 .00271 . x}$

Turner, S., \& Lapan, R. T. (2002). Career self-efficacy and perceptions of parent support in adolescent career development. Career Development Quarterly, 51, 44-55. https://doi.org/10.1002/j.2161-0045.2002.tb00591.x

U.S. Bureau of Labor Statistics (2015). Labor force statistics from the current population survey: How the government measures unemployment. Retrieved from https://www.bls.gov/cps/cps_htgm.htm.

U.S. Census Bureau (2019). QuickFacts: Miami-Dade County, Florida. Retrieved from https://www.census.gov/quickfacts/fact/dashboard/miamidadecountyflorida/RHI2 25218\#RHI225218

Usinger, J. (2005). Parent/guardian visualization of career and academic future of seventh graders enrolled in low-achieving schools. Career Development Quarterly, 53(3), 234-245.

Valerio, M. A., Rodriguez, N., Winkler, P., Lopez, J., Dennison, M., Liang, Y., \& Turner, B. J. (2016). Comparing two sampling methods to engage hard-to-reach communities in research priority setting. BMC Medical Research Methodology, 16(146), 1-11. https://doi.org/10.1186/s12874-016-0242-z

van Bokhoven, H. (2011). Genetic and epigenetic networks in intellectual disabilities. Annual Review of Genetics, 45, 81-104. https://doi.org/10.1146/annurev-genet$\underline{110410-132512}$

Verdonschot, M.L., de Witte, L.P., Reichrath, E., Buntinx, W.E., \& Curfs, L.G. (2009). Impact of environmental factors on community participation of persons with an intellectual disability: A systematic review. Journal of Intellectual Disability Research, 53(1), 54-64. https://doi-org/10.1111/j.1365-2788.2008.01128.x 
Verdugo, M. A., Vicente, E., Fernández-Pulido, R., Gómez-Vela, M., Wehmeyer, M. L., \& Guillén, V. M. (2015). A psychometric evaluation of the ARC-INICO SelfDetermination Scale for adolescents with intellectual disabilities. International Journal of Clinical and Health Psychology, 15(2), 149-159.

Ward, M. J. (2005). An historical perspective of self-determination in special education: Accomplishments and challenges. Research \& Practice for Persons with Severe Disabilities, 30, 108-112.

Wehman, P. (2006). Life beyond the classroom: Transition strategies for young people with disabilities. Brookes Publishing Company.

Wehman, P. (2013). Transition from school to work: Where are we and where do we need to go? Career Development and Transition for Exceptional Individuals, 36, 58-66. https://doi.org/10.1177/2165143413482137

Wehman, P. \& Hill, J.W. (1985). Competitive employment for persons with mental retardation: From research to practice. Richmond: Virginia Commonwealth University, School of Education, Rehabilitation Research and Training Center.

Wehman, P., \& Kregel, J. (1985). A supported work approach to competitive employment of individuals with moderate and severe handicaps. Research and Practice for Persons with Severe Disabilities, 10, 3-11. https://doi.org/10.1177/154079698501000101

Wehman, P., Lau, S., Molinelli, A., Brooke, V., Thompson, K., Moore, C., \& West, M. (2012). Supported employment for young adults with autism spectrum disorder: Preliminary data. Research and Practice for Persons with Severe Disabilities, 37, 160-169. https://doi.org/10.2511/027494812804153606

Wehman, P., Revell, W. G., \& Kregel, J. (1998). Supported employment: A decade of rapid growth and impact. American Rehabilitation, 24, 31-43.

Wehman, P., Sima, A., Ketchum, J., West, M., Chan, F., \& Luecking, R. (2015). Predictors of successful transition from school to employment for youth with disabilities. Journal of Occupational Rehabilitation, 25, 323-334. https://doi.org/10.1007/s10926-014-9541-6

Wehman, P., Taylor, J., Brooke, V., Avellone, L., Whittenburg, H., Ham, W., Brooke, A.M., \& Carr, S. (2018). Toward competitive employment for persons with intellectual and developmental disabilities: What progress have we made and where do we need to go. Research and Practice for Persons with Severe Disabilities, 43, 131-144. https://doi.org/10.1177/1540796918777730

Wehmeyer, M. L. (1996). Self-determination as an educational outcome: Why is it important to children, youth and adults with disabilities? In D. J. Sands \& M. L. 
Wehmeyer (Eds.), Self-determination across the life span: Independence and choice for people with disabilities (pp. 15-34). Brookes.

Wehmeyer, M. L. (1999). A functional model of self-determination: Describing development and implementing instruction. Focus on Autism and Other Developmental Disabilities, 14, 53-61. https://doi.org/10.1177/108835769901400107

Wehmeyer, M. L. (2014). Self-determination: A family affair. Family Relations, 63, 178184. https://doi.org/10.1111/fare.12052

Wehmeyer, M. L \& Bolding, N. (2008). Enhanced self-determination of adults with intellectual disability as an outcome of moving to community-based work or living environments. Journal of Intellectual Disability Research, 45. 371-383. https://doi.org/10.1046/j.1365-2788.2001.00342.x

Wehmeyer, M. L. \& Palmer, S. B. (2003). Adult outcomes for students with cognitive disabilities three-years after high school: The impact of self-determination. Education and Training in Developmental Disabilities, 38, 131-144.

Wehmeyer, M. L., Palmer, S. B., Shogren, K. A., \& Seong, Y. (2014). The Arc's SelfDetermination Scale-adult version procedural guidelines. Lawrence, KS: Beach Center for Disability.

Wehmeyer, M. L., \& Schwartz, M. (1997). Self-determination and positive adult outcomes: A follow-up study of youth with mental retardation or learning disabilities. Exceptional Children, 63, 245-255. https://doi.org/10.1177/001440299706300207

Weiss, J., Diamond, T., Demark, J., \& Lovald, B. (2003). Involvement in Special Olympics and its relations to self-concept and actual competency in participants with developmental disabilities. Research in Developmental Disabilities, 24(4), 281-305. https://doi-org.ezproxy.fiu.edu/10.1016/S0891-4222(03)00043-X

Whiston, S. C, \& Keller, B. K. (2004). The influences of the family of origin on career development: A review and analysis. The Counseling Psychologist, 32, 493-568. https://doi.org/10.1177/0011000004265660

White, J., \& Weiner, J. S. (2004). Influence of least restrictive environment and community-based training on integrated employment outcomes for transitioning students with severe disabilities. Journal of Vocational Rehabilitation, 21, 149156.

Whitman, T. L. (1990). Self-regulation and mental retardation. American Journal on Mental Retardation, 94, 347-362. 
Witwer, A. N., Lawton, K., \& Aman, M. G. (2014). Intellectual disability. In E. J. Mash \& R. A. Barkley (Eds.), Child psychopathology (3rd ed., pp. 593-624). Guilford Press.

Workforce Innovation and Opportunity Act (WIOA), Pub. L. No. 113-128 (2013).

Zafft, C., Hart, D., \& Zimbrich, K. (2004). College career connection: A study of youth with intellectual disabilities and the impact of postsecondary education. Education and Training in Developmental Disabilities, 39, 45-53.

Zhang, D., Grenwelge, C., \& Petcu, S. (2018). Preparing individuals with disabilities for inclusive employment through the postsecondary access and training in human services (PATHS) program. Inclusion, 6, 224-233. https://doi.org/10.1352/2326$\underline{6988-6.3 .224}$ 


\section{Appendix}

\section{Employment Survey}

\section{Instructions:}

This survey starts by asking you a few questions about you. Answer to the best of your ability. There are no wrong answers.

Q1 How old are you?

Q2 What is your gender?

Male (Boy)

Female (Girl)

Prefer not to answer

Q3 Which best describes your race?

African American/Black

Hispanic/Latino

White/Caucasian

Asian

Pacific Islander

Other 
Q3 Do you have a job?

Yes

No

Display This Question:

If Do you have a job? = Yes

Q4 Do you work full-time or part-time?

Full-time is $31-40$ hours per week. Part-time is $1-30$ hours per week.

Full-time

Part-time

Don't Know

Q5 Do you live with your family?

Yes

No 
Q6 Do any of your family members work full-time?
Yes
No
Don't Know

Q7 Do any of your family members have a college degree?
Yes
No
Don't Know

\section{Instructions:}

This section asks about any job training you have had. This can include when you were in high school. Check the boxes next to all that you have had access to. There are no right or wrong answers.

Q8

Vocational-related services 
These are services where someone such as a teacher might have worked directly with you to get you ready for a job. Check the boxes next to all the services you have ever had.

Career/vocational assessment

Career/vocational counseling

Person-centered planning

Job placement services

Transportation training

Q10

Work-based experiences 
These are services where you practiced on the job skills. Check the boxes next to all the work experiences you have ever had.

Career exploration

Job shadowing

Volunteering

Service Learning

Internship/Co-op

Apprenticeships

Paid employment in school

Paid employment out of school

\section{Q11}

\section{Workplace-support services}

These are people or things that help you when you are on the job. Check the boxes next to all the services or support you have ever had.

Job coach

Natural supports

Visual supports

Assistive technology 
Q12

\section{Training on vocational-related services}

These are trainings or workshops you have had that would help you to know your rights or how to stand up for yourself. Check the boxes next to all topics you have had training on.

Disability benefits (SSI, Medicaid)

Work incentives

Transition from training to paid employment

Transition between jobs

Self-advocacy 


\section{Instructions:}

This section is going to have statements about how you typically react to things. Check the answer on each question that BEST tells how you act in that situation. There are no right or wrong answers.

Q13

\section{Independence}

Check the box next to each statement that BEST tells how you act in that situation. There are no right or wrong answers. (If you have a disability that limits you from actually 
performing the activity, but you have control over the activity (such as a personal care attendant), answer like you performed the activity.

I make my own meals or snacks.

I care for my own clothes.

I do chores in my home.

I keep my own personal items together.

I do simple first aid or medical care for myself.

I keep good personal care and grooming.

I make friends with others my age.

I keep my appointments and meetings.

I deal with sales people at stores and restaurants.

I choose my clothes and personal items I use every day.

I choose how to spend my personal money.

Q14

Acting on Preferences, Beliefs, Interests, \& Abilities

Check the box next to each statement that BEST tells how you act in that situation. There are no right or wrong answers. (If you have a disability that limits you from actually 
performing the activity, but you have control over the activity (such as a personal care attendant), answer like you performed the activity.

I do free time activities based on my interests.

I plan weekend activities that I like to do.

I am involved in community activities.

My friends and I choose activities that we want to do.

I text, e-mail, or talk on the phone to friends and family.

I listen to music that I like.

I do free time activities based on my career interests.

I work on activities that will improve my career chances.

I make long-term career plans.

I work or have worked to earn money.

I am or have been in career or job classes or training.

I have looked into job interests by visiting work sites or talking to people in that job.

Q15

\section{Self-Realization}

This section asks some personal questions about how you feel about yourself. Check the 
box next to each statement that describes how you feel about yourself. There are no right or wrong answers.

I accept my own limitations.

I feel I can do many things.

I am confident in my abilities.

I know what I do best.

I know how to make up for my limitations.

I like myself. 


\section{Instructions:}

This section has statements about your family and the ways they support you. Check the boxes next to all statements that BEST describe your family. Remember, think about your family and their support when answering. There are no right or wrong answers.

Q16

\section{General Family Support}

Check the boxes next to all statements that apply. Remember, think about your family support when answering. There are no right or wrong answers.

My family supports me in reaching my goals.

My family wants me to feel proud of my work.

My family wants me to feel happy with myself.

My family is proud of me.

My family wants me to always have enough money to live on. 
Q17

\section{Family Employment Expectations}

Check the boxes next to all statements that BEST describe your family. Remember, think about your family support when answering. There are no right or wrong answers.

My family wants me to go to college or university.

My family wants me to work.

My family wants me to enjoy my job.

My family wants me to find stable work.

My family wants me to have a job coach.

My family wants me to work with people with disabilities.

My family wants me to work with people without disabilities. 
Q18

Family Independence Expectations

Check the boxes next to all statements that BEST describe your family. Remember, think about your family support when answering. There are no right or wrong answers.

My family wants me to get a driver's license.

My family wants me to have a car.

My family wants me to use public transportation.

My family wants me to be involved in my community.

My family helps me find resources in the community.

My family wants me to live on my own.

My family wants me to be more independent. 
Instructions:

Now I am going to ask you about services in the community. I am going to read each possible answer to you with an explanation of what it is. Please check the boxes next to all services you have used or programs you participated in. There are no right or wrong answers.

Q19

Please check the boxes next to all services you have used or programs you participated in. There are no right or wrong answers.

\section{Transportation Services}

I have used Special Transportation Services (STS)

I have used Uber or Lyft

I have used a public bus.

I have used the Metrorail or train.

I have used a taxi.

Q20

Please check the boxes next to all services you have used or programs you participated in. There are no right or wrong answers. 


\section{Community Programs}

I have used Vocational Rehabilitation (VR).

I have been a part of Best Buddies.

I have been a part of Special Olympics.

I have been a part of The ARC.

I have been a part of Aktion Club.

I have been a part of Shake A Leg.

Q21

Please check the boxes next to all services you have used or programs you participated in. There are no right or wrong answers. 


\section{Education Programs}

I have attended a college or university program.

I was in Project Victory.

I was in Project Search.

I was in Project SAIL.

I was in Project Bloom.

I was in Project Strive.

I was in S.T.E.P.S. Program.

Q22

Please check the boxes next to all services you have used or programs you participated in. There are no right or wrong answers.

\section{Other Community Resources}

I have used the public library to search for jobs.

I have gone to a community action center.

I have been involved in the public parks programs . 
VITA

\section{AMANDA M. GIUST}

Born, Canton, Ohio

B.S., Early Childhood Education

Bowling Green State University

Bowling Green, Ohio

2012-2014

Graduate Assistant

Florida International University

Miami, Florida

2014

M.S., Adult Education \& Human

Resource Development

Florida International University

Miami, Florida

2014

Barnes \& Noble Best Faculty-Student Paper Award

2014-2017

Program Coordinator/Manager

Florida International University

Miami, Florida

2016-2020

Doctoral Candidate

Florida International University

Miami, Florida

2017

2017-2019

FIU President's Access \& Equity Award Nominee

Grant Coordinator, Miami Book Fair

Miami Dade College

Miami, Florida

2020

Director, Graduate Student Center

Albizu University

Miami, Florida

\section{PUBLICATIONS}

Giust, A.M., \& Valle-Riestra, D.M. (2016). Supporting mentors working with students with intellectual disabilities in higher education. Journal of Intellectual Disabilities, 1-14. doi: $10.1177 / 1744629516651019$ 
Kross, J. \& Giust, A.M. (2019). Elements of research questions in relation to qualitative research. The Qualitative Report, 24(1), 24-30. 